\title{
Improving Dryer and Press Efficiencies Through Combustion of Hydrocarbon Emissions
}

\author{
Final Report for Project DE-FC36-01GO10620 \\ Supported by the US Department of Energy
}

\author{
By \\ Sujit Banerjee \\ Institute of Paper Science \& Technology \\ Atlanta, GA 30318
}

October 2005

\section{Executive Summary}

Emission control devices on dryers and presses have been legislated into the industry, and are now an integral part of the drying system. These devices consume large quantities of natural gas and electricity and down-sizing or eliminating them will provide major energy savings. The principal strategy taken here focuses on developing process changes that should minimize (and in some cases eliminate) the need for controls. A second approach is to develop lower-cost control options.

It has been shown in laboratory and full-scale work that Hazardous Air Pollutants (HAPs) emerge mainly at the end of the press cycle for particleboard, and, by extension, to other products. Hence, only the air associated with this point of the cycle need be captured and treated. A model for estimating terpene emissions in the various zones of veneer dryers has been developed. This should allow the emissions to be concentrated in some zones and minimized in others, so that some of the air could be directly released without controls.

Low-cost catalysts have been developed for controlling HAPs from dryers and presses. Catalysts conventionally used for regenerative catalytic oxidizers can be used at much lower temperatures for treating press emissions. Fluidized wood ash is an especially inexpensive material for efficiently reducing formaldehyde in dryer emissions.

A heat transfer model for estimating pinene emissions from hot-pressing strand for the manufacture of flakeboard has been constructed from first principles and validated. The model shows that most of the emissions originate from the 1-mm layer of wood adjoining the platen surface. Hence, a simple control option is to surface a softwood mat with a layer of hardwood prior to pressing.

Fines release a disproportionate large quantity of HAPs, and it has been shown both theoretically and in full-scale work that particles smaller than $400 \mu \mathrm{m}$ are principally responsible. Georgia-Pacific is considering green-screening their furnish at several of their mills in order in order to remove these particles and reduce their treatment costs. 


\section{CONTENTS}

1. Overview

2. Timing of HAPs press emissions and their dependence on operational parameters

2.1 Dependence of HAPs emissions on moisture content 4

2.2 Pilot measurements on VOC releases from flakes during pressing 5

2.3 Full-scale measurements of HAPs emission from pressing particle 10

3. Catalytic degradation of HAPs

3.1 Low-temperature destruction of HAPs with Pt-based catalysts 13

3.2 Low-temperature destruction of HAPs with non-Pt-based catalysts 16

$\begin{array}{lll}3.3 & \text { Simulation of a catalyst-platen composite } & 20\end{array}$

3.4 Mechanism of pinene release from board during pressing 20

3.5 Low-temperature catalytic conversion of VOC's released during hot pressing 21

3.6 Catalytic conversion of VOCs released during hot pressing 22

3.7 Urea reduces formaldehyde press emissions 25

$\begin{array}{ll}\text { 4. Modeling emissions from veneer dryers } & 27\end{array}$

5. Heat transfer model for estimating pinene emissions from hot-pressing softwood flakeboard

6. Controlling formaldehyde emissions with boiler ash 43

7. Process-based control of HAPs emissions from drying wood flakes 53

8. Publications and technology transfer 61 


\section{Overview}

Expensive emission control devices on dryers and presses have been legislated into the industry, and are now an integral part of the drying system. The recommended device is the RTO (Regenerative Thermal Oxidation) unit, which is energy-intensive (natural gas) and has high operational and maintenance costs. Our approach focuses on developing process changes that should minimize (and in some cases eliminate) the need for controls. Where control devices will still be needed, they will be smaller and will run more efficiently. The end result is expected to be a substantial decrease in natural gas use coupled with a reduction in capital cost. A second approach is to develop lower-cost control options. This report is divided into several sections, many of which have been published. A summary of each section is provided here.

Timing of HAPs press emissions and their dependence on operational parameters

The wood-MACT defines HAPs as methanol, formaldehyde, acetaldehyde, propionaldehyde, acrolein, and phenol. Of these, only the first three are commonly found. It is important to define when these component emerge in the pressing cycle because the volume of air that needs to be captured and treated can then be reduced. As things presently stand, all the air in the press area must be collected and treated. However, if it can be shown that the HAPs emerge only at the end of the press cycle then a part of these emissions can be vented if a suitable collection arrangement can be devised.

Section 2 describes laboratory, pilot and full-scale work on the timing of press emissions and the dependence of these emissions on operational factors. Section 2.1 describes laboratory work where flakes were pressed and methanol and formaldehyde emissions tracked over time. It was found that these compounds are released as a roughly constant fraction of the steam evolved. This must mean that the steam evolved drives the water out and that the bulk of the emissions will be released late in the press cycle when steam evolution begins. Pilot measurements were then made and the results reported in Section 2.2. As expected from the laboratory work, there was a linear trend between methanol and formaldehyde and steam evolution, but extensive scatter was observed. A theoretical model was developed and the mat thickness was found to be the most important factor affecting the time of steam evolution, and hence the timing of HAPs release. A field trial was run at the Georgia-Pacific, Vienna, GA, particleboard mill in March 2001. The results are provided in Section 2.3.

\section{Catalytic degradation of HAPs}

Regenerative Catalytic Oxidizers (RCOs) are used in the industry for high-efficiency removal of VOCs. These units operate at temperatures of $315-550^{\circ} \mathrm{C}$. The catalysts target all the VOCs released, but if we are principally interested in destroying only HAPs, then a high efficiency may not be necessary. One compliance option under MACT is to reduce the HAPs to below a target level regardless of the concentration of other VOCs. Hence, a cheaper robust catalyst that operates at lower temperatures may suffice. Two options were explored. First, a new hydrophobic catalyst was investigated. Second, the efficiency of a conventionally-used catalyst at lower temperatures was determined.

Catalyst beds are usually run at high temperature since the water produced from the oxidation of formaldehyde and methanol can deactivate the catalyst at low temperature. Embedding the catalyst on a hydrophobic material is expected to minimize this problem since water is re- 
pelled from these surfaces. Platinum impregnated fluorinated carbon $(\mathrm{Pt} / \mathrm{F}-\mathrm{C})$ is reported to be a good catalyst for oxidizing formaldehyde at low temperature.

\section{Modeling emissions from veneer dryers}

A simple model was developed to estimate pinene emissions in various zones of a veneer dryer. Heat transfer to the veneer was calculated and the emissions estimated from two-film theory. The model was tested with field data from two veneer mills. The model was calibrated with data from one mill and was able to reproduce emissions from the other. The model can be used to develop conditions that would enrich emissions in one or more of the zones and reduce those in the others, so that the emissions from at least one zone can be released without treatment.

Heat transfer model for estimating pinene emissions from hot-pressing softwood flakeboard

A heat transfer model for estimating pinene emissions from hot-pressing strand for the manufacture of flakeboard has been constructed from first principles and validated. The model predicts $\alpha$-pinene emissions of $0.4 \mathrm{~kg} / 1000 \mathrm{~kg}$ for a $0.95-\mathrm{cm}$ board, which is within the $0.3-0.6$ $\mathrm{kg} / 1000 \mathrm{~kg}$ range reported for commercial operations. Most of the emissions originate from the hot 1-mm layer of wood adjoining the platen surface. As a result, residual pinene in the board is depleted at the surface for both commercial and laboratory-prepared boards. Emissions are drastically reduced when the mat is surfaced with a layer of aspen.

$\underline{\text { Controlling formaldehyde emissions with boiler ash }}$

Fluidized wood ash reduces formaldehyde in air from about 20 to less than 1 ppmv. Methanol is removed to a much lower extent. The efficiency of formaldehyde reduction increases with increasing moisture content of the ash. Sorption of formaldehyde to ash can be substantially accounted for by partitioning to the water contained in the ash followed by ratecontrolling binding to the ash solids. Adsorption occurs at temperatures of up to $165^{\circ} \mathrm{C}$; oxidation predominates thereafter. It is proposed that formaldehyde could be stripped from an air stream in a fluidized bed containing ash, which could then be returned to a boiler to incinerate the formaldehyde.

\section{Process-Based Control of HAPs Emissions From Drying Wood Flakes}

Industrial wood drying generates methanol, formaldehyde, and other Hazardous Air Pollutants (HAPs). A simple theoretical model shows that particles smaller than $400 \mu \mathrm{m}$ will begin to thermally degrade and release disproportionately large quantities of HAPs. This is confirmed in full-scale practice where particles smaller than $500 \mu \mathrm{m}$ show visible signs of charring. Laboratory measurement of the activation energy for the breakdown of wood tissue into methanol and formaldehyde led to a value of about $17 \mathrm{kcal} / \mathrm{mole}$. The apparent activation energy measured in the field was higher at $45 \mathrm{kcal} / \mathrm{mole}$. This result was obtained under non-isothermal conditions and is biased high by the fines fraction of the furnish which is exposed to elevated temperatures. It is proposed that a combination of screening out the fines fraction smaller than $500 \mu \mathrm{m}$ and reducing dryer inlet temperature will substantially reduce emissions, possibly to the point where control devices can be downsized or eliminated. Our findings allow these HAPs reductions to be semi-quantitatively estimated. 


\section{Timing of HAPs press emissions and their dependence on operational parameters}

2.1 Dependence of HAPs emissions on moisture content

We had previously suggested that HAPs were removed from the furnish during pressing through the movement of steam. This opened the possibility of collecting or treating the emissions only when moisture was released, in which case the size of the control device could be greatly reduced. In order to confirm the moisture-HAPs relationship, flakes were pressed at various starting MC values and the HAPs collected at different levels of pressing. Green pine flakes (from LP, Athens, GA) were dried at $105^{\circ} \mathrm{C}$ to initial MCs of 15,9 , and $6.5 \%$. Core PF resin GP145C 48 was added at $2.2 \%$ of the OD wood mass. Flakes $(15$ g.) were pressed in stainless steel bags at 200 psi for 180 seconds in the small IPST bench-scale press with a top platen temperature of $200^{\circ} \mathrm{C}$; the lower platen was in the range of 110 to $120^{\circ} \mathrm{C}$. An airflow of $0.3 \mathrm{lpm}$ was maintained through the bag during pressing, and the outflow was led to a chilled water impinger. After a pre-determined period, the airflow was switched to a second impinger. Hence, two impinger samples were collected per pressing, with each corresponding to a different part of the pressing period. The MC of the furnish at the end of each period was calculated from the fraction of water collected in each of the two impingers, as well as the average initial and final wood MC.

The results are illustrated in Figure 1. Note that the methanol and formaldehyde track each other closely. The total formaldehyde emission over the total 3-minute period for all three conditions is $120 \pm 20 \mathrm{mg} / \mathrm{kg}$; the corresponding value for methanol is $100 \pm 30 \mathrm{mg} / \mathrm{kg}$. The slope of the line in the top panel (MC: 6.5\%) in Figure 1 is steeper than those of the others, but the changes in moisture content are smaller for the MC 6.5\% experiments, and are, therefore, more difficult to measure. Also, the wood would have reached the final temperature more rapidly due

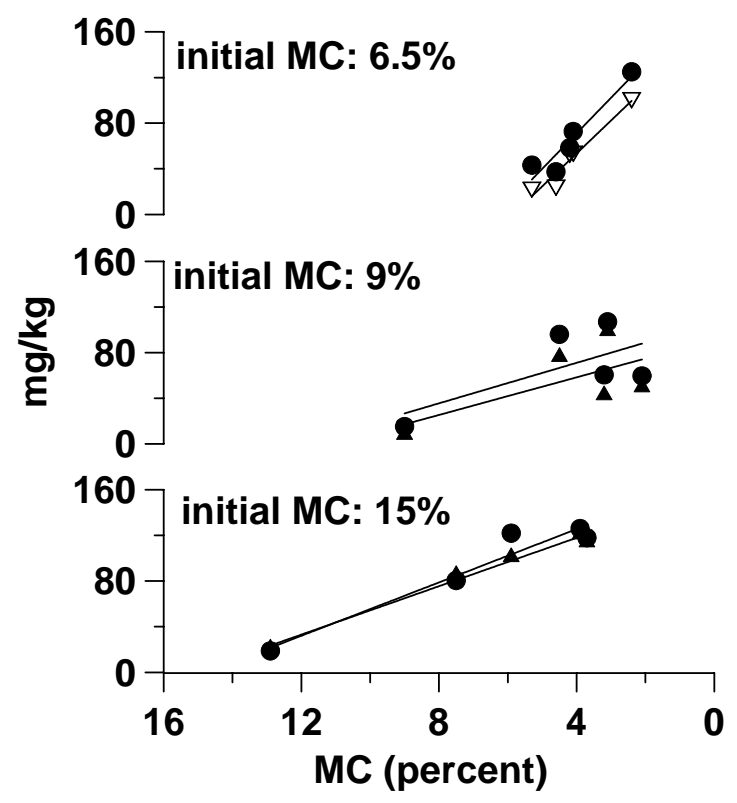

Figure 1: Relationship between HAPs emissions and MC from pressing pine. The circles and triangles represent formaldehyde and methanol, respectively. 
to a lower degree of evaporative cooling. In sum, methanol and formaldehyde are released in equal amounts across most of the MC region as a roughly constant fraction of the steam evolved.

\subsection{Pilot measurements on VOC releases from flakes during pressing}

Measurements were made with the press at the University of Minnesota (NRRI), Duluth, on December 6, 2000. The bottom platen was porous, and the emissions were expressed from a single outlet. Collections were made by pumping the emissions from this outlet through a chilled water impinger at $2 \mathrm{lpm}$. The total press time was 4 minutes. The mat was not oriented, since board strength was not an issue. However, we realized later that this would amplify density differences, which would lead to uneven heat transfer as discussed in the next section. Panels $(3 \times 7 \mathrm{ft} 3 / 8 \mathrm{in})$ were pressed between 182 and $216^{\circ} \mathrm{C}$ with pre-blend flake MC of 2-9\%. PF resin and wax was used.

Four 1-minute collections were made, with the impingers being changed between collections. Each impinger was weighed before and after sampling to determine the water condensed. The reproducibility of the measurements was relatively poor, and possible reasons will be discussed in the next section. The HAPs-moisture relationship is illustrated in Figure 2, and while, significant, it is associated with high scatter. The scatter represents a potential problem since steam (and HAPs) are released over a longer period, and a proportionately larger control device is required. Hence, a model was developed to identify the probable cause of the scatter.

Equations for heat transfer from a source at constant temperature have been reported in Unit Operations of Chemical Engineering (W.L.McCabe, J.C.Smith, P.Harriott, McGraw-Hill, 1985). These have been applied to a pressing operation as follows. Consider the illustration in Figure 3, where a platen impacts a mat of flakes.
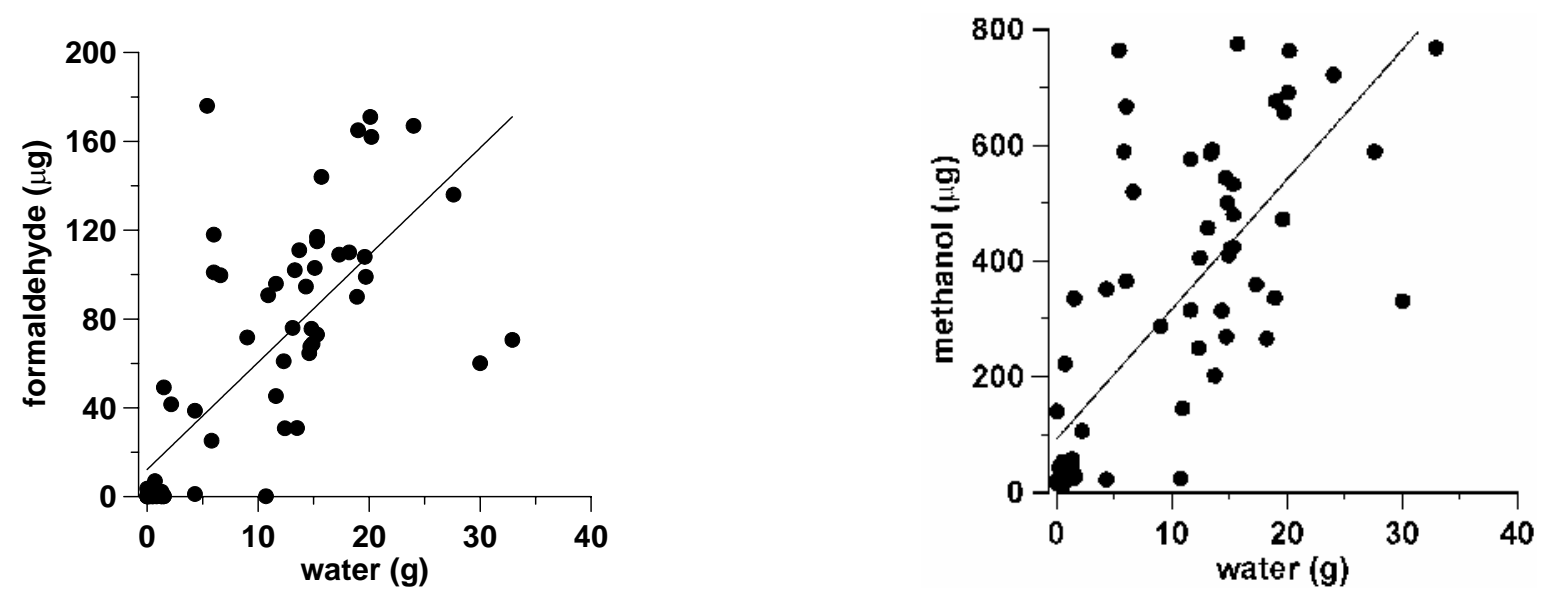

Figure 2: Relationship between formaldehyde and methanol emissions and moisture loss; $\left(r^{2}=0.56\right)$ for both plots. 


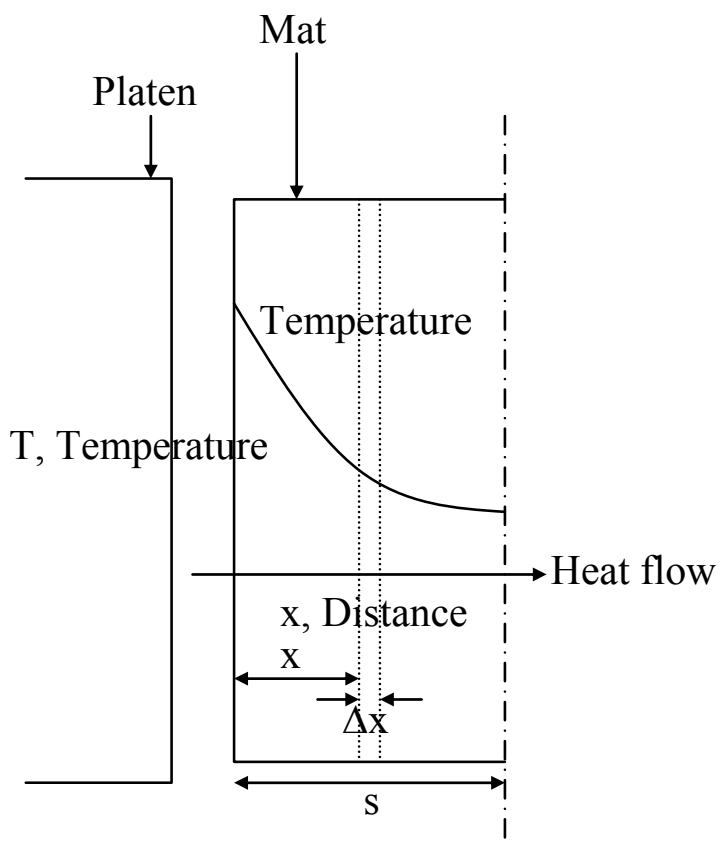

Figure 3: Schematic of a platen impacting a mat.

The temperature gradient at $\mathrm{x}=\frac{\partial T}{\partial x}-\ldots-\ldots(1)$

The heat input in time interval dt at $\mathrm{x}=-k A\left(\frac{\partial T}{\partial x}\right) d t$

where, $\mathrm{A}=$ area of the mat perpendicular to the flow of heat, and

$\mathrm{k}=$ thermal conductivity of the wood

The temperature gradient at $(\mathrm{x}+\mathrm{dx})=\frac{\partial T}{\partial x}+\frac{\partial}{\partial x} \frac{\partial T}{\partial x} d x$

The heat outflow from the mat at $(\mathrm{x}+\mathrm{dx})=-k A\left(\frac{\partial T}{\partial x}+\frac{\partial}{\partial x} \frac{\partial T}{\partial x} d x\right) d t$

Therefore, the difference (in - out) is

$-k A\left(\frac{\partial T}{\partial x}\right) d t+k A\left(\frac{\partial T}{\partial x}+\frac{\partial}{\partial x} \frac{\partial T}{\partial x} d x\right) d t=k A \frac{\partial^{2} T}{\partial x^{2}} d x d t$

The accumulation of heat (resulting in temperature increase) at $d x=\rho c_{p} A d x \frac{\partial T}{\partial t} d t$ 
The heat balance is

$k A \frac{\partial^{2} T}{\partial x^{2}} d x d t=\rho c_{p} A d x \frac{\partial T}{\partial t} d t$

Division by $\rho c_{p} A d x d t$ gives

$\frac{\partial T}{\partial t}=\frac{k}{\rho c_{p}} \frac{\partial^{2} T}{\partial x^{2}}=\alpha \frac{\partial^{2} T}{\partial x^{2}}-\cdots-\cdots(8)$

where, $\alpha=$ thermal diffusivity of wood $=\frac{k}{\rho c_{p}}\left(\mathrm{~cm}^{2} / \mathrm{sec}\right)$

Integration of eq. 8 for heating an infinite slab of known thickness from both sides by a medium at constant surface temperature leads to

$$
\frac{T_{s}-T}{T_{s}-T_{a}}=\frac{8}{\pi^{2}}\left(e^{-a_{1} N_{F 0}}+\frac{1}{9} e^{-9 a_{1} N_{F 0}}+\frac{1}{25} e^{-25 a_{1} N_{F 0}}+\ldots . .\right)
$$

where $T_{s}$ is the constant average temperature of surface of slab

$\mathrm{T}_{\mathrm{a}}=$ initial temperature of slab (ambient temperature)

$\mathrm{T}=$ average temperature of slab at time $\mathrm{t}_{\mathrm{T}}$

$\mathrm{N}_{\mathrm{F} 0}=$ Fourier number $=\frac{\alpha t_{T}}{s^{2}}$

$\alpha=$ thermal diffusivity

$\mathrm{t}_{\mathrm{T}}=$ time of heating

$\mathrm{s}=$ one-half slab thickness

$\mathrm{a}_{1}=\left(\frac{\pi}{2}\right)^{2}$

When $\mathrm{N}_{\mathrm{F} 0}>0.1$ (which is usually the case), only the first term of eq. 9 is significant, so that

$T=T_{s}-\frac{8}{\pi^{2}} e^{-\left(\frac{\pi}{2}\right)^{2} \frac{\alpha t_{T}}{s^{2}}}\left(T_{s}-T_{a}\right)$

Equation 10 was applied to a $5 / 8$ inch mat initially at $25^{\circ} \mathrm{C}$ pressed between $200^{\circ} \mathrm{C}$ platens. The thermal diffusivity, $\left(\alpha, 1.889 \times 10^{-3} \mathrm{~cm}^{2} / \mathrm{sec}\right)$, was obtained from F. F. P. Kollmann and W. A. Côté, Jr., "Principles of Wood Science and Technology, I. Solid Wood", p.251, 1968. It is a function of density, thermal conductivity, specific heat, and moisture content. We assume that 
the mat is at a constant temperature throughout during pressing, which is not the case. However, our purpose here is to estimate the time at which steam will be evolved, and this should be insensitive to temperature variability within the mat. For example, the surface moisture vaporizes first, moves to the core and condenses, but this redistribution heat should not lead to significant evolution of steam from the mat. A steady outflow of steam will occur only when the overall mat temperature approximates $100^{\circ} \mathrm{C}$.

Figure 4 shows results from the application of eq. 10 to $5 / 8$ and $3 / 8$ inch mats. It takes about 50 and 20 seconds for the $5 / 8$ and $3 / 8$ inch mats, respectively, to reach $100^{\circ} \mathrm{C}$. These are the average temperatures through the mat. The temperature is very sensitive to mat thickness. The effect of platen temperature on 5/8" and 3/8" mats is illustrated in Figures 5 and 6, respectively. The time of first appearance of steam is insensitive to small differences in temperature. It is also insensitive to thermal diffusivity, as shown in Figure 7. This means that the mat thickness is the most important factor that affects the time of steam evolution.

Variations in mat thickness prior to pressing will affect the final density of the board. During the UMD trial, the flakes were not oriented, and there were probably large differences in final density. We presently believe that this led to the scatter observed. If so, then a more even mat density should lead to steam and HAPs emissions over a shorter interval. A field trial was run at the G-P, Vienna, GA, particleboard mill in March 2001, and the results should provide a reality check of our hypothesis.

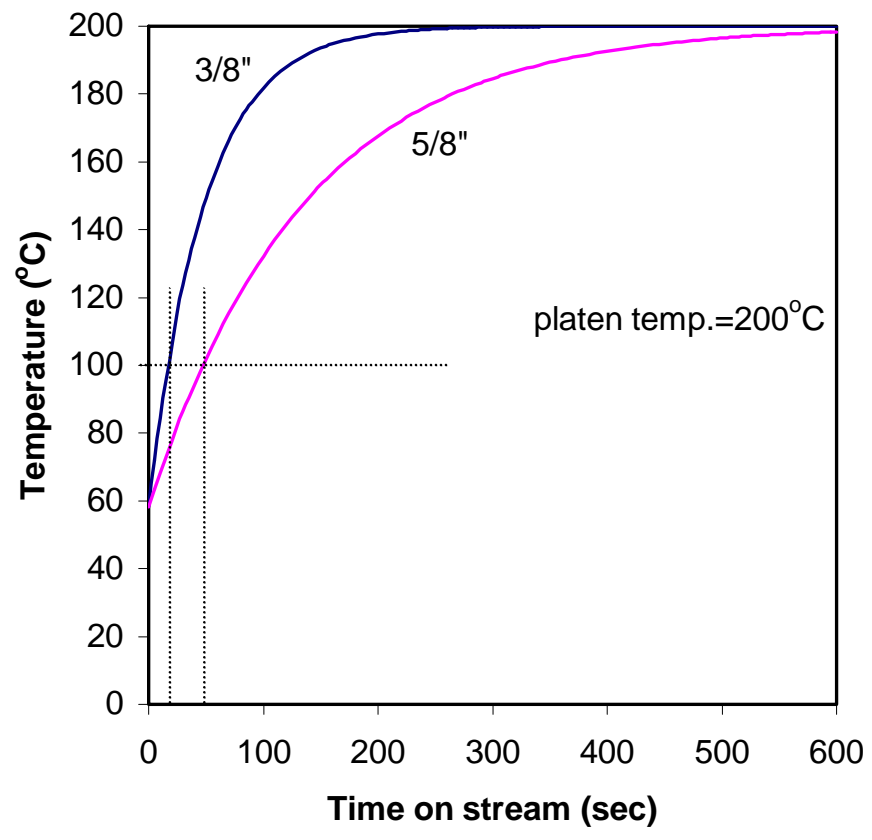

Figure 4: Temperature profiles for two mat thicknesses. 


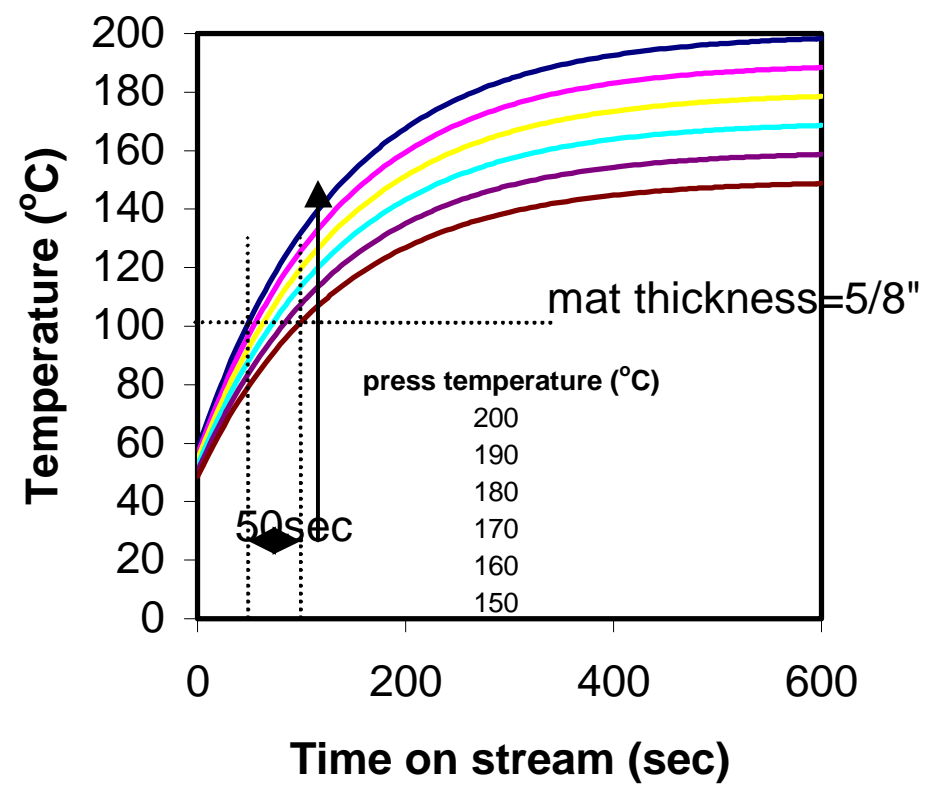

Figure 5: Temperature profiles at various platen temperatures with a 5/8" mat.

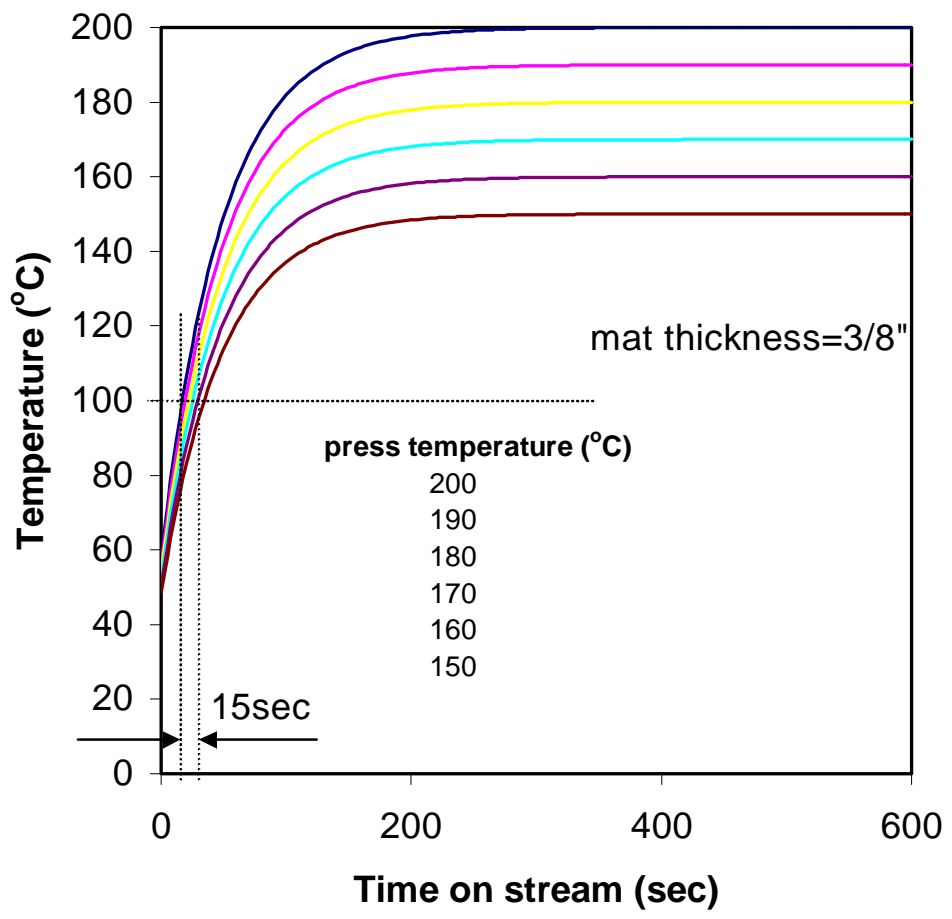

Figure 6: Temperature profiles at various platen temperatures with a 3/8" mat. 


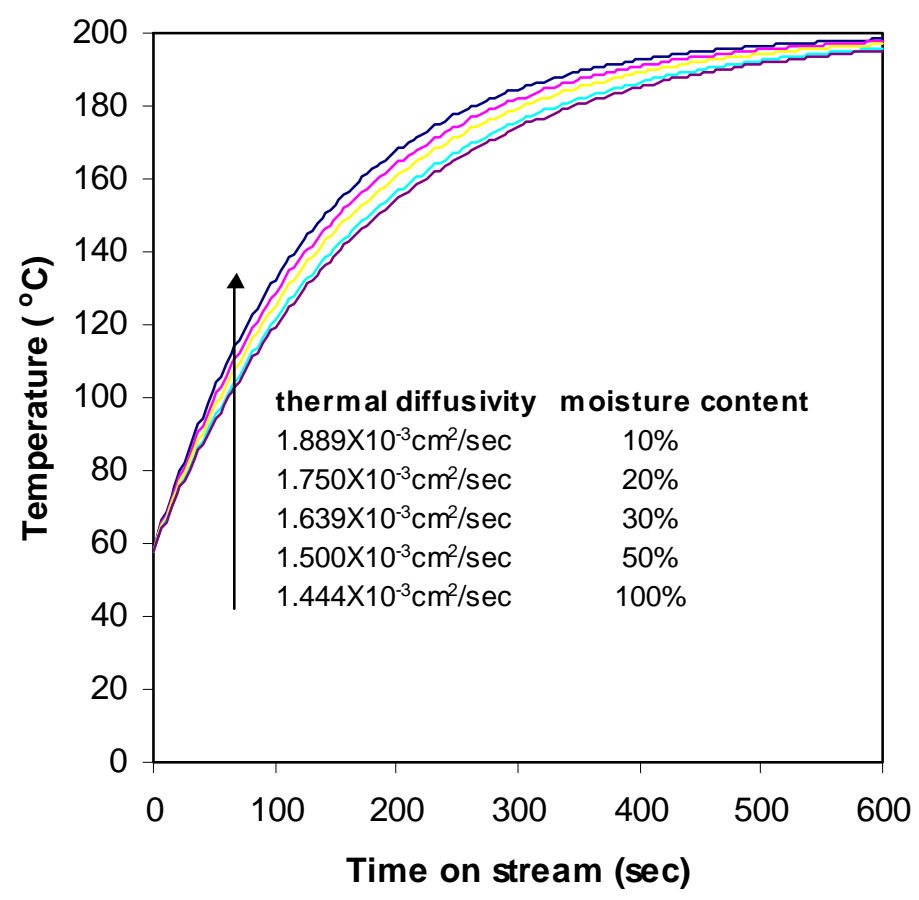

Figure 7: Effect of thermal diffusivity of temperature profiles.

2.3 Full-scale measurements of HAPs emission from pressing particle

These measurements were made at a particleboard mill in the Southeastern US. The mill

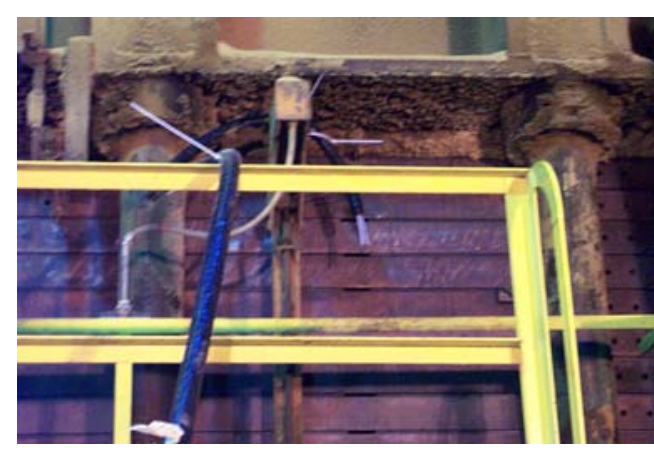

Figure 8: Position of the sampler. uses UF resins $(10 \%$ of od fiber weight in the face and $8 \%$ in the core. The board is $40 \%$ face and $60 \%$ core. A heated $100-\mathrm{ft}$ line was placed adjacent to the press vent as shown in Figure 8. The white inlet tube is visible at the center of the picture. The platens were kept at $313^{\circ} \mathrm{F}$, and a maximum pressure of $2,500 \mathrm{psi}$ was applied. The time for loss of daylight was 13 seconds and the press remained closed for 3 minutes. Five-eight inch boards were pressed during the measurements. The emissions were drawn sequentially at $5 \mathrm{lpm}$ through three chilled water impingers. Collection was begun when the press just

closed. The length of each sampling period was varied from 90-240 seconds to catch the emissions from different stages of pressing, and three evenly-spaced collections were made for each period. For example, for the 90 -second run, the impingers were changed every 30 seconds. The dead volume in the sampling tube was 1 liter, which corresponds to a clearance time of $12 \mathrm{sec}-$ onds.

The results listed in Table 1 show considerable scatter, especially for formaldehyde. This was expected, since the collection point was not tied exclusively to the press exhaust, but was open to the ambient air. The total formaldehyde and methanol from each set of runs are related as shown in Figure 9. If the marked outlier is excluded, then the relationship is exceptionally 


\begin{tabular}{|c|c|c|c|c|c|}
\hline \multicolumn{6}{|c|}{ Table 1: Volatiles $(\mu \mathrm{g})$ collected during pressing. ${ }^{1}$} \\
\hline ID & duration & methanol & acetone & formaldehyde & total \\
\hline GP-A1 & 80 & 300 & 230 & 0 & 530 \\
\hline GP-A2 & 80 & 250 & 270 & 10 & 530 \\
\hline GP-A3 & 80 & 290 & 340 & 150 & 770 \\
\hline total & 240 & 840 & 840 & 160 & 1830 \\
\hline GP-B1 & 30 & 140 & 380 & 240 & 750 \\
\hline GP-B2 & 30 & 210 & 240 & 30 & 480 \\
\hline GP-B3 & 30 & 300 & 220 & 0 & 520 \\
\hline total & 90 & 650 & 840 & 270 & 1750 \\
\hline GP-C1 & 40 & 340 & 280 & 10 & 620 \\
\hline GP-C2 & 40 & 120 & 90 & 0 & 220 \\
\hline GP-C3 & 40 & 0 & 0 & 140 & 140 \\
\hline total & 120 & 460 & 370 & 150 & 980 \\
\hline GP-D1 & 50 & 570 & 30 & 300 & 900 \\
\hline GP-D2 & 50 & 190 & 490 & 0 & 680 \\
\hline GP-D3 & 50 & 320 & 160 & 800 & 1280 \\
\hline total & 150 & 1080 & 680 & 1100 & 2860 \\
\hline GP-E1 & 60 & 370 & 330 & 320 & 1020 \\
\hline GP-E2 & 60 & 120 & 240 & 110 & 480 \\
\hline GP-E3 & 60 & 960 & 90 & 1000 & 2060 \\
\hline \begin{tabular}{|l} 
total \\
\end{tabular} & 180 & 1450 & 660 & 1430 & 3560 \\
\hline GP-F1 & 70 & 220 & 310 & 0 & 540 \\
\hline GP-F2 & 70 & 170 & 270 & 0 & 450 \\
\hline GP-F3 & 70 & 510 & 240 & 930 & 1680 \\
\hline total & 210 & 900 & 820 & 930 & 2670 \\
\hline GP-G1 & 30 & 370 & 450 & 0 & 820 \\
\hline GP-G2 & 30 & 120 & 190 & 0 & 310 \\
\hline GP-G3 & 30 & 120 & 150 & 310 & 580 \\
\hline total & 90 & 610 & 790 & 310 & 1710 \\
\hline GP-H1 & 40 & 120 & 150 & 0 & 270 \\
\hline GP-H2 & 40 & 250 & 270 & 10 & 530 \\
\hline GP-H3 & 40 & 250 & 310 & 220 & 780 \\
\hline total & 120 & 620 & 730 & 230 & 1580 \\
\hline
\end{tabular}




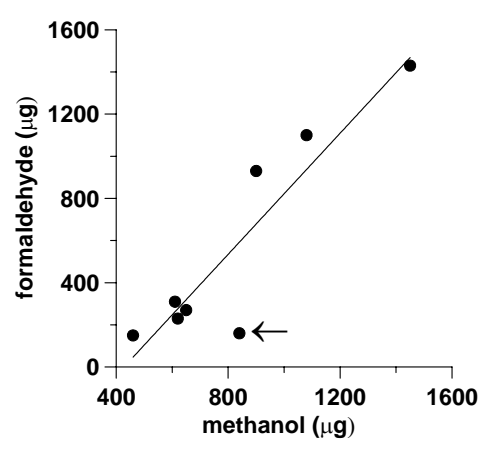

Figure 9: Relationship between formaldehyde and methanol emissions at Vienna.

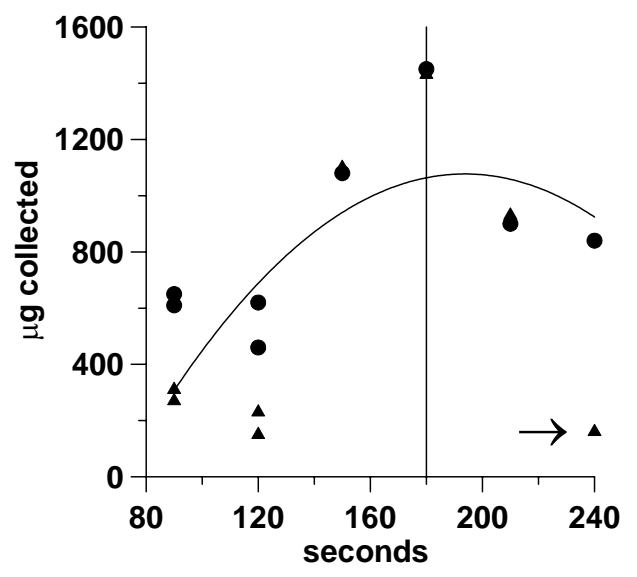

Figure 10: Methanol ( $\bullet$ ) and formaldehyde ( $\Delta$ ) collected at Vienna. The line represents the time at which the press opens.

good for field work. This correlation has been previously observed in laboratory work. Figure 10 illustrates the quantities of methanol and formaldehyde collected over various periods. The Figure 9 outlier seems to derive from an unexpectedly low value for formaldehyde, and if this (marked) value is also excluded from Figure 10, then the emissions would seem to rise and then level off. The curve is drawn without considering the outlier. Some of the HAPs measured in the early stages of pressing could well be carryover from the previous run. If this is the case, then most of the HAPs could be released when the press opens. We have previously shown that most of the HAPs released during pressing come from the resin and only a small fraction derives from the degradation of wood.

The variability in formaldehyde is much higher than that in methanol, and it is also released in smaller amounts. Formaldehyde is quite reactive, and we speculate that it could be lost through contact with the hot surface of the metal caul plate. We have no evidence for this, but we explore it further, since it represents a potential removal option. 


\section{Catalytic degradation of HAPs}

3.1 Low-temperature destruction of HAPs with Pt-based catalysts

RCOs used in the industry achieve high removal efficiencies of over $90 \%$ and operate at high temperatures of $315-550^{\circ} \mathrm{C}$. These catalysts target turpentine, but if we are principally interested in destroying HAPs, then a high efficiency may not be necessary. Furthermore, if strategies to reduce press-vent HAPs through changing production methods are employed, then a cheaper robust catalyst that operates at lower temperatures may suffice. Two options were explored. First, a new hydrophobic catalyst was investigated. Second, the efficiency of a conventionally-used catalyst at lower temperatures was determined.

Catalyst beds are usually run at high temperature since the water produced from the oxidation of formaldehyde and methanol can deactivate the catalyst at low temperature. Embedding the catalyst on a hydrophobic material is expected to minimize this problem since water is repelled from these surfaces. Chuang et al. (Ind. Eng. Chem. Res., 33, 1680, 1994) reported that Pt-impregnated fluorinated carbon (Pt/F-C) was an excellent catalytic system for oxidizing formaldehyde at low temperature without catalytic deactivation. The only products were water and $\mathrm{CO}_{2}$. Chuang et al. did not study the oxidation of methanol with this catalyst, which we have now done.

The catalyst was prepared by impregnating fluorinated carbon with Pt and dip-coating on a ceramic honeycomb. The source of platinum was hydrogen hexachloroplatinate hydrate $\left(\mathrm{H}_{2} \mathrm{PtCl}_{6} 6 \mathrm{H}_{2} \mathrm{O}\right)$. The hydrophobic fluorinated carbon (FtorCarb-CB/65) was obtained from Lodestar, Inc. Ceramic honeycomb (64 cells/in ${ }^{2}$, square-shaped) was supplied by Applied Ceramics, Inc., and Teflon primer and top coating were obtained from Intech Services, Inc. The catalyst decomposes at $500^{\circ} \mathrm{C}$ and its life is shortened if used continuously at $350^{\circ} \mathrm{C}$.

The procedure for preparing the catalyst was established by trial and error. The required amount of $\mathrm{H}_{2} \mathrm{PtCl}_{6} 6 \mathrm{H}_{2} \mathrm{O}$ was dissolved in acetone and 5-10 $\mathrm{g}$ of fluorinated carbon was added

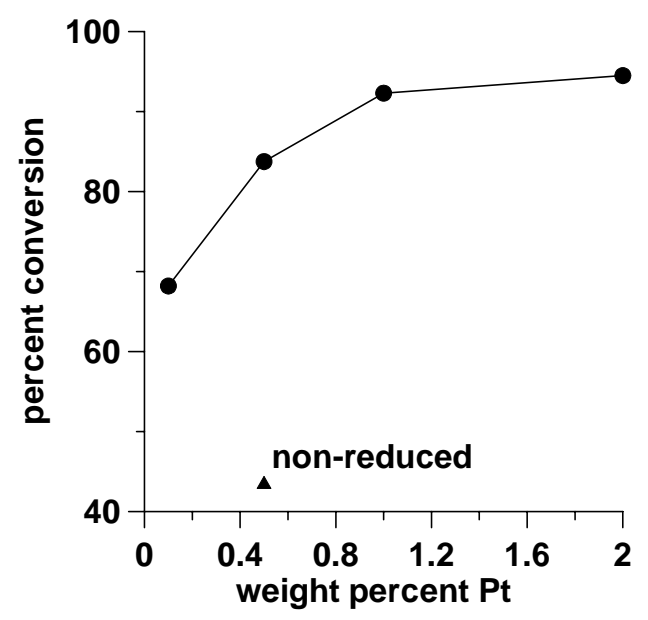

Figure 1: Steady-state formaldehyde conversion on $\mathrm{Pt} / \mathrm{F}-\mathrm{C}$.

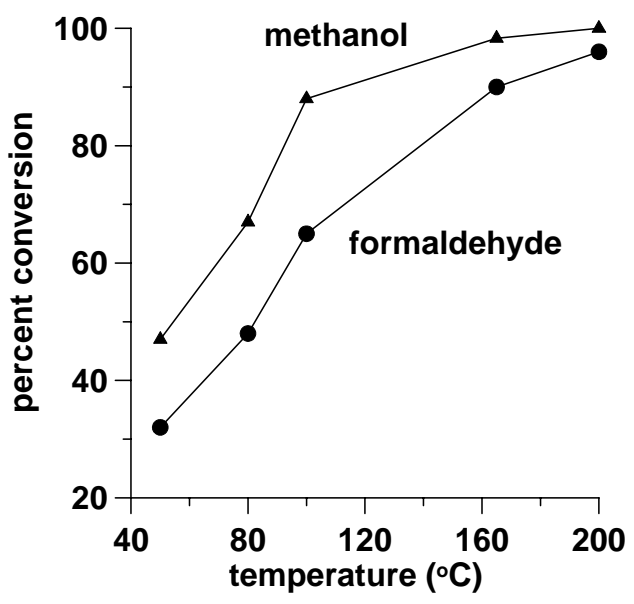

Figure 2: Conversion of formaldehyde and methanol on $1 \mathrm{wt} \% \mathrm{Pt} / \mathrm{F}-\mathrm{C}$. 
with vigorous stirring. Chuang et al. used methanol in place of acetone. In our hands, methanol caused catalyst burning when calcined. The acetone was evaporated, and the residue dried at $60^{\circ} \mathrm{C}$ overnight. The Pt/F-C was calcined at $330^{\circ} \mathrm{C}$ for 5 hours under an airflow of $30 \mathrm{~mL} / \mathrm{min}$ and then reduced at $300^{\circ} \mathrm{C}$ under hydrogen $(30 \mathrm{~mL} / \mathrm{min})$ for 2 hours. Chuang et al. ran the calcination at $360^{\circ} \mathrm{C}$ for 15 minutes, but we found that the fluorinated carbon burned at this temperature. A ceramic honeycomb was cut into $1 \times 2$ in pieces and coated with a Teflon primer. The prepared Pt/F-C catalyst and Teflon top coating powder were mixed, ground with a mortar, and sprinkled on the honeycomb through a 100-mesh sieve. The fluidized powder was coated on the primer-treated honeycomb, dried overnight at $100^{\circ} \mathrm{C}$, and then cured at $370^{\circ} \mathrm{C}$ for 15 minutes.

The feed formaldehyde and methanol stream was prepared by bubbling air at $0.5 \mathrm{lpm}$ through a $37 \%$ aqueous formaldehyde solution, which also contained $7 \%$ methanol. The feed stream was first passed through an empty tube furnace and collected in a chilled water impinger. The formaldehyde and methanol in the impinger were determined by the chromotropic acid method and by gc, and these results were used as baseline values. The catalyst was then placed in the tube furnace and the measurement was repeated at catalyst temperatures of $50-200^{\circ} \mathrm{C}$. The trapping efficiency was determined to be $60 \%$ by stripping a $500 \mathrm{ppm}$ formaldehyde solution at various flow rates for 1 minute. Methanol recovery was near-quantitative.

Figure 1 shows that catalytic efficiency increases with increasing Pt loading. The efficiency levels off at $90 \%$ at $1 \mathrm{wt} \% \mathrm{Pt} / \mathrm{F}-\mathrm{C}$. Figure 1 also shows the difference between reduced and non-reduced catalyst. The reduced Pt is twice as efficient. Steady state conditions are reached after about 10 minutes, which reflects the time required for the reactants to sorb on to the active sites. Conversion efficiencies for formaldehyde and methanol at various catalyst loadings

\begin{tabular}{|c|c|c|}
\hline Table 1: Steady-state catalyst efficiency ${ }^{1}$. \\
\hline Pt/F-carbon (wt \%) & $\begin{array}{c}\text { percent conversion of formalde- } \\
\text { hyde }\end{array}$ & $\begin{array}{c}\text { percent conversion of metha- } \\
\text { nol }\end{array}$ \\
\hline 0.1 & $67(70)$ & 98.3 \\
\hline 0.5 & $86(82)$ & 100 \\
\hline 1.0 & $90(95)$ & 100 \\
\hline 2.0 & $95(94)$ & 100 \\
\hline \multicolumn{2}{|c|}{} \\
\hline${ }^{1}$ formaldehyde: 414 ppmv; methanol: 153 ppmv (uncorrected for recovery) \\
\hline
\end{tabular}

\begin{tabular}{|l|c|c|}
\hline \multicolumn{3}{|c|}{ Table 2: Catalytic treatment of press emissions $(\boldsymbol{\mu g} / \mathbf{g}$ OD wood) } \\
\hline & methanol & Formaldehyde \\
\hline without catalyst & $33(11)$ & $70(8)$ \\
\hline with catalyst & $20(6)$ & $44(11)$ \\
\hline \multicolumn{3}{|c|}{} \\
\hline 1 average of 6 determinations \\
\hline
\end{tabular}


are listed in Table 1. Figure 2 shows the result of formaldehyde and methanol conversion (steady-state) at various catalyst temperatures. Although the catalyst works best at temperatures exceeding $165^{\circ} \mathrm{C}$, it retains appreciable efficiency down to $120^{\circ} \mathrm{C}$.

The catalyst was then tested with emissions from wood drying. Dry softwood flakes $(\mathrm{MC}<3 \%)$ were heated in a ceramic boat at $130^{\circ} \mathrm{C}$ under an airflow of $0.5 \mathrm{lpm}$. The emissions from the wood were then passed through the catalyst (maintained at 165 or $200^{\circ} \mathrm{C}$ ), and then into the sampling port of a MIDAC FTIR instrument. The conversion of methanol and formaldehyde at 165 and $200^{\circ} \mathrm{C}$ is shown in Figure 3. Roughly half of each component is removed. Similar results were obtained at either temperature. The degree of formaldehyde removal is higher than apparent since methanol is first oxidized to formaldehyde as shown below.

$$
\begin{aligned}
& \mathrm{CH}_{3} \mathrm{OH}+1 / 2 \mathrm{O}_{2} \rightarrow \mathrm{HCHO}+\mathrm{H}_{2} \mathrm{O}^{1)} \\
& \mathrm{HCHO}+\mathrm{O}_{2} \rightarrow \mathrm{CO}_{2}+\mathrm{H}_{2} \mathrm{O}^{3)}
\end{aligned}
$$

The catalyst showed surprisingly high efficiency towards $\alpha$-pinene as shown in Figure 4. Carbon monoxide was also completely oxidized at $165^{\circ} \mathrm{C}$.

Next, we tested the catalyst with emissions from pressing. A small electrohydraulic press (MTS) was used, and flakes were pressed in a stainless steel bag fitted with inlet and exit tubes. Pine flakes (15 g) were mixed with $0.4 \mathrm{~g}$ of PF resin pressed for 3 minutes under an airflow of $0.5 \mathrm{lpm}$. The emissions were passed through the $1 \mathrm{wt} \% \mathrm{Pt} / \mathrm{F}-\mathrm{C}$ catalyst bed described above. The temperatures of the upper and lower platens were set at 200 and $110^{\circ} \mathrm{C}$, respectively, and the catalyst bed was kept at $165^{\circ} \mathrm{C}$. The emissions were collected in chilled impingers and analyzed by gc. The results are shown in Table 2 . Although there is high scatter on account of wood variability, the average conversions of methanol and formaldehyde were 35 and $32 \%$, respectively.

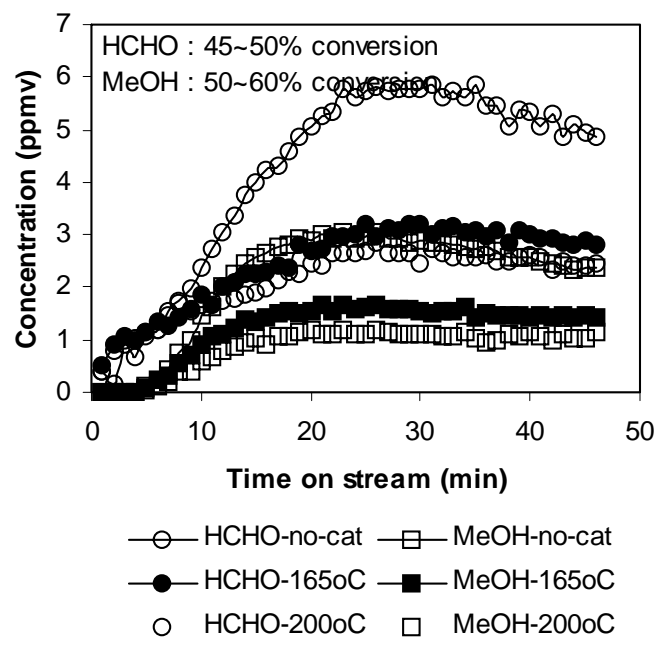

Figure 3: Conversion of formaldehyde and methanol on $1 \mathrm{wt} \% \mathrm{Pt} / \mathrm{SiO}_{2}$ catalyst. 


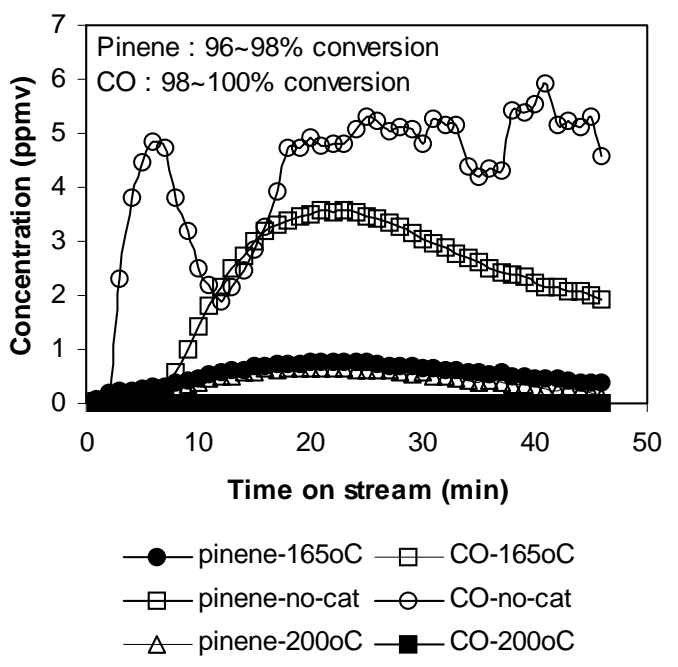

Figure 4: Conversion of $\alpha$-pinene and $\mathrm{CO}$ on $1 \mathrm{wt} \% \mathrm{Pt} / \mathrm{SiO}_{2}$ catalyst.

A preliminary cost was developed using the following assumptions.

Gas flow rate: $100,000 \mathrm{cfm}$

Reaction temperature: $165^{\circ} \mathrm{C}$

Conversion efficiency: $90 \%$

Space velocity (gas flow rate: bed volume) $=100,000 \mathrm{hr}^{-1}$

The bed volume is based on the gas flow rate and the space velocity and works out to $60 \mathrm{ft}^{3}$; i.e.

1,440 ( $6 \times 6 \times 2$ in.) honeycombs units are needed. The honeycomb cell size should be

16 cells $/$ in $^{2}$ to eliminate a pressure drop

$1 \mathrm{wt} \% \mathrm{Pt} / \mathrm{F}-\mathrm{Carbon}$ coated on the cordierite (ceramic) honeycomb

One honeycomb $=\$ 25$; total price of honeycombs $=\$ 36,000$

The cost of chemicals to make the catalyst and coat the honeycombs:

Binder (Teflon) - \$258/2 kg (top coat); $\$ 18,600$ (144 kg)

Primer - $\$ 157 /$ gal; $\$ 11,000$ (72 gal)

Fluorinated carbon - $\$ 250 / \mathrm{kg} ; \$ 4,000(16 \mathrm{~kg})$

Chloroplatinic acid (Pt precursor): $440 \mathrm{~g} ; \underline{\$ 16,000}$

\section{Total: $\mathbf{\$ 8 5 , 6 0 0}$}

\subsection{Low-temperature destruction of HAPs with non-Pt-based catalysts}

An alternative to platinum-based catalysts is the manganese oxide on aluminum oxide catalyst currently used in RCOs, and the performance of these materials (obtained from Envirochem) was measured. These catalysts operate at about $315-540^{\circ} \mathrm{C}$. We determined their efficiency towards HAPs at lower temperatures because HAPs should be cleanly oxidized and a lower temperature was expected to be adequate. GP145C 48 core PF resin was added to pine flakes $(15 \mathrm{~g}, 5 \% \mathrm{MC})$ at $2.2 \%$ of wood mass. The wood was pressed in a stainless steel bag fitted with inlet and outlet tubes for airflow, and pressed at 150 psig for 3 minutes in an MTS electrohydraulic press (Water Res., 32, 258, 1998). A $0.3 \mathrm{lpm}$ airflow was maintained through the bag during pressing and for three minutes thereafter. The upper and lower platens were kept at 220 
and $110^{\circ} \mathrm{C}$, respectively. The air from the bag was fed into a heated (3-cm diameter) column containing a manganese oxide on aluminum oxide catalyst. The catalyst was donut-shaped with the following dimensions: $15 \mathrm{~mm}$ od, $9 \mathrm{~mm}$ id, $10-13 \mathrm{~mm}$ thick. Its bulk density was $0.7 \mathrm{~g} / \mathrm{mL}$. The emissions from the column were trapped in impinger, which was analyzed spectrophotometrically for formaldehyde by Method 3500 and for methanol by gc.

The catalytic efficiency was high at temperatures exceeding $150^{\circ} \mathrm{C}$ as shown by the results in Table 3. The column height was $24 \mathrm{~cm}$. The efficiency falls somewhat at shorter column heights as shown in Table 4 . The packing geometry is particularly important for the $2 \mathrm{~cm}$ runs. The contact time is lower for the coaxially packed catalyst, which depressed catalytic efficiency. Reducing airflow increases catalytic efficiency, as shown in Table 5.

A cost estimate for a 100,000 cfm system was developed using the following assumptions.

Catalyst temperature: $170^{\circ} \mathrm{C}$

Conversion efficiency for formaldehyde: $90 \%$

Retention time: 12 seconds

The bed volume is based on the gas flow rate and the retention time and works out to be $20,000 \mathrm{ft}^{3}$, based on a packing density of $0.63 \mathrm{~kg} / \mathrm{cu} \mathrm{ft}$.

The cost of catalyst is $\$ 12.5 / \mathrm{kg}$, which gives a total cost of $\$ 159 \mathrm{~K}$.

A catalyst temperature of $170^{\circ} \mathrm{C}$ was assumed in order to inhibit condensation of pinene (bp: $165^{\circ} \mathrm{C}$ ) and related compounds. These costs will be at least an order of magnitude lower if vented platens are used, since the volume of air to be treated will be much smaller. The cost of the two catalysts is a factor of two apart, which is small given the level of approximation used. Either material can be used for our application, but since the manganese oxide catalyst is already utilized in RTOs, it would appear to be the better candidate.

\begin{tabular}{|c|c|c|c|c|c|c|}
\hline \multicolumn{2}{|c|}{\begin{tabular}{c|} 
catalyst \\
tempera- \\
ture
\end{tabular}} & \multicolumn{3}{|c|}{$\begin{array}{c}\text { concentration } \\
(\mu \mathrm{g} / \mathrm{g}, \text { dry basis })\end{array}$} & \multirow{2}{*}{$\begin{array}{c}\begin{array}{c}\text { average } \\
(\boldsymbol{\mu g} / \mathrm{g})\end{array} \\
66.9 \\
\end{array}$} & \multirow[t]{3}{*}{$\begin{array}{l}\text { percent conver- } \\
\text { sion }\end{array}$} \\
\hline \multirow[t]{2}{*}{ no catalyst } & formaldehyde & 58.5 & 47.2 & 94.8 & & \\
\hline & methanol & 13.0 & 12.2 & 17.0 & 14.1 & \\
\hline \multirow[t]{2}{*}{150} & formaldehyde & 1.96 & 3.36 & 1.62 & 2.31 & 97 \\
\hline & methanol & 2.01 & 2.33 & 2.03 & 2.12 & 85 \\
\hline \multirow[t]{2}{*}{165} & formaldehyde & 1.03 & 1.25 & 2.69 & 1.66 & 98 \\
\hline & methanol & 1.89 & 1.36 & 1.98 & 1.74 & 88 \\
\hline \multirow[t]{2}{*}{175} & formaldehyde & 0 & 0 & 2.02 & 0.67 & 99 \\
\hline & methanol & 1.65 & 1.21 & 1.15 & 1.34 & 91 \\
\hline \multirow[t]{2}{*}{175} & formaldehyde & 0 & 0 & 0 & 0 & 100 \\
\hline & methanol & 1.01 & 1.03 & 1.26 & 1.10 & 92 \\
\hline
\end{tabular}




\begin{tabular}{|c|c|c|c|c|c|c|}
\hline $\begin{array}{c}\text { column } \\
\text { height }(\mathrm{cm})\end{array}$ & & \multicolumn{3}{|c|}{$\begin{array}{c}\text { concentration } \\
(\mu \mathrm{g} / \mathrm{g}, \text { dry basis })\end{array}$} & $\begin{array}{c}\text { average } \\
(\mu \mathrm{g} / \mathrm{g})\end{array}$ & $\begin{array}{l}\text { percent con- } \\
\text { version }\end{array}$ \\
\hline \multicolumn{7}{|c|}{ catalyst temperature: $175^{\circ} \mathrm{C}$} \\
\hline \multirow[t]{2}{*}{ no catalyst } & formaldehyde & 58.5 & 47.2 & 94.8 & 66.9 & \\
\hline & methanol & 13.0 & 12.2 & 17.0 & 14.1 & \\
\hline \multirow[t]{2}{*}{$20 \mathrm{~cm}$} & formaldehyde & 2.31 & 3.56 & 1.68 & 2.52 & 96 \\
\hline & methanol & 2.02 & 1.36 & 2.02 & 1.80 & 87 \\
\hline \multirow[t]{2}{*}{$18 \mathrm{~cm}$} & formaldehyde & 1.69 & 3.33 & 3.65 & 2.89 & 96 \\
\hline & methanol & 2.69 & 2.79 & 3.16 & 2.88 & 80 \\
\hline \multicolumn{7}{|c|}{ catalyst temperature: $170^{\circ} \mathrm{C}$} \\
\hline \multirow[t]{2}{*}{ no catalyst } & formaldehyde & 71.0 & 60.6 & 60.9 & 64.2 & \\
\hline & methanol & 12.4 & 14.6 & 13.7 & 13.65 & \\
\hline \multirow[t]{2}{*}{$8 \mathrm{~cm}$} & formaldehyde & 17.7 & 9.09 & 11.7 & 12.8 & 80 \\
\hline & methanol & 4.03 & 3.66 & 3.26 & 3.65 & 73 \\
\hline \multirow[t]{2}{*}{$4 \mathrm{~cm}$} & formaldehyde & 21.7 & 26.2 & 18.1 & 22.0 & 66 \\
\hline & methanol & 6.3 & 5.96 & 5.43 & 5.90 & 56 \\
\hline \multirow{2}{*}{$\begin{array}{l}2 \mathrm{~cm} \\
(\text { coaxial })\end{array}$} & formaldehyde & 69.4 & 53.3 & 45.5 & 56.1 & 12 \\
\hline & methanol & 13.7 & 13.1 & 13.1 & 13.3 & 2 \\
\hline \multirow{2}{*}{$\begin{array}{l}2 \mathrm{~cm} \\
\text { (not coaxial) }\end{array}$} & formaldehyde & 46.7 & 51.6 & 36.2 & 44.9 & 30 \\
\hline & methanol & 11.1 & 10.3 & 11.4 & 10.9 & 19 \\
\hline
\end{tabular}

\begin{tabular}{|c|l|c|c|c|c|c|}
\hline \multicolumn{2}{|c|}{ Table 5: Effect of airflow on catalytic efficiency (8-cm column, 0.2 lpm). } \\
\hline $\begin{array}{c}\text { catalyst } \\
\text { present }\end{array}$ & \multicolumn{2}{|c|}{$\begin{array}{c}\text { concentration } \\
(\boldsymbol{\mu g} / \mathbf{g}, \mathbf{d r y} \text { basis })\end{array}$} & $\begin{array}{c}\text { average } \\
(\boldsymbol{\mu g} / \mathbf{g})\end{array}$ & $\begin{array}{c}\text { percent conver- } \\
\text { sion }\end{array}$ \\
\hline \multirow{2}{*}{ no } & formaldehyde & 71.0 & 60.6 & 60.9 & 64.2 & \\
\cline { 2 - 7 } & methanol & 12.4 & 14.6 & 13.7 & 13.6 & \\
\hline \multirow{2}{*}{ yes } & formaldehyde & 2.55 & 5.82 & 4.18 & 4.18 & 94 \\
\cline { 2 - 7 } & methanol & 3.27 & 3.51 & 3.19 & 3.32 & 76 \\
\hline
\end{tabular}




\begin{tabular}{|c|l|c|c|c|c|c|}
\hline Table 6: Catalyst performance at various MCs. \\
\hline \multirow{2}{*}{ MC (percent) } & \multicolumn{3}{|c|}{$\begin{array}{c}\text { Mg/g OD wood, } \\
\text { dry basis }\end{array}$} & $\begin{array}{c}\text { average } \\
(\boldsymbol{\mu g} / \mathbf{g})\end{array}$ & $\begin{array}{c}\text { percent } \\
\text { conversion }\end{array}$ \\
\hline \multirow{2}{*}{ no catalyst } & formaldehyde & 84.7 & 68.0 & 47.4 & 66.7 & \\
\cline { 2 - 7 } & methanol & 22.0 & 15.0 & 11.3 & 16.1 & \\
\hline \multirow{2}{*}{0} & formaldehyde & 3.47 & 3.50 & 3.19 & 3.38 & 94.9 \\
\cline { 2 - 7 } & methanol & 2.19 & 1.56 & 1.53 & 1.76 & 89.1 \\
\hline \multirow{2}{*}{50} & formaldehyde & 2.54 & 2.57 & 2.22 & 2.44 & 96.3 \\
\cline { 2 - 7 } & methanol & 1.51 & 1.38 & 1.68 & 1.52 & 90.5 \\
\hline \multirow{2}{*}{100} & formaldehyde & 2.57 & 3.47 & 4.21 & 3.42 & 94.9 \\
\cline { 2 - 7 } & methanol & 1.62 & 1.71 & 2.24 & 1.86 & 88.4 \\
\hline \multirow{2}{*}{150} & formaldehyde & 2.60 & 2.91 & 2.55 & 2.68 & 96.0 \\
\cline { 2 - 7 } & methanol & 2.02 & 2.17 & 2.38 & 2.17 & 86.5 \\
\hline
\end{tabular}

\begin{tabular}{|c|l|c|c|c|c|c|}
\hline \multicolumn{2}{|c|}{ Table 7: Effect of pH on catalytic efficiency. } \\
\hline \multirow{2}{*}{$\mathbf{p H}$} & \multicolumn{2}{|c|}{$\begin{array}{c}\boldsymbol{\mu} \text { /g OD wood, } \\
\text { dry basis }\end{array}$} & $\begin{array}{c}\text { average } \\
(\boldsymbol{\mu g} / \mathbf{g})\end{array}$ & $\begin{array}{c}\text { percent } \\
\text { conversion }\end{array}$ \\
\hline \multirow{2}{*}{ no catalyst } & formaldehyde & 68.3 & 85.7 & 78.0 & 77.3 & \\
\cline { 2 - 7 } & methanol & 16.0 & 19.4 & 17.2 & 17.5 & \\
\hline \multirow{2}{*}{4} & formaldehyde & 2.76 & 1.58 & 1.86 & 2.07 & 97.3 \\
\cline { 2 - 7 } & methanol & 2.82 & 2.16 & 1.70 & 2.23 & 87.3 \\
\hline \multirow{2}{*}{7} & formaldehyde & 1.73 & 0.62 & 0.79 & 1.05 & 98.7 \\
\cline { 2 - 6 } & methanol & 1.75 & 1.23 & 1.15 & 1.38 & 92.2 \\
\hline \multirow{2}{*}{10} & formaldehyde & 2.06 & 1.62 & 0.90 & 1.53 & 98.0 \\
\cline { 2 - 6 } & methanol & 1.91 & 1.51 & 1.22 & 1.55 & 91.2 \\
\hline
\end{tabular}

The robustness of the catalyst was determined as a function of moisture and $\mathrm{pH}$. Flakes were bone-dried at $105^{\circ} \mathrm{C}$ and various amounts of moisture were then added to them. GP145C48 core PF resin was added at $2.2 \%$ of flake dry weight and the mixture was pressed in a steel bag with an MTS electrohydraulic press at an upper platen temperature of $220^{\circ} \mathrm{C}$. The lower platen was kept at $110^{\circ} \mathrm{C}$. The flakes were pressed under the conditions described above. The catalyst was held in a $2.5 \times 24 \mathrm{~cm}$ column held at $175^{\circ} \mathrm{C}$. The results (Table 6) show that moisture has no effect on catalytic efficiency.

In order to determine whether catalytic activity was $\mathrm{pH}$-dependent, the catalyst was soaked in various buffers, dried at room temperature, and placed in a $16-\mathrm{cm} 175^{\circ} \mathrm{C}$ column. The results, presented in Table 7 , demonstrate that catalytic efficiency is maintained under both acidic and basic conditions. 


\begin{tabular}{|c|l|c|c|c|c|c|}
\hline Table 8: Results from pressing catalyst and wood. \\
\hline \multirow{2}{*}{ catalyst } & \multicolumn{3}{|c|}{$\begin{array}{c}\boldsymbol{\mu g} / \mathbf{g} \text { OD wood, } \\
\text { dry basis }{ }^{1}\end{array}$} & $\begin{array}{c}\text { average } \\
(\boldsymbol{\mu g} / \mathbf{g})\end{array}$ & $\begin{array}{l}\text { percent } \\
\text { conversion }\end{array}$ \\
\hline \multirow{2}{*}{$\mathrm{Y}$} & formaldehyde & 84.7 & 68.0 & 47.4 & 66.7 & \\
\cline { 2 - 7 } & methanol & 22.0 & 15.0 & 11.3 & 16.1 & \\
\hline \multirow{2}{*}{$\mathrm{N}$} & formaldehyde & 61.0 & 63.9 & 48.4 & 57.8 & 13.4 \\
\cline { 2 - 6 } & methanol & 13.4 & 11.5 & 11.0 & 12.0 & 20.6 \\
\hline \multicolumn{7}{|l|}{ from separate pressings } \\
\hline
\end{tabular}

\begin{tabular}{|c|c|c|c|c|c|c|}
\hline \multirow{3}{*}{ no catalyst } & \multirow[b]{2}{*}{ formaldehyde } & \multicolumn{3}{|c|}{$\begin{array}{c}\mu \mathrm{g} / \mathrm{g} \text { OD wood, } \\
\text { dry basis }\end{array}$} & \multirow{2}{*}{$\begin{array}{c}\begin{array}{c}\text { average } \\
(\boldsymbol{\mu g} / \mathbf{g})\end{array} \\
77.3 \\
\end{array}$} & \multirow[t]{3}{*}{$\begin{array}{l}\text { percent } \\
\text { conversion }\end{array}$} \\
\hline & & 68.3 & 85.7 & 77.8 & & \\
\hline & methanol & 16.0 & 19.4 & 17.2 & 17.5 & \\
\hline \multirow[t]{2}{*}{$\mathrm{A}$} & formaldehyde & 85.9 & 67.7 & 66.4 & 73.3 & 5.08 \\
\hline & methanol & 17.9 & 15.8 & 14.3 & 16.0 & 8.87 \\
\hline \multirow[t]{2}{*}{ B } & formaldehyde & 65.0 & 75.2 & 61.6 & 67.2 & 13.0 \\
\hline & methanol & 14.2 & 16.5 & 15.9 & 15.5 & 11.5 \\
\hline
\end{tabular}

\subsection{Simulation of a catalyst-platen composite}

We envisage a situation where the emissions would pass through a porous upper platen and contact a catalyst bed. Our press would need to be modified to accommodate such a platen, and before we committed to this expense we ran a few experiments to determine whether the concept had any merit. Initially, we included the ceramic catalyst $(5 \mathrm{~g})$ with the wood in the steel bag. The ceramic would crush under pressure, but we hoped that there would be sufficient contact between the crushed catalyst media and the emissions to provide proof of concept. Most of these runs were unsuccessful because the bags broke during pressing. Table 8 shows the results of one set of experiments (run under the conditions described above) where the integrity of the bag was maintained. While the conversion is low because of insufficient contact between the emissions and the catalyst, the process is clearly viable.

To circumvent the problem of the catalyst being crushed and rupturing the bag, the catalyst (5 g.) was ground into $2 \mathrm{~mm}$ particles and placed over the wood in the steel bag (set A). The results, shown in Table 9, reveal that catalytic efficiency is low, because of channeling and/or low contact time. Nevertheless, there is a measurable difference and a modified platen, which would allow controlled experiments to be run was constructed. Here, both the catalyst and the furnish are contained within the press, bit no pressure is applied to the platen. The press emissions pass through a porous plate and then through the catalyst bed.

\subsection{Mechanism of pinene release from board during pressing}

Southern pine flakes were dried to $10 \% \mathrm{MC}$ (dry basis) and $25 \mathrm{~g}$ of the flakes were sealed 
in a 6"x7" stainless steel bag. Two stainless steel tubes at two corners allowed airflow. Resin was added in the following proportions:

1) $2.5 \%$ (by wt.) added uniformly to the flakes;

2) $5 \%$ (by wt.) added uniformly to the flakes

3) $2.5 \%$ applied only to the mat surface; this was done by placing about $12 \mathrm{~g}$ of flakes in the bag, applying resin to the remaining flakes, and carefully placing them on the top and bottom of the clean flakes;

4) $2.5 \%$ applied only to the flakes in the core.

The bag was pressed for 3 minutes at $1170 \mathrm{KPa}$. The upper platen was kept at $210^{\circ} \mathrm{C}$ and the lower at $110^{\circ} \mathrm{C}$. Ambient air was passed through the bag at $0.5 \mathrm{lpm}$ throughout pressing. The emissions were trapped in either chilled water for formaldehyde and methanol, or acetone for the terpenes. Formaldehyde was determined by the chromotropic acid method, methanol by gc, and the terpenes by gc-ms.

The emissions of both formaldehyde and methanol double when the resin content is doubled as shown in Table 5. This is expected since these emissions mainly originate from the resin. The emissions seem to be slightly for the surface application although the difference is the range of the analytical uncertainty. The results were opposite for the terpenes ( $\alpha$ and $\beta$ pinene), where $92 \mu \mathrm{g} / \mathrm{g}$ were released from the $2.5 \%$ resin experiment and $64 \mu \mathrm{g} / \mathrm{g}$ from the $5 \%$ resin measurement. It is likely that terpene emissions are controlled by their diffusion to the surface and the resin will obstruct diffusion.

If diffusion controls pinene emissions, it follows that the terpenes in the core of a commercially prepared mat would be higher than that near the surface. Material from a piece of purchased OSB was scratched from just below both surfaces and the core. The powder was added to about one $\mathrm{ml}$ of acetone and stirred vigorously. The acetone was analyzed by GC-MS. The terpene content in the core $(31.1 \mu \mathrm{g} / \mathrm{g}$ of wood) was threefold greater than that at the surface (11.0 $\mu \mathrm{g} / \mathrm{g})$. Hence, we conclude that the diffusion of terpenes is driven by the concentration gradient across the depth of the mat.

\subsection{Low-temperature catalytic conversion of VOC's released during hot pressing}

We previously showed that the manganese oxide on aluminum oxide catalyst conventionally used in RCOs was able to oxidize HAPs at lower than conventional temperatures. The catalyst could be incorporated into the platen assembly (as discussed later in this report) and the HAPs would be treated as they emerged from the press. In order to determine the robustness of the catalyst, catalytic efficiency was determined as a function of moisture and $\mathrm{pH}$.

Flakes were bone-dried at $105^{\circ} \mathrm{C}$ and various amounts of moisture were then added to them. GP145C48 core PF resin was added at 2,2\% of flake dry weight and the mixture was pressed in a steel bag with an MTS electrohydraulic press at an upper platen temperature of $220^{\circ} \mathrm{C}$. The lower platen was kept at $110^{\circ} \mathrm{C}$. The flakes were pressed under the conditions described above. The catalyst (obtained from Envirochem) was held in a $2.5 \times 24 \mathrm{~cm}$ column held at $175^{\circ} \mathrm{C}$. The results (Table 10) show that moisture has no effect on catalytic efficiency. 


\begin{tabular}{|c|c|c|c|c|c|c|}
\hline \multicolumn{7}{|c|}{ Table 10: Catalyst performance at various MCs. } \\
\hline MC (percent) & & \multicolumn{3}{|c|}{$\begin{array}{c}\mu \mathrm{\mu g} / \mathrm{g} \text { OD wood, } \\
\text { dry basis }^{1}\end{array}$} & $\begin{array}{c}\text { average } \\
(\mu \mathrm{g} / \mathrm{g})\end{array}$ & $\begin{array}{c}\text { percent } \\
\text { conversion }\end{array}$ \\
\hline \multirow{2}{*}{ no catalyst } & formaldehyde & 84.7 & 68.0 & 47.4 & 66.7 & \\
\hline & methanol & 22.0 & 15.0 & 11.3 & 16.1 & \\
\hline \multirow[t]{2}{*}{0} & formaldehyde & 3.47 & 3.50 & 3.19 & 3.38 & 94.9 \\
\hline & methanol & 2.19 & 1.56 & 1.53 & 1.76 & 89.1 \\
\hline \multirow[t]{2}{*}{50} & formaldehyde & 2.54 & 2.57 & 2.22 & 2.44 & 96.3 \\
\hline & methanol & 1.51 & 1.38 & 1.68 & 1.52 & 90.5 \\
\hline \multirow[t]{2}{*}{100} & formaldehyde & 2.57 & 3.47 & 4.21 & 3.42 & 94.9 \\
\hline & methanol & 1.62 & 1.71 & 2.24 & 1.86 & 88.4 \\
\hline \multirow[t]{2}{*}{150} & formaldehyde & 2.60 & 2.91 & 2.55 & 2.68 & 96.0 \\
\hline & methanol & 2.02 & 2.17 & 2.38 & 2.17 & 86.5 \\
\hline
\end{tabular}

\begin{tabular}{|c|l|c|c|c|c|c|}
\hline \multicolumn{2}{|c|}{$\begin{array}{c}\text { Table 11: Effect of pH on catalytic efficiency. } \\
\text { pH }\end{array}$} & \multicolumn{2}{|c|}{$\begin{array}{c}\boldsymbol{\mu g} / \mathbf{g} \text { OD wood, } \\
\text { dry basis } \mathbf{1}\end{array}$} & $\begin{array}{c}\text { average } \\
(\boldsymbol{\mu g} / \mathbf{g})\end{array}$ & $\begin{array}{c}\text { percent } \\
\text { conversion }\end{array}$ \\
\hline \multirow{2}{*}{ no catalyst } & formaldehyde & 68.3 & 85.7 & 78.0 & 77.3 & \\
\cline { 2 - 7 } & methanol & 16.0 & 19.4 & 17.2 & 17.5 & \\
\hline \multirow{2}{*}{4} & formaldehyde & 2.76 & 1.58 & 1.86 & 2.07 & 97.3 \\
\cline { 2 - 7 } & methanol & 2.82 & 2.16 & 1.70 & 2.23 & 87.3 \\
\hline \multirow{2}{*}{7} & formaldehyde & 1.73 & 0.62 & 0.79 & 1.05 & 98.7 \\
\cline { 2 - 7 } & methanol & 1.75 & 1.23 & 1.15 & 1.38 & 92.2 \\
\hline \multirow{2}{*}{10} & formaldehyde & 2.06 & 1.62 & 0.90 & 1.53 & 98.0 \\
\cline { 2 - 7 } & methanol & 1.91 & 1.51 & 1.22 & 1.55 & 91.2 \\
\hline
\end{tabular}

In order to determine whether catalytic activity was $\mathrm{pH}$-dependent, the catalyst was soaked in various buffers, dried at room temperature, and placed in a $16-\mathrm{cm} 175^{\circ} \mathrm{C}$ column. The results, presented in Table 11, demonstrate that catalytic efficiency is maintained under both acidic and basic conditions.

\subsection{Catalytic conversion of VOCs released during hot pressing}

The efficiency of conventional RCO catalysts in removing HAPs at typical platen temperatures was measured at LP's pilot facilities at Sherwood, OR. An illustration of the press is provided in Figure 5. The lower platen is porous and the emissions were collected and fed through a tube (in the foreground of Figure 5) containing the catalyst. The tube was heated through conduction from the lower platen. Two catalysts were used: a honeycomb material acquired by LP from Sud-Chemie Pyrotech (Pro VOC2 ceramic monolith catalyst) and a ringshaped product from Matros Technologies HPM (Z-2). According to the manufacturer, the honeycomb contained $<1 \% \mathrm{Pt}$ and $\mathrm{Pt}$ (IV) oxide and proprietary compounds on $20-23 \%$ alumina. However, SEM analysis did not show any alumina as discussed below. The Matros catalyst was specified to be more than $10 \% \mathrm{Mn}_{2} \mathrm{O}_{3}$ on alumina. Both structures were analyzed by SEM EDS (Energy Dispersive Spectroscopy); the results are listed in Table 12. 
Pine flakes $(22 \mathrm{lbs}, 8.1 \% \mathrm{MC})$ were mixed with resin and wax. PF face resin $(45.4 \%$ moisture) and MDI core resin (7\% dry-basis) was used throughout. Wax (1\% dry-basis) was added to the face at $1 \%$ of dry wood weight. The target panel thickness was 0.77 inches and the final board $\mathrm{MC}$ was $4 \%$. The emissions were continuously analyzed by FTIR after a 2.5 -fold dilution with ambient air to lower the water vapor concentration in the FT-IR cell. The results are presented in Table 13. Peak (rather than integrated) emissions are reported because the press opened before the emissions had decreased to their baseline values. However, it is very likely that the peak and total emissions are related and changes in one will track the other. Conversion efficiencies are provided in Table 14. The honeycomb catalyst works better for formaldehyde, although this could be due to better contact. A potential downside of this is catalyst plugging.
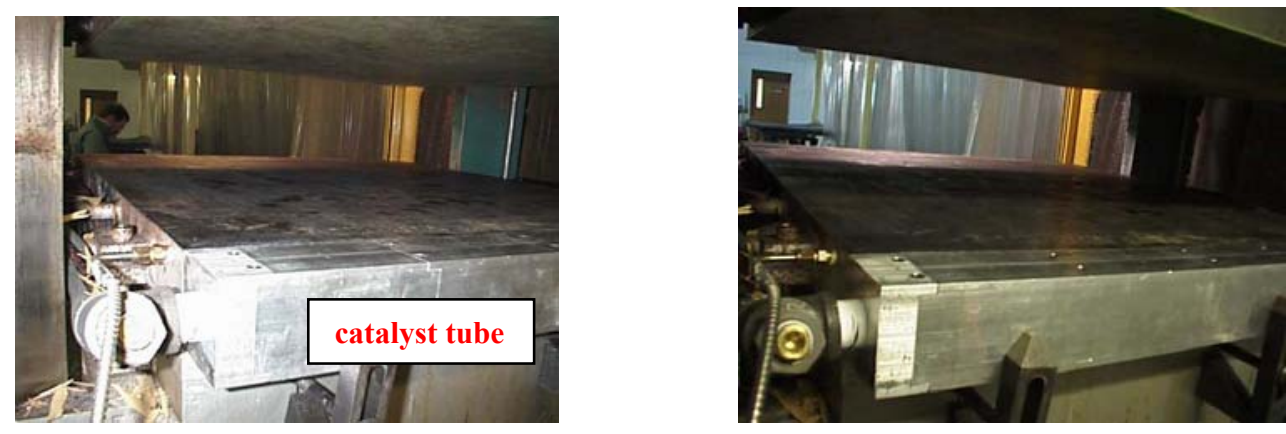

Figure 5: Illustrations of the pilot press. The lower platen is porous. The emissions are collected and passed through catalyst held in the rectangular tube in the foreground. The tube is heated through conduction from the platen.

\begin{tabular}{|c|c|}
\hline \multicolumn{2}{|c|}{ Table 12: Elemental composition of catalysts. } \\
\hline $\begin{array}{c}\text { element } \\
\text { honeycomb catalyst }\end{array}$ \\
\hline oxygen & 46.8 \\
\hline aluminum & 27.2 \\
\hline silicon & 13.5 \\
\hline carbon & 4.2 \\
\hline magnesium & 4.2 \\
\hline iron & 1.1 \\
\hline titanium & 0.8 \\
\hline cerium & 2.2 \\
\hline ring catalyst & \\
\hline aluminum & 43.7 \\
\hline oxygen & 38.0 \\
\hline manganese & 15.8 \\
\hline carbon & 2.4 \\
\hline silicon & 0.2 \\
\hline
\end{tabular}




\begin{tabular}{|l|c|c|c|c|}
\hline Table 13: Peak VOC emissions during pressing under various conditions. \\
\hline peak emissions (ppmv) & $\begin{array}{c}\text { acetalde- } \\
\text { hyde }\end{array}$ & $\begin{array}{c}\text { formalde- } \\
\text { hyde }\end{array}$ & $\begin{array}{c}\text { metha- } \\
\text { nol }\end{array}$ & $\begin{array}{c}\text { a- } \\
\text { pinene }\end{array}$ \\
\hline no catalyst; 6\% PF \& MDI & 54 & 110 & 480 & 48 \\
\hline honeycomb catalyst; 6\% PF \& MDI $^{\text {hing }}$ & 15 & 16 & 360 & 52 \\
\hline ring catalyst; 6\% PF \& MDI & 17 & 32 & 310 & 59 \\
\hline ring catalyst; PF only & 20 & 67 & 380 & 56 \\
\hline ring catalyst; MDI only & & 14 & 180 & 62 \\
\hline no catalyst, no resin & 19 & 30 & 89 & 38 \\
\hline no catalyst, MDI only & 61 & 26 & 68 & 42 \\
\hline no catalyst, 3\% PF & 45 & 80 & 270 & 47 \\
\hline honeycomb catalyst; no resin & 51 & 6.5 & 87 & 51 \\
\hline honeycomb catalyst; MDI only & 42 & 7 & 86 & 53 \\
\hline honeycomb catalyst; 3\% PF & 20 & 8 & 200 & 48 \\
\hline${ }^{1} 688$ grams of the ring catalyst were used. & & & \\
\hline
\end{tabular}

\begin{tabular}{|l|c|c|c|}
\hline \multicolumn{4}{|c|}{ Table 14: Conversion efficiencies of the catalysts. } \\
\hline efficiency (\%) & acetaldehyde & formaldehyde & methanol \\
\hline honeycomb & 76 & 85 & 28 \\
\hline ring & 61 & 43 & 33 \\
\hline
\end{tabular}

\begin{tabular}{|l|c|c|c|c|}
\hline \multicolumn{5}{|l|}{ Table 15: HAPs concentration in the press exhaust. } \\
\hline & acetaldehyde & formaldehyde & methanol & total \\
\hline lbs/odt & & & & \\
\hline no catalyst & 0.0256 & 0.0668 & 0.308 & 0.4 \\
\hline honeycomb & 0.0054 & 0.0099 & 0.212 & 0.228 \\
\hline Ring & 0.00722 & 0.0198 & 0.176 & 0.202 \\
\hline $\boldsymbol{l b s} / \boldsymbol{M S F}$ & & & & \\
\hline no catalyst & 0.0225 & 0.0588 & 0.271 & 0.35 \\
\hline honeycomb & 0.0048 & 0.0087 & 0.187 & 0.201 \\
\hline ring & 0.0064 & 0.0175 & 0.155 & 0.179 \\
\hline
\end{tabular}

\begin{tabular}{|l|l|l|l|l|l|}
\hline \multicolumn{6}{|l|}{ Table 16: Projected emissions with the catalysts for OSB presses. } \\
\hline $\begin{array}{l}\text { emissions } \\
\text { lbs/MSF }\end{array}$ & $\begin{array}{l}\text { acetalde- } \\
\text { hyde }\end{array}$ & $\begin{array}{l}\text { formalde- } \\
\text { hyde }\end{array}$ & methanol & $\begin{array}{l}\text { total } \\
(\mathbf{3 / 8} \text { ') }\end{array}$ & total (3/4”) \\
\hline hardwood & 0.0065 & 0.034 & 0.27 & 0.311 & 0.621 \\
\hline honeycomb & 0.00156 & 0.0051 & 0.194 & 0.201 & 0.402 \\
\hline ring & 0.00254 & 0.0194 & 0.181 & 0.203 & 0.406 \\
\hline softwood & 0.0099 & 0.042 & 0.35 & 0.402 & 0.804 \\
\hline honeycomb & 0.00328 & 0.0063 & 0.252 & 0.261 & 0.521 \\
\hline ring & 0.00386 & 0.0239 & 0.235 & 0.262 & 0.525 \\
\hline
\end{tabular}


Table 15 gives the concentration of the HAPs in the exit gases from the press, adjusted for dilution with ambient air. The water in the mat derives from the moisture in the flakes, water added to the resin and the water content of wax. The final moisture content of the flakes after pressing was $4 \%$. This allows calculation of the amount of steam lost during pressing. The average HAPs emissions are known and since they are all carried out by the steam, we are able to estimate the HAPs load in the steam. Now, the steam evolved is related to the amount of wood pressed, which allows calculation of the HAPs released as a function of the amount of wood processed. These values are provided in Table 15. It is clear that the catalyst reduces the emissions to just below the proposed production-based limit of $0.3 \mathrm{lb} / \mathrm{MSF}$ of $3 / 4$ " board.

Crawford and Word (NCASI Technical Bulletin, no. 772, 1999) reported HAPs emissions data from hardwood and softwood presses. The catalytic efficiencies from Table 10 were applied to their results and the projected values are listed in Table 16. These are about $70 \%$ higher than the production-based limits. In this instance, doubling the catalyst used should reduce the HAPs below the regulatory limit.

In conclusion, a small amount of conventional RCO catalyst heated through conduction with the platen should be able to bring HAPs emissions to within the production-based limit for the pilot trial. Estimates with literature data show that the limit could be exceeded somewhat in other instances. It seems fair to conclude that the catalyst:wood ratio used reduces emissions to the regulatory level. The limit should be easily met if the amount of catalyst is doubled, which should be doable.

\subsection{Urea reduces formaldehyde press emissions}

Urea reacts with formaldehyde and is usually added along with the resin to minimize formaldehyde bleed from finished board. Formaldehyde emissions are reduced when ureaimpregnated chips are heated in water (Huster and Roffael, Holz RohWerkst. 57(6), 446, 1999). Urea must also reduce press emissions and it should be possible to optimize the amount of urea added. GP145C48 core PF resin was added to pine flakes (15 g., 5\% MC) at $2.2 \%$ of wood mass. For some experiments, urea was also added at $2.2 \%$ of wood mass. Flakes kept in a steel bag fitted with inlet and outlet tubes were pressed in an MTS press for 3 minutes at approximately 100 psi. The upper platen of the press was held at $212^{\circ} \mathrm{C}$ and the lower one was at $110^{\circ} \mathrm{C}$. An airflow of $0.3 \mathrm{lpm}$ was maintained through the bag during pressing and for three minutes thereafter.

The results, shown in Table 17 demonstrate that urea reduces the amount of formaldehyde evolved by half. The platen pressure was pulsed briefly at the end in some experiments. The purpose was to convert the mat moisture to steam and then back to liquid. We know that formaldehyde is moved through the mat by steam, and our intent was to circulate the steam within the mat. This would also circulate the formaldehyde and increase its probability of reacting with urea and other species. Hence, after the three-minute press period the pressure was reduced to $1.8 \mathrm{~atm}$. and then cycled between 1.8 and $2.2 \mathrm{~atm}$ over ten seconds. At $120^{\circ} \mathrm{C}$ (the measured mat temperature) the pressure at which water converts to steam is 2 atm. Hence, pulsing should have led to several steam-to-water conversions within the mat. Contrary to 


\begin{tabular}{|c|c|c|c|c|c|}
\hline & \multicolumn{5}{|c|}{ formaldehyde (ug/g OD wood) } \\
\hline & 1 & 2 & 3 & 4 & average \\
\hline \multicolumn{6}{|l|}{ without pulse } \\
\hline wood + resin & 57.5 & 109 & 78.0 & 74.5 & $80 \pm 15$ \\
\hline wood + resin + urea & 35.4 & 43.6 & 44.4 & 20.2 & $36 \pm 8$ \\
\hline \multicolumn{6}{|l|}{ with pulse (0.5 s) } \\
\hline wood + resin & 53.6 & 59.2 & 123 & 159 & $100 \pm 40$ \\
\hline wood + resin + urea & 47.1 & 36.6 & 57.7 & 83.2 & $56 \pm 14$ \\
\hline
\end{tabular}

\begin{tabular}{|c|c|c|c|c|c|}
\hline Table 18: Effect of pulse duration on formaldehyde release. \\
\hline & \multicolumn{5}{|c|}{ formaldehyde (ug/g OD wood) } \\
\hline pulse duration (sec) & $\mathbf{1}$ & $\mathbf{2}$ & $\mathbf{3}$ & $\mathbf{4}$ & average \\
\hline 0 & 69.8 & 74.4 & 93.3 & 89.3 & $80 \pm 10$ \\
\hline 0.5 & 53.6 & 59.2 & 123 & 159 & $100 \pm 40$ \\
\hline 1 & 75.7 & 133 & 68.5 & 86.8 & $90 \pm 20$ \\
\hline 2 & 1.98 & 102 & 90.3 & 77.8 & $90 \pm 30$ \\
\hline 4 & 77.7 & 65.5 & 88.5 & 81.2 & $78 \pm 7$ \\
\hline 10 & 85.8 & 88.3 & 61.0 & 113 & $87 \pm 14$ \\
\hline
\end{tabular}

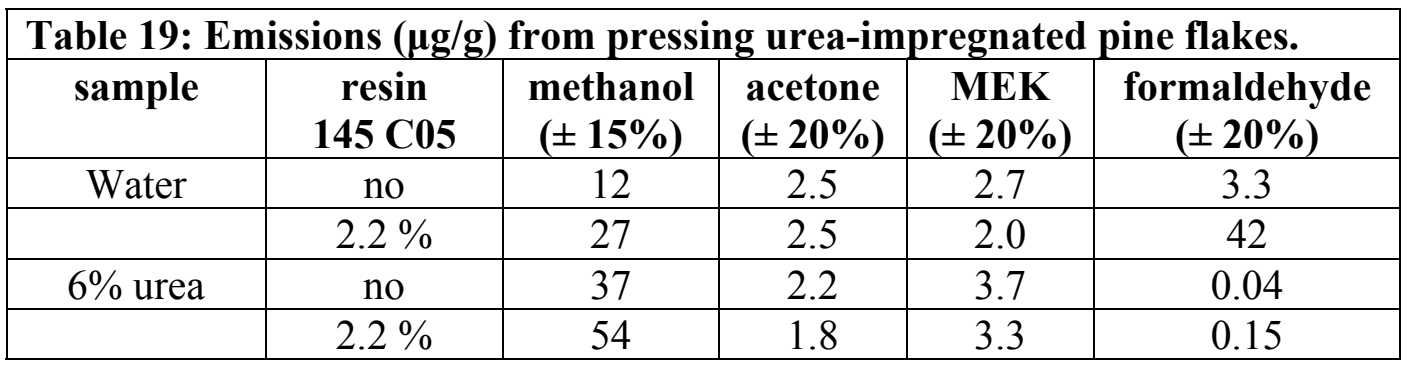

expectation, pressure-pulsing increased the formaldehyde released; the reasons are unknown. Varying the duration of the pulse did not significantly alter the results are shown in Table 18.

It seemed likely that a larger formaldehyde reduction could be obtained if the urea was mixed more intimately with the furnish. Pine flakes were bone-dried in a $105^{\circ} \mathrm{C}$ oven over 36 hours. The flakes were then soaked in water, and a $6 \%$ urea solution, and were then air-dried for 5 days to approximately $6-8 \% \mathrm{MC}$. The flakes were pressed in duplicate as described above. The emissions collected are listed in Table 19, and show that formaldehyde is almost completely eliminated in the presence of urea. This represents an extreme situation; the flakes would not be soaked in the field. Nevertheless, the results illustrate that better mixing of urea into the mat could decrease formaldehyde significantly at relatively low cost. 


\section{Modeling emissions from veneer dryers}

Veneer dryers typically have three or four independent zones that are heated by internal fans that transfer heat from steam-heated coils. The veneer is typically conveyed in $3 \times 3$ layers. A model for estimating pinene concentration in the three zones was derived with the following assumptions:

- veneer and heated air are supplied at a constant rate;

- the surface temperature of veneer is that of the heated air;

- the mass transfer of water from the interior of the veneer to the surface is not limiting owing to the large specific area of veneer.

The evaporation rate for water can be calculated by performing the energy balance for each zone as follows:

$Q_{\text {air }}\left(T_{\text {air }, 1}-T_{\text {air }, 2}\right) q_{\text {air }}=Q_{\text {water }} q_{\text {water }}\left(100-T_{\text {water }, 1}\right)+Q_{\text {vaporizedwater }} \Delta H+$

$Q_{\text {vapor }} q_{\text {vapor }}\left(T_{\text {air }, 2}-100\right)+Q_{\text {veneer }} q_{\text {veneer }}\left(T_{\text {veneer }, 1}-T_{\text {veneer }, 2}\right)$

where $\mathrm{q}$ is the flowrate for water contained in veneer, water vapor, air, and veneer, respectively, $\mathrm{Q}$ is the specific heat requirement for water evaporation, water vapor, air and veneer, respectively, $T_{\text {air, }, 1}$ and $T_{\text {air, } 2}$ are the temperatures of the incoming and exiting air, respectively, $T_{\text {veneer, } 1}$ and $\mathrm{T}_{\text {veneer, } 2}$ are corresponding temperatures for veneer, and $\Delta \mathrm{H}$ is the heat of vaporization of water. The water evaporation flowrate, $\mathrm{q}$, can be determined by performing the energy balance described in equation 1 . The values of the various parameters used are

$\mathrm{Q}_{\text {water }}$ and $\mathrm{Q}_{\text {veneer: }}: 4.2 \mathrm{~J} / \mathrm{K} / \mathrm{g}$;

$\mathrm{Q}_{\text {vapor }}: 1.98 \mathrm{~J} / \mathrm{K} / \mathrm{g}$ (at $\left.1 \mathrm{~atm}, 500^{\circ} \mathrm{K}\right)$;

$\Delta \mathrm{H}: 33.468 \mathrm{~kJ} / \mathrm{mol}\left(\right.$ at $\left.428^{\circ} \mathrm{K}\right)$

The mass transfer rate, $K_{L} a_{i}$, for a solute from surface water to the gas phase can be determined as follows:

$$
\text { mass transfer rate for component } \mathrm{i}=K_{L} a_{i} \times\left(C_{i, H}-C_{i, \text { real }}\right)
$$

where $K_{L} a_{i}$ is the overall mass transfer coefficient from liquid to gas phase for component $i$, and $\mathrm{C}_{\mathrm{i}, \mathrm{H}}$ and $\mathrm{C}_{\mathrm{i}, \text { real }}$ are equilibrium and actual gas phase concentrations for component $i$, respectively. Most of the moisture is contained close to the surface of veneer on account of its high specific area and it is reasonable to assume good contact between water and air. The correlation proposed by Alexander and Shah (Can. J. Chem. Eng., 54: 556, 1976) was used to calculate the overall mass transfer of oxygen, $K_{\mathrm{LO} 2}$ from the gas-phase to the liquid-phase $\left(\mathrm{s}^{-1}\right)$ :

$$
K_{L} a_{O_{2}}=0.06371 \times\left(V_{L}^{\prime}\right)^{0.3014} \times\left(V_{G}^{\prime}\right)^{0.4484}
$$


where $\mathrm{V}_{1}$ ' represents the liquid-phase superficial mass velocity $\left(\mathrm{kg} \cdot \mathrm{m}^{2} \cdot \mathrm{s}^{-1}\right)$ and $\mathrm{V}_{\mathrm{g}}$ ' stands for the gas-phase superficial mass velocity $\left(\mathrm{kg} \cdot \mathrm{m}^{2} \cdot \mathrm{s}^{-1}\right)$. Equation 4 can be derived from the two film theory and was used to calculate the overall mass transfer coefficient, $\mathrm{k}_{\mathrm{L}} \mathrm{a}_{\mathrm{i}}$, for each compound, $\mathrm{i}$ :

$$
K_{L} a_{i}=K_{L} a_{O_{2}}\left(\frac{D_{l, i}}{D_{l, O_{2}}}\right)^{0.5}\left[1+\frac{1}{H_{i}\left(\frac{k_{g, i}}{k_{l, i}}\right)}\right]^{-1}
$$

where $K_{L} a_{i}$ is equal to the overall mass transfer coefficient between gas and liquid phase $\left(\mathrm{s}^{-1}\right)$ for compound $\mathrm{i}, \mathrm{D}_{1, \mathrm{i}}$ equals the liquid diffusivity of compound $\mathrm{i}\left(\mathrm{cm}^{2} \cdot \mathrm{s}\right), \mathrm{D}_{1, \mathrm{O} 2}$ is equal to the liquid phase diffusion coefficient of oxygen $\left(\mathrm{cm}^{2} \cdot \mathrm{s}\right), \mathrm{H}_{\mathrm{i}}$ equals the dimensionless Henry's law constant of compound $\mathrm{i}$, and $\mathrm{k}_{\mathrm{g}, \mathrm{i}} / \mathrm{k}_{\mathrm{l}, \mathrm{i}}$ equals the ratio of gas phase mass transfer coefficient to the liquid phase mass transfer coefficient for compound i (dimensionless).

Hsieh et al. (J. Environ. Eng., 119, 6, 1993) reported that the ratio $\mathrm{k}_{\mathrm{g}, \mathrm{i}} / \mathrm{k}_{\mathrm{l}, \mathrm{i}}$ was relatively constant for bubble aeration and ranged between 2.2 and 3.6; a conservative value of 2.5 was assumed. $\mathrm{D}_{\mathrm{L}, \mathrm{i}}$ was determined from the correlation presented by Hayduk and Laudie (AIChEJ. 20, 611, 1974)

$$
D_{L, i}=\frac{13.26 \times 10^{-5}}{\mu^{1.14} V_{b}^{0.589}}
$$

where $\mu$ is the viscosity of liquid water (centipoise) and $\mathrm{V}_{\mathrm{b}}$ is the molar volume of the solute at the normal boiling point $\left(\mathrm{cm}^{3} \cdot \mathrm{gmol}^{-1}\right)$. $\mathrm{D}_{1, \mathrm{O} 2}$ was adjusted with temperature and water viscosity $\left(\mathrm{D}_{1, \mathrm{O} 2}\right.$ at $25^{0} \mathrm{C}$ is $3.25 \times 10^{-5} \mathrm{~cm}^{2} \cdot \mathrm{s}^{-1}$, and the viscosity of water at $25^{0} \mathrm{C}$ is $\left.0.0089 \mathrm{~g} \cdot \mathrm{cm}^{-1} \cdot \mathrm{s}^{-1}\right)(\mathrm{CRC}$ Handbook, 1998).

$$
D_{L, O_{2}}=\frac{3.25 \times 10^{-5} \times 0.0089 \times \text { Temperature }}{298.15 \times \mu}
$$

where $\mu$ equals viscosity of liquid water $\left(\mathrm{g} \cdot \mathrm{cm}^{-1} \cdot \mathrm{s}^{-1}\right)$ and temperature is in degrees Kelvin. The Henry's Law constants used for various solutes are presented in Table 1.

\begin{tabular}{|l|c|}
\hline Table 1: Henry's Law constants for various solutes. \\
\hline formaldehyde & 6.37 \\
\hline methanol & 2.39 \\
\hline ethanol & 3.02 \\
\hline acetone & 1.13 \\
\hline pinene & 1.66 \\
\hline
\end{tabular}




\begin{tabular}{|c|c|}
\hline \multicolumn{2}{|c|}{ Table 2: Results of sensitivity analysis. } \\
\hline $\begin{array}{c}\text { change in parameters } \\
(90-110 \%)\end{array}$ & $\begin{array}{c}\text { effect on model } \\
\text { output }(\%)\end{array}$ \\
\hline $\mathrm{D}_{\mathrm{L}, \mathrm{O}}\left(\mathrm{cm}^{2} \cdot \mathrm{s}\right)$ & $95 \sim 105$ \\
\hline $\mathrm{D}_{\mathrm{L}, \mathrm{I}}\left(\mathrm{cm}^{2} \cdot \mathrm{s}\right)$ & $105 \sim 95$ \\
\hline $\mathrm{V}_{\mathrm{L}}{ }^{\prime}\left(\mathrm{kg} \cdot \mathrm{m}^{2} \cdot \mathrm{s}^{-1}\right)$ & $97 \sim 102$ \\
\hline $\mathrm{V}_{\mathrm{G}}{ }^{\prime}\left(\mathrm{kg} \cdot \mathrm{m}^{2} \cdot \mathrm{s}^{-1}\right)$ & $95 \sim 104$ \\
\hline $\mathrm{K}_{\mathrm{L}} \mathrm{a}_{\mathrm{O} 2}\left(\mathrm{~s}^{-1}\right)$ & $50 \sim 150$ \\
\hline $\mathrm{K}_{\mathrm{L}} \mathrm{a}_{\mathrm{i}}\left(\mathrm{s}^{-1}\right)$ & $50 \sim 150$ \\
\hline
\end{tabular}

\begin{tabular}{|l|l|l|}
\hline \multicolumn{2}{|l|}{ Table 3: Estimated parameters for pinene. } \\
\hline $\mathrm{D}_{\mathrm{L}, \mathrm{O}}\left(\mathrm{cm}^{2} \cdot \mathrm{s}\right)$ & $1.98 \mathrm{E}-4$ & $D_{L, O_{2}}=\frac{3.25 \times 10^{-5} \times 0.0089 \times \text { Temperature }}{298.15 \times \mu}$ \\
\hline $\mathrm{D}_{\mathrm{L}, \mathrm{I}}\left(\mathrm{cm}^{2} \cdot \mathrm{s}\right)$ & $1.46 \mathrm{E}-4$ & $D_{L, i}=\frac{13.26 \times 10^{-5}}{\mu^{1.14} V_{b}^{0.589}}$ \\
\hline $\mathrm{V}_{\mathrm{L}}{ }^{\prime}\left(\mathrm{kg} \cdot \mathrm{m}^{2} \cdot \mathrm{s}^{-1}\right)$ & 5.83 & Determined from water flow rate \\
\hline $\mathrm{V}_{\mathrm{G}}{ }^{\prime}\left(\mathrm{kg} \cdot \mathrm{m}^{2} \cdot \mathrm{s}^{-1}\right)$ & 0.117 & Determined from airflow rate \\
\hline $\mathrm{K}_{\mathrm{L}} \mathrm{a}_{\mathrm{o}}\left(\mathrm{s}^{-1}\right)$ & 0.0414 & $K_{L} a_{O_{2}}=0.06371 \times\left(V_{L}^{\prime}\right)^{0.3014} \times\left(V_{G}^{\prime}\right)^{0.4484}$ \\
\hline $\mathrm{K}_{\mathrm{L}} \mathrm{a}_{\mathrm{i}}\left(\mathrm{s}^{-1}\right)$ & 0.02866 & $K_{L} a_{i}=K_{L} a_{O_{2}}\left(\frac{D_{l, i}}{D_{l, O_{2}}}\right)^{0.5}\left[1+\frac{1}{H_{i}\left(\frac{k_{g, i}}{k_{L, i}}\right)}\right]^{-1}$ \\
& & \\
\hline
\end{tabular}

Table 2 shows the sensitivity of the modeled result on the major input parameters. The effect was obtained by changing each parameter to between $90-110 \%$ of the original value while keeping the others unchanged. Clearly, the output is most sensitive to $\mathrm{K}_{\mathrm{L}} \mathrm{a}_{\mathrm{O} 2}$ and $\mathrm{K}_{\mathrm{L}} \mathrm{a}_{\mathrm{i}}$.

Data were collected from the G-P Madison, GA, mill. The airflow ( $\mathrm{scfm}$ ) in each of the four zones were 1: (green zone): 625, 2: 3,310, 3: 1,908, 4: 11,2000. The load of veneer was 350 $\mathrm{kg} / \mathrm{min}$ (dry basis), assuming $100 \% \mathrm{MC}$ before drying. The temperature was assumed to be $410^{\circ} \mathrm{F}$ throughout. The model was calibrated with data for the first zone and then applied to the other zones.

The pinene concentration in the first zone was $462 \mathrm{ppm}$. Since the airflow for this zone is $625 \mathrm{scfm}$, the rate of pinene release should be $0.289\left(625 \times 462 \times 10^{-6}\right) \mathrm{scfm}$. The estimated parameters for pinene are shown in Table 3 , from which $\left(\mathrm{C}_{\mathrm{i}, \mathrm{H}^{-}} \mathrm{C}_{\mathrm{i}, \text { real }}\right)$ is calculated to be $6.48 \times 10^{-}$ ${ }^{3} \mathrm{~mol} / \mathrm{L}$. The mass transfer rate, $K_{L} a_{i}$, was then obtained from eq. 2 . This value was then used to calculate the pinene concentration for the other zones as shown in Table 4. This was straightforward, since the temperature was the same for all the zones. If the model were calibrated based on the data for the fourth zone, then the values in Table 5 resulted. 


\begin{tabular}{|c|c|c|c|}
\hline \multicolumn{4}{|c|}{ Table 4: Pinene emissions calibrated with Madison zone 1 data. } \\
\hline & flow (scfm) & pinene (ppm, actual) & pinene (ppm, estimated) \\
\hline 4 & 11,220 & 60.3 & 26.0 \\
\hline 3 & 1,908 & 221 & 151 \\
\hline 2 & 3,310 & 79.7 & 87.0 \\
\hline 1 & 625 & 462 & 462 \\
\hline
\end{tabular}

\begin{tabular}{|c|c|c|c|}
\hline \multicolumn{5}{|c|}{ Table 5: Pinene emissions calibrated with Madison zone 4 data. } \\
\hline zone & flow (scfm) & pinene (ppm, actual) & pinene (ppm, estimated) \\
\hline 4 & 11,220 & 60.3 & 60.3 \\
\hline 3 & 1,908 & 221 & 355 \\
\hline 2 & 3,310 & 79.7 & 204.4 \\
\hline 1 & 625 & 462 & 1080 \\
\hline
\end{tabular}

\begin{tabular}{|l|c|c|c|}
\hline \multicolumn{4}{|c|}{ Table 6: Monticello dryer $\mathbf{2}$ parameters. } \\
\hline \multicolumn{1}{|c|}{ zone: } & $\mathbf{1}$ & $\mathbf{2}$ & $\mathbf{3}$ \\
\hline stack temperature $\left({ }^{\circ} \mathrm{F}\right)$ & 326 & 339 & 343 \\
\hline air flowrate $(\mathrm{acfm})$ & 6,375 & 6,618 & 10,118 \\
\hline air flowrate $(\mathrm{scfm})$ & 4,252 & 4,342 & 6,606 \\
\hline dry scfm & 2,551 & 2,866 & 5,285 \\
\hline moisture content & $40 \%$ & $34 \%$ & $20 \%$ \\
\hline
\end{tabular}

\begin{tabular}{|c|c|c|c|}
\hline \multicolumn{4}{|c|}{ Table 7: Pinene emissions at Monticello calibrated with data from Madison. } \\
\hline zone & flow (scfm) & $\begin{array}{c}\text { pinene (ppmv, } \\
\text { measured) }\end{array}$ & pinene (ppmv, modeled) \\
\hline 1 & 4,252 & 58.4 & 56.3 \\
\hline 2 & 4,342 & 80.8 & 54.4 \\
\hline 3 & 6,606 & 32.1 & 35.7 \\
\hline
\end{tabular}

\begin{tabular}{|c|c|c|c|}
\hline \multicolumn{4}{|c|}{ Table 8: Moisture content (\%) in air and veneer at Monticello. } \\
\hline zone & $\begin{array}{c}\text { MC (air, } \\
\text { measured) }\end{array}$ & $\begin{array}{c}\text { MC (air, } \\
\text { modeled) }\end{array}$ & MC (veneer) \\
\hline 1 & 40 & 39 & 74 \\
\hline 2 & 34 & 34 & 51 \\
\hline 3 & 20 & 32 & 12 \\
\hline
\end{tabular}




\begin{tabular}{|c|c|c|c|c|c|}
\hline & $\begin{array}{l}\text { tempera- } \\
\text { ture }\left({ }^{0} \mathbf{F}\right)\end{array}$ & $\begin{array}{c}\text { airflow } \\
\text { (cfm) }\end{array}$ & $\begin{array}{c}\text { pinene } \\
\text { (ppm) }\end{array}$ & $\begin{array}{c}\mathrm{MC} \text { in } \\
\operatorname{air}(\%)\end{array}$ & $\begin{array}{c}\text { wood MC } \\
(\%)^{1}\end{array}$ \\
\hline \multicolumn{6}{|l|}{ current } \\
\hline zone 1 & 326 & 4252 & 60 & 40 & 73 \\
\hline zone 2 & 339 & 4342 & 58 & 36 & 48 \\
\hline zone 3 & 343 & 6606 & 46 & 34 & 6 \\
\hline \multicolumn{6}{|c|}{$10 \%$ increase in airflow } \\
\hline zone 1 & 326 & 4677 & 57 & 40 & 70 \\
\hline zone 2 & 339 & 4778 & 55 & 36 & 43 \\
\hline zone 3 & 343 & 7267 & 44 & 34 & 0 \\
\hline \multicolumn{6}{|c|}{$10 \%$ increase in temperature } \\
\hline zone 1 & 359 & 4252 & 57 & 48 & 63 \\
\hline zone 2 & 373 & 4342 & 55 & 45 & 27 \\
\hline zone 3 & 377 & 6606 & 44 & 43 & 0 \\
\hline \multicolumn{6}{|c|}{ suggested conditions } \\
\hline zone 1 & 370 & 3500 & 63 & 50 & 67 \\
\hline zone 2 & 360 & 4000 & 59 & 42 & 38 \\
\hline zone 3 & 340 & 5200 & 53 & 33 & 6 \\
\hline
\end{tabular}

The model was verified by applying the $\mathrm{K}_{\mathrm{L}} \mathrm{a}_{\mathrm{i}}$ and $\left(\mathrm{C}_{\mathrm{i}, \mathrm{H}}-\mathrm{C}_{\mathrm{i}, \text { real }}\right)$ parameters calculated above to a second mill. VOC emissions were collected on December 5, 2001 from the G-P, Monticello, GA, facility, which makes 3/8" board. Measurements were made at dryer 2, which has a capacity of about $145.11 \mathrm{~kg} / \mathrm{min}$; its parameters are provided in Table 6 . Pinene was monitored by FTIR for 30 minutes at each location.

The $\mathrm{K}_{\mathrm{L}} \mathrm{a}_{\mathrm{i}}$ and $\left(\mathrm{C}_{\mathrm{i}, \mathrm{H}}-\mathrm{C}_{\mathrm{i} \text {,real }}\right)$ for pinene determined from the Madison trial were used to make model prediction for this case. $\mathrm{K}_{\mathrm{L}} \mathrm{a}_{\mathrm{i}}$ was calibrated as described in Equation 4, and the results are shown in Table 7. Although the predictions are reasonable overall, the pinene surge in zone 2 is not accounted for. The estimated MC of the veneer in each zone is provided in Table 8.

The model described above was coded into an Excel spreadsheet. The sensitivity of the mass transfer rate, $\mathrm{K}_{\mathrm{L}} \mathrm{a}$ (determined from an earlier mill trial) to experimental parameters was determined. A 10\% change in airflow, veneer flow, and temperature under the conditions used at the G-P, Monticello, GA, facility, altered $\mathrm{K}_{\mathrm{L}}$ a by 5, 3 and $6 \%$, respectively, which is an acceptably small change.

The effect of changing airflow and temperature at Monticello are provided in Table 9. Note that changing airflow and temperature changes the moisture parameters as expected, but does not significantly alter the pinene concentrations. Increasing temperature increases the risk of dryer fires. However, the odds of this happening are lowest in zone 1 where the wood is still quite wet. The advantage of doing this is that airflow can be reduced, which translates to a pro- 
portional decrease in the size of the control device. In the last panel in Table 9, an increase in temperature, particularly in zone 1 leads to an overall decrease in airflow of $17 \%$. Other scenarios will now be modeled. The concentration of pinene in air required to sustain combustion is being computed under various conditions, and the size of each zone will be reproportioned to enrich pinene in at least one zone. 


\section{Heat transfer model for estimating pinene emissions from hot-pressing softwood flake- board}

This section is excerpted from J.P. Radhakrishnan, S.Banerjee, A simple heat transfer model for estimating terpene emissions from hot-pressing softwood, Holzforschung, 58, 384 (2004).

\section{Introduction}

Oriented strand board and particleboard are made by mixing resin with dry flakes or particle, respectively, and hot-pressing a mat prepared from the resinated wood. Terpenes, principally $\alpha$-pinene, are the main volatile organic compounds (VOCs) released from pressing softwood. Methanol, formaldehyde, acetaldehyde, propionaldehyde, and other compounds are released in much smaller quantities, but are important and are regulated separately as "Hazardous Air Pollutants" or HAPs (Jiang et al. 2002). The terpenes are lost through simple evaporation (Banerjee 2001). Hence, terpene emissions must relate to parameters such as the rate of heat transfer and wood porosity. In this paper we develop and validate a simple heat transfer model for the release of pinene during hot-pressing strand.

\section{Materials and Methods}

Green pine flakes were oven-dried at $105^{\circ} \mathrm{C}$ to a dry-basis moisture content of about $8 \%$. The flakes were trimmed to approximately 2 x $10 \mathrm{~cm}$ and mixed with GP145C 48 core PF resin (from Georgia-Pacific) at $2.75 \%$ of oven-dried wood mass. A known weight (15 or $20 \mathrm{~g}$ ) of the dried flakes was oriented into $11 \times 11 \times 1-\mathrm{cm}$ mats containing between six and eight flakes in the $\underline{z}$ direction. Each mat was inserted into a foil bag constructed from $0.005-\mathrm{cm} 309$ highchromium stainless steel and fitted with air intake and outflow tubes as described earlier (Martino et al. 2002). The bag was sealed and placed between the heated $\left(210^{\circ} \mathrm{C}\right)$ top platen $(15$ x $15 \mathrm{~cm})$ and lower cold $\left(110^{\circ} \mathrm{C}\right)$ platen of an electrohydraulic press. This arrangement simulates half of the mat in an industrial press where heat is applied from both platens. The mat was pressed at $1500 \mathrm{kPa}$ for $3 \mathrm{~min}$. The final (dry basis) moisture content (MC) was less than $1 \%$. Airflow of $0.3 \mathrm{lpm}$ was maintained through the bag during pressing and for 4 mins thereafter, and the emissions were vented through heated aluminum tubing $\left(165^{\circ} \mathrm{C}\right)$ into $25 \mathrm{ml}$ of chilled acetone. The trap solvent was then analyzed by gas chromatography $(\mathrm{gc})$. Breakthrough was measured by placing a second trap after the first; carryover was insignificant. For the experiments with a pine core and an aspen surface, either 12 or $15 \mathrm{~g}$ of pine flakes were sandwiched between 4 or $5 \mathrm{~g}$ of aspen flakes, respectively, so that aspen constituted $25 \%$ of the total furnish.

The pinene content of the wood tissue in oriented strand board (OSB) was determined using several sheets obtained from a local hardware store and from boards pressed in the laboratory. The commercial board was very lightly sanded, and a $10 \times 10 \mathrm{~cm}$ square was cut from the center of each board. Surface and core material was filed out and the filings soaked in acetone overnight and analyzed by gc.

\section{Results and Discussion}

Modeling the release of pinene during hot-pressing

Terpenes are released from the mat during pressing due to the differential vapor pressure created by the temperature gradient. The amount of terpenes released depends on the temperature distribution within the mat, and thus on the heat transfer to the mat. The diffusion of ter- 
penes from an OSB mat during pressing can be modeled using simple heat and mass transfer considerations. For diffusion in solids, the diffusion depth, the effective thickness of penetration of the diffusing species during time (t), is given by Eq. 1.

$$
z_{i}=4 \sqrt{D_{i} t}
$$

where $D_{i}$ is the diffusion coefficient of the diffusing species (Bird et al.1994).

$\alpha$-Pinene is the principal terpene released from softwood (Cronn et al.1983) and is used as a representative compound in this study. Its $\mathrm{D}_{\mathrm{i}}$ value for diffusion in wood is not available, and the following approximations were made to arrive at an estimate. The diffusion coefficient of water vapor, $D_{w}$, has been reported to be $3.8 \times 10^{-10} \mathrm{~m}^{2} \mathrm{~s}^{-1}$ and $4.9 \times 10^{-10} \mathrm{~m}^{2} \mathrm{~s}^{-1}$, respectively for Scots pine heartwood and sapwood at $60^{\circ} \mathrm{C}$, respectively (Sehlstedt-Persson 2001). Since our mat was principally composed of sapwood, the second value is more appropriate for our application. The diffusion coefficient of a gas in a porous medium is given by Eq. (2)

$$
D_{A}=\frac{d}{3}\left(\frac{8 R T}{\pi M_{A}}\right)^{\frac{1}{2}}
$$

where $d$ is pore diameter, $R$ is the gas constant, $T$ is absolute temperature, and $M_{A}$ represents the molecular weight of the gas (Treybal 1980).

Thus, for diffusion of two different gases through the same medium we get

$$
\frac{D_{2}}{D_{1}}=\left(\frac{T_{2}}{T_{1}} \frac{M_{1}}{M_{2}}\right)^{\frac{1}{2}}
$$

where $\mathrm{D}_{1}$ and $\mathrm{D}_{2}$ are the diffusivities of species 1 and 2 respectively. The diffusivity of water is $4.9 \times 10^{-10} \mathrm{~m}^{2} \mathrm{~s}^{-1}$ at $60^{\circ} \mathrm{C}$ as noted above, from which we obtain $1.9 \times 10^{-10} \mathrm{~m}^{2} \mathrm{~s}^{-1}$ for the diffusion coefficient of $\alpha$-pinene in wood at $100{ }^{\circ} \mathrm{C}$. This temperature was chosen, since water from the wood matrix and the resin formulation evaporates during pressing. The actual mat temperature varies with time and location, but a small change in temperature does not materially affect the results.

Equation (1) predicts an effective diffusion depth of $0.77 \mathrm{~mm}$ for $\alpha$-pinene in wood for a three-minute press cycle, which means that most of the terpenes are lost from the surface layer. For these small depths, heat transfer is controlled by slow conduction near the surface and the mat can be assumed to be semi-infinite in our calculations. At the onset of pressing, the surface of the mat is exposed to a temperature of typically $200{ }^{\circ} \mathrm{C}\left(\mathrm{T}_{\mathrm{s}}\right)$. The temperature distribution in the mat near the surface as a function of time and depth can be obtained by solving the transient one-dimensional heat equation 


$$
\frac{\partial T}{\partial t}=\alpha \frac{\partial^{2} T}{\partial z^{2}}
$$

where $\alpha$ is the thermal diffusivity of the mat $\left(1.17 \times 10^{-7} \mathrm{~m}^{2} / \mathrm{s}\right)$ (Simpson and TenWolde 1999) and $z$ is the depth from the surface in meters subject to the following initial and boundary conditions: $\mathrm{T}=\mathrm{T}_{0}$ at $\mathrm{t}=0, \mathrm{~T}=\mathrm{T}_{\mathrm{s}}$ (surface temperature) at $\mathrm{z}=0$, and $\mathrm{T}=\mathrm{T}_{0}$ at $\mathrm{z} \rightarrow \infty$. The last condition is based on the assumption that the mat is semi-infinite compared to the small diffusion depth under consideration and the time of heating in the experiment (3-minutes) is too small to cause large temperature changes inside the mat due to the low thermal conductivity of wood. A schematic is provided in Figure 1.

The temperature profile within the mat at any time, $T(z, t)$, is obtained by solving the above equation with the corresponding initial and boundary conditions using a combination of variables technique (Bird et al.1994).

$$
T(z, t)=T_{0}+\left(T_{s}-T_{0}\right) \operatorname{erf}(\eta)
$$

where

$$
\eta=\frac{z}{\sqrt{4 \alpha t}}
$$

The function $\operatorname{erf}(\eta)$ is the error function defined by Eq. 7.

$$
\operatorname{erf}(\eta)=\frac{2}{\sqrt{\pi}} \int_{0}^{\eta} e^{-\eta^{2}} \mathrm{~d} \eta
$$

Equation 5 is only valid for very small thicknesses near the surface and over small time intervals. The time-averaged temperature at a particular depth can be obtained by integrating the instantaneous temperatures given by Eq. 5 with respect to time, for a given value of $\mathrm{z}(0.7 \mathrm{~mm})$ over the $180 \mathrm{~s}$ time interval. The average temperature at the surface layer was found to be $169{ }^{\circ} \mathrm{C}$ using graphical integration and assuming $\mathrm{T}_{0}=25^{\circ} \mathrm{C}$. The average diffusivity of the surface layer can be calculated from the time-averaged temperature as an approximation. The magnitude of change in diffusivity is less than the change in the temperature causing it. The change in diffusivity due to the maximum possible temperature rise (from room temperature to the peak surface layer temperature of $183^{\circ} \mathrm{C}$ ) is only $20 \%$ and thus, this assumption is valid. From Eq. 3 , the average diffusion coefficient of $\alpha$-pinene at the surface is calculated to be $2.05 \times 10^{-10} \mathrm{~m}^{2} \mathrm{~s}^{-1}$.

The pinene flux from the surface layer can be calculated by solving the one-dimensional transient mass transfer equation for a stationary medium (Fick's second law) (Bird et al. 1994) assuming a semi-infinite solid with constant surface concentration and an infinite supply of the diffusing species. These assumptions are justified because the diffusion of terpenes in wood is very slow. The mass transfer equation is solved with the necessary boundary conditions (Crank 1983). The flux (moles of terpene diffused per time per area) is given by 


$$
j=\sqrt{\frac{\mathrm{D}_{\mathrm{eff}}}{\pi \mathrm{t}}}\left(c_{0}-c_{\infty}\right)
$$

where $\mathrm{D}_{\text {eff }}$ is the effective diffusivity of terpenes through the wood, $\mathrm{c}_{0}$ represents the concentration of terpenes at the layer under consideration (given by the vapor pressure), and $\mathrm{c}_{\infty}$ is the concentration of terpenes at the surface (taken to be zero). Integrating Eq. 8 over time from $t=0$ to $\mathrm{t}_{0}$, the press time, gives the total terpenes released per unit area.

$$
J_{T O T}=\sqrt{\frac{4 \mathrm{D}_{\mathrm{eff}} t_{0}}{\pi}}\left(c_{0}-c_{\infty}\right)
$$

The vapor pressure of $\alpha$-pinene is related to temperature through Eq. 10

$$
\mathrm{P}=1.578 \times 10^{10} \exp \{-5146 / \mathrm{T}\}
$$

which was fitted to experimental data (Perry and Green 1985). P represents vapor pressure in Pa and $\mathrm{T}$ is the absolute temperature $(\mathrm{K})$. The equation is nonlinear and the average vapor pressure cannot be calculated from the average temperature of the layer. Instead, instantaneous vapor pressure values were calculated at different time intervals for $\mathrm{t}=0$ to $180 \mathrm{~s}$ using the corresponding temperature values obtained from equation 5 , and the average vapor pressure determined by graphical integration of the vapor pressure values. Thus, the time-averaged vapor pressure of $\alpha$ pinene is $153 \mathrm{kPa}$, which corresponds to a molar concentration of $41.8 \mathrm{~mol} \mathrm{~m}^{-3}$, assuming ideal gas behavior. Substituting this value in Eq. (9) gives a molar flux of $\mathrm{J}_{\mathrm{TOT}}=9.07 \times 10^{-3} \mathrm{~mol} \mathrm{~m}^{-2}$.

The diffusion from the interior of the mat contributes minimally to the overall pinene release due to the slow diffusion of pinene and the thickness of the mat. Diffusion from the body of the mat is slow, and can be approximated as a steady state process. The contributions from the surface layer and the body of the mat in terpene emissions can be modeled separately. The pinene released from the core can be estimated from the time and thickness-averaged temperature of the mat, since the temperature variation is not large. The average temperature of a mat cross-section of known thickness, subjected to constant surface temperatures on both sides, $\mathrm{T}_{<\mathrm{z}>}(\mathrm{t})$, is given by Eq. (11).

$$
T_{<\mathrm{z}>}(t)=T_{s}-\left(T_{s}-T_{0}\right) \frac{8}{\pi^{2}} \exp \left(-\left(\frac{\pi}{2}\right)^{2} \frac{\alpha t}{s^{2}}\right)
$$

where $s$ is the half-thickness of the mat (McCabe et al 1993). The time and thickness - averaged temperature of the mat over the width $(2 \mathrm{~s})$ and duration of pressing $\left(t_{0}\right)$ is obtained by integrating equation (11) from $\mathrm{t}=0$ to $\mathrm{t}_{0}$, and is given by Eq. (12) 


$$
T_{<z, t>}=T_{s}-\frac{\left(T_{s}-T_{0}\right)}{t_{0}} \frac{32 s^{2}}{\pi^{4} \alpha}\left\{1-\exp \left(-\left(\frac{\pi}{2}\right)^{2} \frac{\alpha t_{0}}{s^{2}}\right)\right\}
$$

The average temperatures obtained from Eq. 12 can be used to calculate the pinene flux in the body of the mat since the temperature variations inside the mat is much smaller than those near the surface. The average temperature of a $9.5 \mathrm{~mm}$ mat during a press cycle of $3 \mathrm{~min}$ is calculated to be $144^{\circ} \mathrm{C}$. The corresponding vapor pressure is $69.6 \mathrm{kPa}$ from Eq. 10. The amount of terpenes diffusing from the interior to the surface is given by

$$
J_{T O T}=\frac{\mathrm{D}_{\mathrm{eff}}\left(c_{0}-c_{\infty}\right) t_{0}}{\overline{\mathrm{Z}}}
$$

where $\bar{z}$ is the harmonic mean thickness of diffusion from the core to the surface. It is used as an approximation for diffusion in the body of the mat and is given by

$$
\frac{1}{\bar{z}}=\frac{1}{\left(z_{2}-z_{1}\right)} \int_{z_{1}}^{z_{2}} \frac{1}{z} d z
$$

where $\mathrm{z}_{1}$ is the thickness at the surface layer $(0.7 \mathrm{~mm})$ and $\mathrm{z}_{2}$ is the thickness at the core $(\mathrm{s})$. Equation 13 gives the average amount of terpenes diffusing from the center. From the above equations, the total amount of $\alpha$-pinene diffusing from the core is found to be $3.41 \times 10^{-4}$ mol m${ }^{-2}$, which is only about $4 \%$ of the total emissions.

Diffusion from the mat edges was neglected since there is no temperature gradient and thus, no concentration gradient across the horizontal axes. Thus the driving force for diffusion through the edges is much lower than that through the surfaces. For a mat density of $650 \mathrm{~kg} \mathrm{~m}^{-3}$ (Humphrey and Bolton 1989), the combined $\alpha$-pinene emission from the core and both surfaces is $2.56 \mathrm{~g} \mathrm{~m}^{-2}$ of wood, or $0.41 \mathrm{~kg} / 1000 \mathrm{~kg}$ as calculated from the model. The data in Table 1 are for $121 \mathrm{~cm}^{2}$ surfaces of boards weighing an average of $17.5 \mathrm{~g}$, which translates to an average $\alpha$ pinene emission of $0.8 \mathrm{~g} \mathrm{~m}^{-2}$. However, only one side of the board is heated, whereas both sides would contact the hot platen in commercial practice. The emissions should, therefore, be doubled to $1.6 \mathrm{~g} \mathrm{~m}^{-2}$, which is $63 \%$ of the model-derived value of $2.56 \mathrm{~g} \mathrm{~m}^{-2}$. The estimate also compares well with field data reported at $2 \times 10^{-3}-4.0 \times 10^{-3} \mathrm{~kg} / \mathrm{m}^{-2}$ (or $0.3-0.6 \mathrm{~kg} / 1000 \mathrm{~kg}$ ) for two southern pine strand presses (Crawford and Word 1999). Hence, our model is able to account for press emissions without using any parameters fitted to the emissions data.

It follows from our arguments that the pinene emissions should be greatly suppressed if the top layer of the mat was replaced with a hardwood such as aspen. The width of an aspen flake is approximately $0.7 \mathrm{~mm}$, which is comparable to the diffusion depth of $0.77 \mathrm{~mm}$. Hence, one layer of aspen should "insulate" the mat for terpene emissions. Table 2 lists the amount of $\alpha$ and $\beta$ pinenes released during pressing of the pine/aspen mats against an all-pine control. Emissions from the all-pine boards in Table 2 are lower than those from Table 1 because of batch-to- 
batch variability in the wood. Pressing mats with aspen on the surface leads to a $60-69 \%$ reduction in pinene emission. This range is much higher than the $25 \%$ reduction expected on the basis of dilution of the softwood with hardwood, and provides strong support for the importance of the surface in governing pinene emissions.

Since terpene should be preferentially lost from the surface of a board during pressing, the terpene content in the finished product should be higher in the core. Results from the analysis of four commercially prepared boards and three laboratory-pressed boards are listed in Table 3 and are illustrated in Figure 2. The pinene content in the core is consistently higher than that in the surface, but there is considerable board-to-board variability. Some pinene must have evaporated from the commercial boards during storage, but this is unlikely to be significant, since the same trends are found in boards prepared in the laboratory which were analyzed immediately upon preparation. Knots and other resinous regions could have also contributed to the variability because they are unevenly distributed in wood. However, the major source of the variability is likely to be the sampling. The pinene gradient in the surface is very steep. A simulation of the flux over depth is illustrated in Figure 3. Some of the variability in the surface samples probably originates from uneven sampling.

Our model only applies to emission of terpene and not to all VOCs released from pressing. Substantial quantities of methanol, formaldehyde and other compounds are also released. Most of these compounds derive from the added resin (Wolcott et al. 1996; Jiang et al. 2002), but wood tissue degradation is also a significant source (Su et al.1999). These compounds are transported out of wood by the steam generated from the moisture in the mat.

In conclusion, terpene emissions from pressing flakes originate predominantly from the layer of wood adjoining the hot platen surface. Other potential mechanisms of pinene release such as loss of pinene through transport by steam are evidently not significant. A simple heat transfer model based on conduction of heat from the platens is able to estimate these emissions within the uncertainty of measurement. The terpene emissions depend predominantly on press time and platen temperature. The relationships in Figure 3 suggest that any means to reduce either variable should lead to significant VOC reductions. These could be achieved through strategies such as steam-injection pressing or preheating the furnish, e.g. with microwave.

Acknowledgements

This study was funded by the Office of Industrial Technology of the US Department of Energy. 


\section{References}

Banerjee, S. 2001. Mechanisms of terpene release during sawdust and flake drying. Holzforschung 55:413-416.

Bird, R.B., W.E. Stewart and E.N. Lightfoot. 1994. Transport Phenomena. Wiley, New York. pp $354,558$.

Crank, J. 1983. The Mathematics of Diffusion. Oxford University Press, London. p 32.

Crawford, R.J. and D.H. Word. 1999. Volatile organic compound emissions from wood products manufacturing facilities; Part V - Oriented Strandboard, NCASI Technical Bulletin, no. 772.

Cronn, D.R., S.G. Truitt and M.J. Campbell. 1983. Chemical characterization of plywood veneer drying emissions. Atmos. Environ. 17:201-211.

Humphrey, P.E. and A.J. Bolton. 1989. The hot pressing of dry-formed wood-based composites, Part II. A simulation model for heat and moisture transfer, and typical results. Holzforschung 43:199-206.

Jiang, T., D.J. Gardner and M.G.D. Baumann. 2002. Volatile organic compound emissions arising from the hot-pressing of mixed-hardwood particleboard. Forest Prod. J., 52(11/12): 66-77.

Martino, C.J., S. Shrauti, S.Banerjee, L.P. Otwell and E.W. Price. 2002. Flake drying temperature affects mat properties during pressing. Holzforschung 56: 558-562.

McCabe, W.L., J.C. Smith and P. Harriot. 1993. Unit Operations of Chemical Engineering, $5^{\text {th }}$ ed., McGraw-Hill Inc., Burr Ridge, IL, p 301.

Perry, R.H. and D.W. Green. 1985. Perry's Chemical Engineer's Handbook”, 6th ed., McGrawHill. New York. p 3-58.

Sehlstedt-Persson, M. 2001. COST Action E15. Advances in the drying of wood (1999 - 2003). 3rd Workshop on Softwood Drying to Specific End-Uses. Helsinki, Finland, June 11-13, 2001.

Simpson, W., and A. TenWolde. The US department of Agriculture's Forest Service Forest Products Laboratory, Madison, WI, Wood Handbook (Wood as an engineering material). 1999.

Su, W., H. Yan, S. Banerjee, L.P. Otwell and M.E. Hittmeier. 1999. Field-proven strategies for reducing VOCs from hardwood drying Environ. Sci. Technol. 33:1056-1059.

Treybal, R.E. 1980. Mass Transfer Operations McGraw-Hill. p 97.

Wolcott J.J., W.K. Motter, N.K. Daisy, S.C. Tenhaeff and W.D. Detlefsen. 1996. Investigation of variables affecting hot-press formaldehyde and methanol emissions during laboratory production of urea-formaldehyde-bonded particleboard. Forest Prod. J. 46(9):62-68. 
Table 1. Pinene emissions ( $\mu \mathrm{g} \mathrm{g}_{-}{ }^{1}$ ) from laboratory-pressed boards.

\begin{tabular}{lll} 
Sample & $\alpha$-pinene & $\beta$-pinene \\
\hline 1 & 519 & 51.0 \\
2 & 787 & 118 \\
3 & 439 & 32.0 \\
4 & 409 & 57.3 \\
5 & 449 & 130 \\
6 & 807 & 259 \\
7 & 680 & 129 \\
8 & 355 & 105 \\
Average & 556 & 110 \\
\hline
\end{tabular}

Table 2. Effect of a surface layer of aspen on terpene emissions ( $\mu \mathrm{g} \mathrm{g}^{-1}$ wood) during hot pressing.

\begin{tabular}{lll}
\hline & $\alpha$-pinene & $\beta$-pinene \\
$\begin{array}{l}\text { 16-g mats } \\
\text { pine only }\end{array}$ & $111(129,112,95.4)$ & $25.1(35.1,27.9,12.4)$ \\
pine and aspen & $36.1(35.1,44.1,29.2)$ & $\begin{array}{l}9.2(8.7,11.8,7.1) \\
\text { reduction }(\%)\end{array}$ \\
$\begin{array}{l}\text { 20-g mats } \\
\text { pine only }\end{array}$ & $48.3(49.5,50.7,46.1,47.1)$ & $11.0(12.2,12.1,9.5,10.3)$ \\
pine and aspen & $14.9(15.3,14.4,14.8,15.2)$ & $4.4(4.1,2.9,5.0,5.6)$ \\
reduction $(\%)$ & 69 & 60 \\
\hline
\end{tabular}

Table 3. Terpene content ( $\mu \mathrm{g} / \mathrm{g}$ in wood) in commercial and laboratory-pressed board.

\begin{tabular}{|c|c|c|c|c|c|c|}
\hline \multirow[b]{2}{*}{ Board } & \multicolumn{2}{|c|}{ Surface } & \multicolumn{2}{|c|}{ Core } & \multicolumn{2}{|c|}{ Core : Surface } \\
\hline & $\alpha$-pinene & $\beta$-pinene & $\alpha$-pinene & $\beta$-pinene & $\alpha$-pinene & $\beta$-pinene \\
\hline \multicolumn{7}{|c|}{ Commercial board } \\
\hline 1 & 9.98 & 0.97 & 28.4 & 2.72 & 2.9 & 2.8 \\
\hline 2 & 14.2 & 13.0 & 29.1 & 15.0 & 2.0 & 1.2 \\
\hline 3 & 21.7 & 13.8 & 25.9 & 15.6 & 1.2 & 1.1 \\
\hline 4 & 15.4 & 6.41 & 45.7 & 17.6 & 3.0 & 2.1 \\
\hline \multicolumn{7}{|c|}{ Laboratory-pressed board } \\
\hline 1 & 34.4 & 19.9 & 50.7 & 56.5 & 1.7 & 2.8 \\
\hline 2 & 16.4 & 14.3 & 23.5 & 14.3 & 1.4 & 1.0 \\
\hline 3 & 27.5 & 19.2 & 46.2 & 39.8 & 1.7 & 2.1 \\
\hline
\end{tabular}




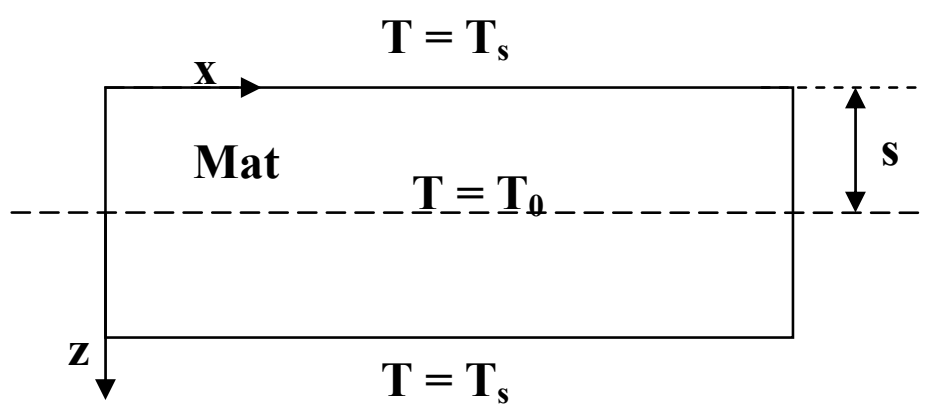

Fig. 1. Schematic of heat transfer to the mat.

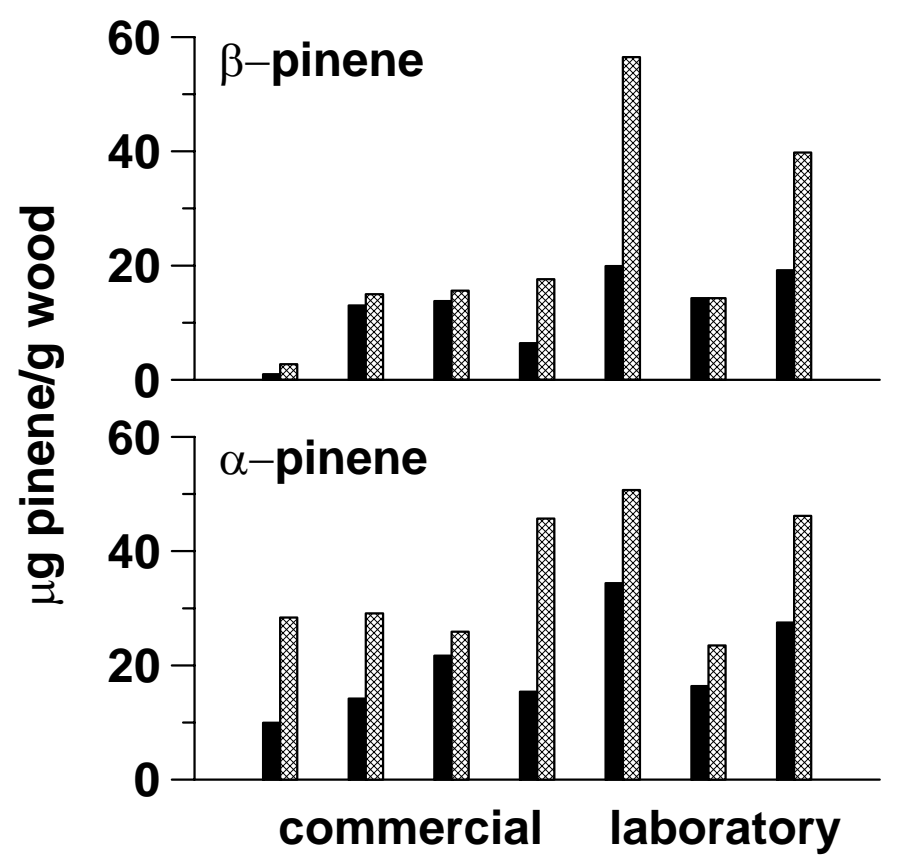

Fig. 2. Terpene content of wood after pressing. The solid and hatched bars are for the surface and core, respectively. The left four boards were obtained commercially; the three rightmost boards were prepared in the laboratory. 


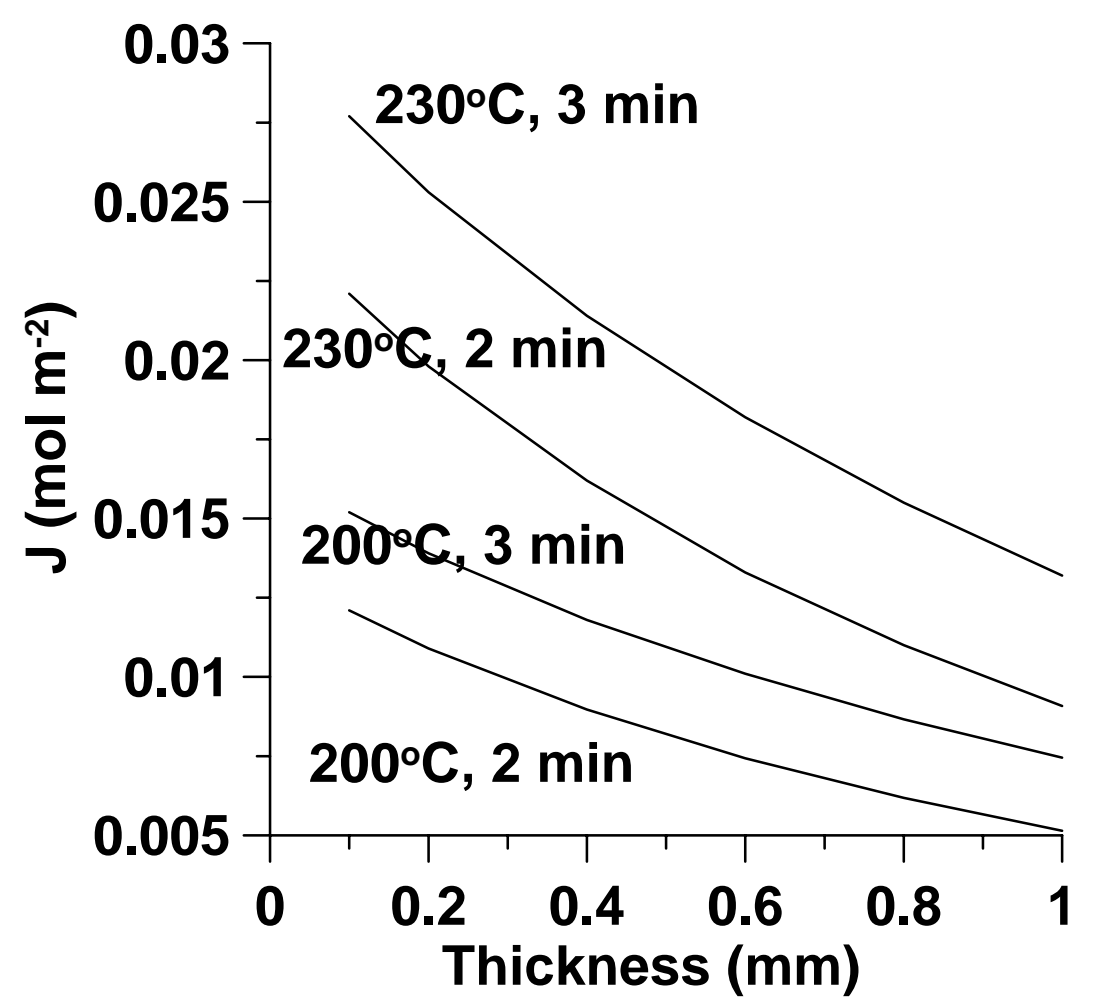

Fig. 3. Simulation of $\alpha$-pinene emissions from various depths from the surface exposed to the hot platen. 


\section{Controlling formaldehyde emissions with boiler ash}

This section was excerpted from J.Cowan, M.Abu-Daabes, S.Banerjee, Controlling formaldehyde emissions with boiler ash, Environ. Sci. Technol., 39, 5101 (2005).

\section{Introduction}

The engineered wood industry emits methanol and formaldehyde among other Hazardous Air Pollutants (HAPs) during drying and pressing operations and will be required to comply with the wood MACT rule (1) when it is finalized. Over one hundred relatively large facilities in the US will be subject to these regulations. Regenerative thermal (2) or catalytic (3) oxidizers are presently used to control HAPs and other VOCs. The natural gas cost of operating these units is high because the VOCs are present at low concentrations of about $20 \mathrm{ppmv}$ (4) in large volumes $\left(\sim 1,500 \mathrm{~m}^{3} / \mathrm{min}\right)$ of air, which must be heated to oxidative temperatures. Biofilters $(5-7)$ are used at some facilities (8), but they are capital- and space-intensive.

Removal of gaseous formaldehyde by adsorption has typically utilized activated carbon treated with various additives (9). Hydrophobic compounds are easily adsorbed, and a combination of adsorption and oxidation has been used to remove hydrophilic compounds such as methanol. In one example, methanol was adsorbed on nutshell carbon pre-oxidized to enhance its affinity for hydrophilic compounds (10). In another, methanol and other VOCs released from the manufacture of printed circuit boards were trapped and concentrated in activated carbon beds before being oxidized (11). VOCs have also been treated by polymer-coated zeolites (12) and polymeric membrane (13), but the large volumes of air involved in our application make these procedures cost-prohibitive.

One compliance option permitted under the proposed MACT rule (1) is to decrease either methanol or formaldehyde emissions to less than 1 ppmv. The engineered wood industry generates energy by burning wood residues, and it seemed possible that the ash from these residues could be used to strip formaldehyde from the air stream. The ash contains unburned organic carbon (14) and it appeared likely that it would display some of the adsorptive properties of activated carbon. In this paper, we examine the feasibility of using wood ash from several facilities to remove formaldehyde from contaminated airstreams. Interest in these compounds is widespread and our findings should find application beyond the engineered wood industry.

\section{Experimental Section}

Ash was collected from the burner and the electrostatic precipitator (ESP) of the Norbord, Guntown, MS, mill. Other ash samples were provided by Bowater, Catawba, SC (bark burner), Georgia-Pacific mills at Skippers, VA (bark burner), Whiteville NC (plywood mill fly ash), and by Inland Container, Rome, GA mill (bark burner). Bulk density was determined from ash dried $\left(105^{\circ} \mathrm{C}\right)$ and sieved through a 3.4-mm screen. $\mathrm{pH}$ was measured from a settled suspension obtained by mixing $20 \mathrm{~g}$ of dry ash with $100 \mathrm{~mL}$ of water. The total carbon and inorganic carbon contents of the ashes were determined by coulometric titration (15); the organic carbon was then obtained by difference. The properties of the various ashes are summarized in Table 1. The burner ash from Guntown was also ground in a ball mill for several hours. The particle size distribution of the ashes, determined by screening, appears in Table 2. 
For the sorption experiments air was passed through ash placed in a glass bottle with a fritted glass base, which distributed the air and fluidized the ash. A cylinder of vacuum cleaner bag paper (closed at the top) was placed over the neck of the vessel to prevent fine ash particles from escaping. A stainless steel cylinder was then placed over the bag and onto a rubber spacer resting on the shoulders of the glass vessel. The cylinder was clamped to ensure a secure connection with the ash bed exhaust and was connected to the cell of an FTIR spectrometer (Midac Corporation, Irvine, CA) through a bulkhead fitting. The glass cylinder was heated to $105^{\circ} \mathrm{C}$ prior to beginning the experiment with heating tape; the temperature was controlled with a thermocouple placed between the heating tape and the glass. The stainless steel cylinder and tubing were also heat-traced to prevent condensation.

The feed solution was freshly prepared for each experiment by diluting $0.5 \mathrm{~mL}$ of formalin (an aqueous solution with $37 \%$ formaldehyde and $15 \%$ methanol) to $100 \mathrm{~mL}$. The solution was placed in a gas-washing bottle with a fritted glass impinger through which ultra zero grade air was passed at $2.0 \mathrm{~L} / \mathrm{min}$. Fluidized bed work was done with 150-170 g ash. The formaldehyde concentration in the feed stream was 16-21 ppmv, methanol was at 40-50 ppmv, and water constituted 3.5-3.7\%. Methanol, formaldehyde and carbon dioxide levels were continuously monitored by FTIR; the instrument was calibrated with standard permeation tubes (Precision Gas Standards Generator, Model 491M-B, Kin-Tek Laboratories, Inc, La Marque, TX). The limit of detection was about $0.1 \mathrm{ppmv}$ for both methanol and formaldehyde. Spectra were acquired every 69 seconds.

Ash moisture content was measured just before each experiment. The effect of moisture on the degree of sorption of formaldehyde was studied with ash from Catawba and Guntown by adding water to the ash sample and mixing with a spatula. The wetted ash sample was sieved through a screen ( 25 mesh, $710 \mu$ openings) to break up any wet clumps and then shaken for several minutes. Some moisture loss occurred during the experiment; the moisture content of Catawba ash (30 g) dropped from 2.9 to $1.3 \%$ when exposed to an $18.7 \mathrm{ppmv}$ formaldehyde feed stream at $110^{\circ} \mathrm{C}$ for 90 minutes.

The effect of temperature on desorption was determined with $30 \mathrm{~g}$ of Catawba ash preexposed to a $0.75 \mathrm{~L} / \mathrm{min} 20 \mathrm{ppmv}$ formaldehyde feedstream at $108^{\circ} \mathrm{C}$ for five hours. Clean air was then passed through the loaded ash at $0.75 \mathrm{~L} / \mathrm{min}$. The bed temperature was initially set at $116^{\circ} \mathrm{C}$, increased to $138^{\circ} \mathrm{C}$ after 48 minutes, and then to $165^{\circ} \mathrm{C}$ after 98 minutes.

\section{Results and Discussion}

The ash is ineffective for reducing methanol to our target concentration of $1 \mathrm{ppmv}$ as shown by the results in Table 3. Formaldehyde is removed much more efficiently, as illustrated by the typical breakthrough curve shown in Figure 1; results for the sorption capacity of various ashes are summarized in Table 4. The relationship between initial moisture content and the sorption capacity at $105^{\circ} \mathrm{C}$ is illustrated in Figure 2. The Whiteville ash is an outlier, but this was also the only fly ash used. A complicating factor is that the ash moisture content changes over the course of the run, and any differences in the rate of moisture removal will add to the scatter. Nevertheless, moisture clearly increases the carrying capacity of the ash. 
More direct evidence for the importance of water was obtained with the Guntown ESP ash. When used as received at a moisture content of $1.4 \%$ it lowered the formaldehyde concentration to $2.5 \mathrm{ppm}$. Increasing the moisture content to $4.5 \%$ decreased formaldehyde to less than 1 ppmv for nearly 40 minutes. Surprisingly, neither the carbon content nor the particle size of the ash seems to be important for trapping formaldehyde. Thus, our initial expectation that the carbon in unburned ash would mimic activated carbon was not borne out. The Skippers ash performs quite well despite its low organic carbon content of only $4.1 \%$. The carbon content of ash from Catawba and Whiteville was roughly equal, but while the Whiteville ash had the highest sorptive capacity, the Catawba ash had the lowest. Analogous results have been reported (16) in a study of formaldehyde adsorption to various activated carbons where the presence of hydrophilic $\mathrm{O}-\mathrm{H}, \mathrm{C}=\mathrm{O}, \mathrm{C}-\mathrm{O}$ groups on the surface exhibited the highest adsorption capacity for formaldehyde vapor. Activated carbon containing hydrophobic surface groups of $\mathrm{C}-\mathrm{H}, \mathrm{C}=\mathrm{C}$ adsorbed formaldehyde to a less extent. Hence, the hydrophilicity of the surface promotes the adsorption capacity, whereas the texture, surface area, and pore volume play a relatively minor role.

Consider the Figure 1 result where $150 \mathrm{~g}$ of ash at a moisture content of $1.4 \%$ reduces formaldehyde from a $20 \mathrm{ppmv}$ feed stream to below the detection limit for 50 minutes. If the formaldehyde merely partitioned into the water in the ash and equilibrium is assumed, then an air:water Henry's Law Constant of $1.8 \times 10^{-6}$ atm m $\mathrm{m}^{3} / \mathrm{mol}$ (at $105^{\circ} \mathrm{C}$ ) can be calculated if the formaldehyde is assumed to be present in air at the detection limit of $0.1 \mathrm{ppmv}$. The known Henry's Law Constant at $25^{\circ} \mathrm{C}$ is sixfold lower at $3.4 \times 10^{-7}$ atm- $\mathrm{m}^{3}$ mole (17). The disparity could derive from our assumption of $0.1 \mathrm{ppmv}$ for the concentration of formaldehyde and/or from the difference in temperature; a lower value is expected at the lower temperature. Alternatively, formaldehyde could interact differently with ash water and with pure water, giving rise to different Henry's Law Constants. Despite these uncertainties, the two values differ by less than on order of magnitude.

The Henry's Law Constant reported for methanol is $4.6 \times 10^{-6} \mathrm{~atm} \mathrm{m^{3 }} / \mathrm{mol}$ (18), which is tenfold higher than that for formaldehyde. Hence, if stripping efficiency depended only on partitioning to the water contained in ash, then methanol should be stripped much less efficiently, as observed. The importance of water in influencing sorption has been noted by others. Gambaro (19) found that sorption of methanol to $\mathrm{V}_{2} \mathrm{O}_{5}$ only occurred when water was present in the sorbent, and suggested that the methanol was linked to the solid through water molecules.

Figures 1 and 3 profile the concentrations of formaldehyde and water, respectively, from the same experiment. The formaldehyde is retained for about fifty minutes in Figure 1, whereas the water peaks at about five minutes in Figure 3. If formaldehyde partitioning into ash water were the only process that was occurring, i.e. if the compound had no affinity for the ash itself, then its breakthrough would track that of water. Water is clearly necessary to hold the formaldehyde, as emphasized by the Figure 2 result and the other water-related measurements discussed earlier. The finding that the amount of formaldehyde removed is of the same magnitude as that expected from the Henry's Law Constant suggests that formaldehyde rapidly partitions into ash water. The observation that its breakthrough lags that of water must mean that formaldehyde binds to the ash after partitioning into the water layer. The binding to the ash solids must be rate-controlling; otherwise the partitioning of formaldehyde to the ash water would not follow 
Henry's Law. Hence, it appears that formaldehyde partitions into particle-held water and then adsorbs to the surface of the ash particle while the water is being removed.

The adsorptive capacity of Catawba ash for formaldehyde at room temperature was measured to be $0.14 \mathrm{mg} / \mathrm{g}$ ash. This capacity decreased to about $0.002 \mathrm{mg} / \mathrm{g}$ ash at $105^{\circ} \mathrm{C}$. Profiles for the desorption of methanol and formaldehyde from loaded ash are shown in Figure 4; the carbon dioxide trace is illustrated in Figure 5. The carbon dioxide level rose sharply at $165^{\circ} \mathrm{C}$; it presumably came from formaldehyde which is known to thermally decompose at $150^{\circ} \mathrm{C}(20)$. No change in carbon dioxide occurred with increasing temperature when the ash alone was heated, confirming that the increased carbon dioxide in Figure 5 derived from the sorbed materials. A potential complication in interpreting the formaldehyde profiles is that the compound can be formed from the oxidation of methanol $(19,21)$. However, methanol is adsorbed to a much smaller degree than is formaldehyde (Table 3), and Figure 4 demonstrates that it is released at higher levels, so any conversion to formaldehyde should be quite small.

Our results demonstrate that boiler ash is able to remove formaldehyde from a contaminated airstream. Returning the loaded ash to the boiler would then incinerate the formaldehyde at the expense of a small increase in ash deadload. The technology should be more appropriate for press, rather than dryer emissions, because of the lower air volumes involved. The capital cost of a fluidized bed is much lower than that of a thermal oxidizer, and the cost of natural gas required to operate the oxidizer is removed. The ash handling is an additional cost, but the overall economics seem favorable. The application is not limited to the engineered wood industry but should extend to any situation where formaldehyde removal is required and ash handling facilities are available.

In conclusion, formaldehyde can potentially be stripped from an air stream through contact with boiler ash to incinerate the formaldehyde. Methanol would be removed to a much lower extent. The efficiency of collection increases with increasing ash moisture; the optimum moisture will probably be dictated by materials handling considerations. Typical temperatures of wood drying and pressing emissions are about $70-110^{\circ} \mathrm{C}$, so the formaldehyde would be mostly sorbed by the ash; the temperature will not be high enough to initiate oxidation. Reducing formaldehyde to below $1 \mathrm{ppmv}$ would fully satisfy the regulatory limit for the proposed wood MACT rule (1).

\section{Acknowledgment}

We thank the Department of Energy for financial support under contract DE-FC36$01 \mathrm{GO} 10620$. 


\section{Literature Cited}

1. U.S. EPA. National Emission Standards for Hazardous Air Pollutants: Plywood and Composite Wood Products, Effluent Limitations Guidelines and Standards for the Timber Products Point Source Category, List of Hazardous Air Pollutants, Lesser Quantity Designations, Source Category List, 2004.

2. Sauer, B.; Franklin, W.; Miner, R.; Word, D.; Upton, B. Environmental tradeoffs: life cycle approach to evaluate the burdens and benefits of emission control systems in the wood panal industry. For. Prod. J. 2002, 52, 50-59.

3. Strader, R. Selection and experience with VOC and HAPs control technologies at wood products plants. Proceedings of TAPPI International Environmental Conference and Exhibit, Portland, OR. 2003, 348-352.

4. Su, W.; Yan, H.; Banerjee, S.; Otwell, L. P.; Hittmeier, M. E. Field-proven strategies for reducing volatile organic carbons from hardwood drying. Environ. Sci. Technol. 1999, 33, 1056-1059.

5. Mackowiak, J. Removal of formaldehyde from waste gas in a biofilter. Stud. Environ. Sci. 1992, 51 (Biotech. Air Pollut. Abatement Odour Control Policies), 273-8.

6. Mackowiak, J. Large-scale process for formaldehyde removal. WLB, Wasser, Luft und Boden 1995, 39(5), 55-6.

7. Ferranti, M. M. ; Conca, A. Formaldehyde biological removal from exhaust air in the composite panel board industry from pilot tests to industrial plant. Proceedings of the Air \& Waste Management Association's Annual Conference \& Exhibition, 93rd, Salt Lake City, UT, 2000, 2037-2052.

8. Pisotti, D. A. Biofilter eliminates more than just VOCS from a press exhaust. TAPPI Environmental Conference \& Exhibit, Minneapolis, 1997, 271-275.

9. Sekine, Y.; Nishimura, A. Removal of formaldehyde from indoor air by passive type aircleaning materials. Atmos. Environ. 2001, 35, 2001-2007.

10. Bailey, A.; Williams, M.; Dunne, L.; Beames, L. Enhanced adsorption of methanol by oxidized nutshell carbon. Ads. Sci. Technol. 2000, 18, 261-266.

11. Biedell, E. L.; Buckley, W.; Altshuler, B.; Miller, B. A cost effective approach to control of VOC emissions from printed circuit board operations. Proceedings of the Air \& Waste Management Association's Annual Conference \& Exhibition, 93rd, Salt Lake City, UT, 2000, 1964-1976.

12. Bhardwaj, B.; Perera, S. P.; Crittenden, B. D. Hybrid membrane adsorbents for fluidized bed separations. Chem. Eng. Res. Des. 2000, 78, 1089-1097.

13. Klug, A.; Pfromm, P. H.; Rezac, M. E.; Czermak, P. Selective Removal of Methanol from Humid Air Streams Using a Water-Vapor-Purged Membrane Separator. Ind. Eng. Chem. Res. 2001, 40, 2685-2692.

14. Rosenfeld, P.; Grey, M.; Suffet, M. Controlling odors using high carbon wood ash. BioCycle 2002, 43(3), 42-45.

15. Douek, M.; Ing, J. A new method for determining carbonate in samples from the pulp and paper industry. TAPPI International Process and Materials Quality Evaluation Conference, 1986, 115-122.

16. Boonamnuayvitaya, V.; Sae-Ung, S.; Tanthapanichakoon, W. Preparation of activated carbons from coffee residue for the adsorption of formaldehyde. Sep. Purif. Technol. 2005, 42, 159-168. 
17. Betterton, E. A.; Erel, Y.; Hoffmann, M. R. Aldehyde-bisulfite adducts: prediction of some of their thermodynamic and kinetic properties. Environ. Sci. Technol. 1988, 22, 92-99.

18. Gaffney, J. S., Streit, G. E., Spall, W. D., Hall, J. H., Beyond acid rain. Do soluble oxidants and organic toxinsinteract with $\mathrm{SO} 2$ and NOx to increase ecosystem effects? Environ. Sci. Technol. 1987, 21, 519-524.

19. Gambaro, L. A. Methanol adsorption-oxidation over $\mathrm{V}_{2} \mathrm{O}_{5}$-a mass spectrometry study. $J$. Mol. Catal. A, 2004, 214, 287-291.

20. World Health Organization. Formaldehyde. Environmental Health Criteria 89, International Programme on Chemical Safety, Geneva (1989).

21. Sambeth, J. E.; Centeno, M. A.; Paul, A.; Briand, L. E.; Thomas, H. J.; Odriozola, J. In situ DRIFTS study of the adsorption-oxidation of $\mathrm{CH} 3 \mathrm{OH}$ on $\mathrm{V}_{2} \mathrm{O}_{5}$. A. J. Mol. Catal. A 2000, 161, 89-97.

\begin{tabular}{|l|l|l|l|}
\hline \multicolumn{4}{|l|}{ TABLE 1. Bulk Properties of Ash. } \\
\hline ash & dry bulk density $\left(\mathbf{g} / \mathbf{c m}^{\mathbf{3}}\right)$ & $\mathbf{p H}$ in water & organic C (\%) \\
\hline Guntown burner & 0.50 & 12.1 & 16.0 \\
\hline Guntown ESP & 0.63 & 12.2 & 13.5 \\
\hline Catawba & 0.80 & 6.3 & 21.4 \\
\hline Skippers & 0.88 & 12.5 & 4.10 \\
\hline Whiteville & 0.67 & 10.8 & 19.5 \\
\hline Inland, Rome & & & 24.0 \\
\hline
\end{tabular}

\begin{tabular}{|l|l|l|l|l|l|l|l|}
\hline TABLE 2. Ash Particle Size Distribution. \\
\hline \multicolumn{7}{|l|}{ particle size $(\boldsymbol{\mu})$} \\
\hline percent & $\mathbf{7 1 0}$ & $\mathbf{5 0 0 - 7 0 9}$ & $\mathbf{2 5 0 - 4 9 9}$ & $\mathbf{1 5 0 - 2 4 9}$ & $\mathbf{1 0 6 - 1 4 9}$ & $\mathbf{0 - 1 0 6}$ \\
\hline $\begin{array}{l}\text { Guntown, } \\
\text { burner }\end{array}$ & 47.9 & 2.8 & 5.6 & 5.6 & 3.5 & 34.7 \\
\hline $\begin{array}{l}\text { Guntown, } \\
\text { burner ground }\end{array}$ & 1.8 & 2.5 & 7.6 & 8.0 & 5.4 & 74.7 \\
\hline Guntown, ESP & 1.6 & 0.8 & 4.0 & 8.9 & 16.1 & 68.5 \\
\hline Catawba & 0 & 0 & 4.9 & 19.0 & 35.1 & 41.0 \\
\hline Skippers & 0 & 0 & 0 & 23.0 & 18.9 & 58.1 \\
\hline Whiteville & 4.3 & 7.4 & 20.9 & 20.9 & 14.7 & 31.9 \\
\hline
\end{tabular}




\begin{tabular}{|l|l|l|l|}
\hline Table 3. Removal of Methanol by Ash at $\mathbf{1 0 5}^{\mathbf{}} \mathbf{C}$. \\
\hline ash type & $\begin{array}{l}\text { feed methanol } \\
\text { (ppmv) }\end{array}$ & $\begin{array}{l}\text { minimum methanol } \\
\text { (ppmv) }\end{array}$ & \% reduction \\
\hline Guntown, not ground & 42.9 & 26.9 & 37 \\
\hline Guntown, ground & 44.5 & 43.6 & 0 \\
\hline Guntown, ground & 45.3 & 37.7 & 17 \\
\hline Guntown, ESP & 39.8 & 13 & 70 \\
\hline Guntown, ESP & 46 & 26 & 43 \\
\hline Catawba & 40 & 13.4 & 67 \\
\hline Skippers & 39.7 & 21.7 & 45 \\
\hline Whiteville & 49.7 & 4.7 & 90 (for $40 \mathrm{~min}$ ) \\
\hline
\end{tabular}

\begin{tabular}{|c|c|c|c|}
\hline ash type & $\begin{array}{l}\text { ash initial mois- } \\
\text { ture content }(\%)\end{array}$ & $\begin{array}{l}\text { ash final moisture } \\
\text { content }(\%)\end{array}$ & $\begin{array}{l}\text { capacity (mg for- } \\
\text { maldehyde/g ash) }\end{array}$ \\
\hline Guntown, not ground & 2.8 & 1.4 & 0.003 \\
\hline Guntown, ground & 2.8 & 0.1 & 0.004 \\
\hline Guntown, ground & 4.4 & 2.8 & 0.002 \\
\hline Guntown, ESP & 1.4 & 0 & 0 \\
\hline Guntown, ESP & 4.5 & 1.2 & 0.015 \\
\hline Catawba $^{2}$ & 3.2 & 0.9 & 0.002 \\
\hline Skippers $^{2}$ & 8.7 & 4.9 & 0.047 \\
\hline Whiteville $^{3}$ & 6.6 & 2.4 & 0.083 \\
\hline \multicolumn{4}{|c|}{$\begin{array}{l}{ }^{1} \text { formaldehyde adsorbed while the breakthrough concentration was }<1 \mathrm{ppm} \text {. } \\
{ }^{2} \text { the portion of ash passing a } 60 \text {-mesh screen was used. } \\
{ }^{3} \text { the portion of ash passing an } 18 \text {-mesh screen was used. }\end{array}$} \\
\hline
\end{tabular}




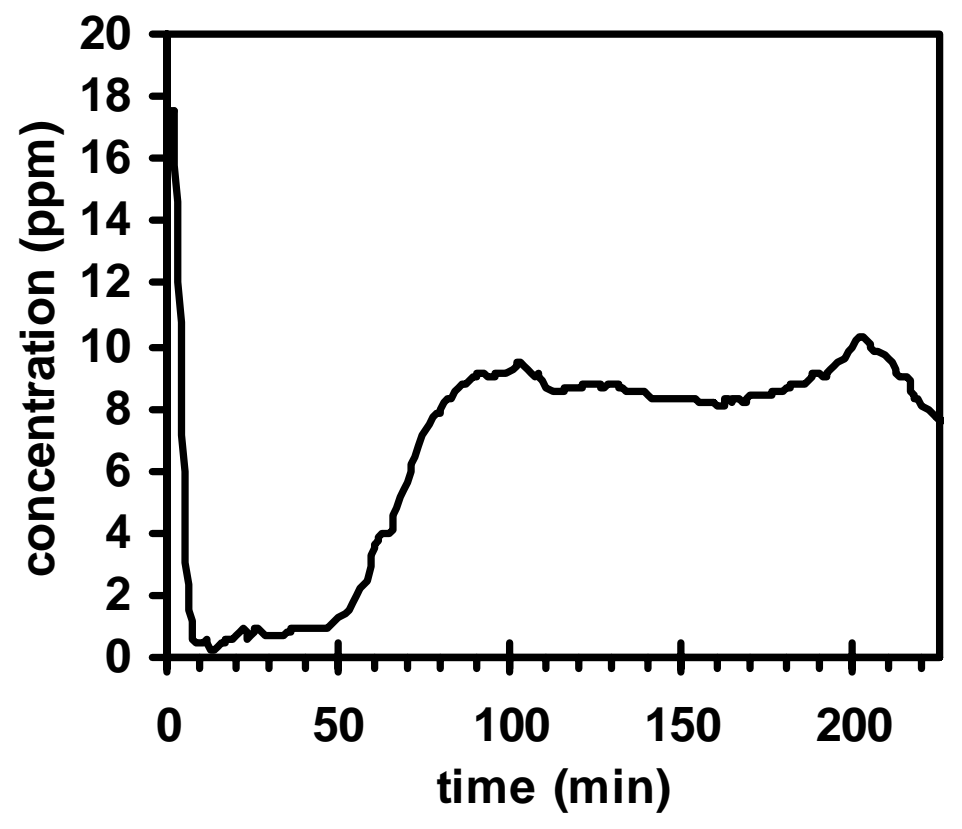

FIGURE 1. Removal of formaldehyde by Guntown ESP ash.

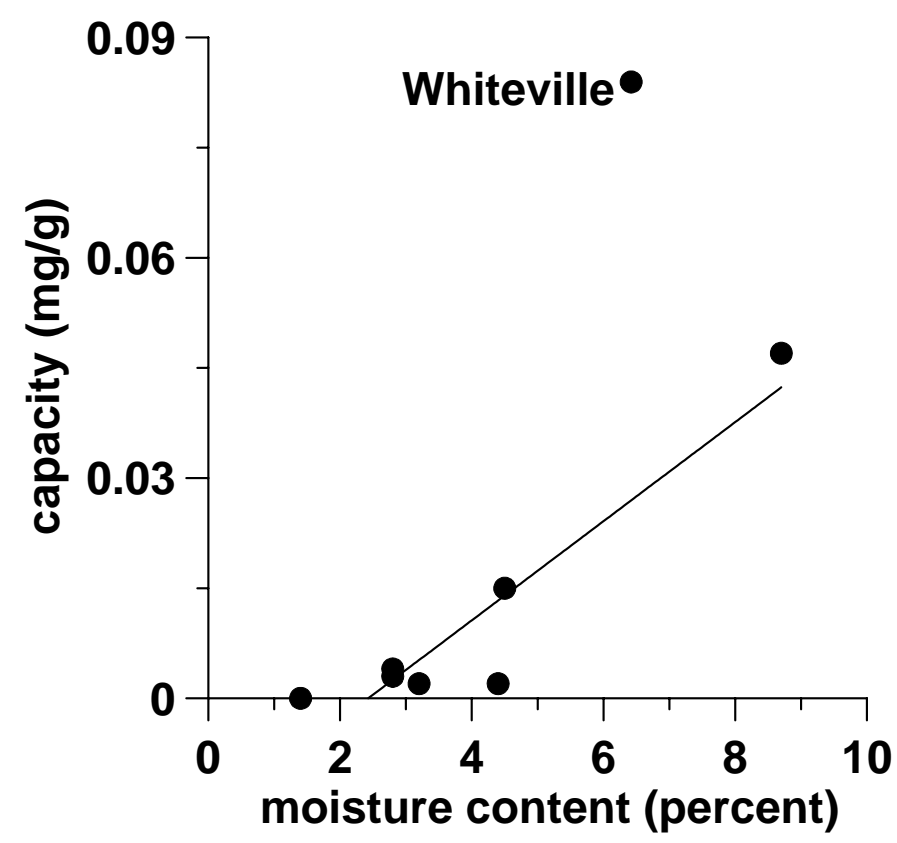

FIGURE 2. Effect of initial moisture content on the capacity of ash for formaldehyde sorption. 


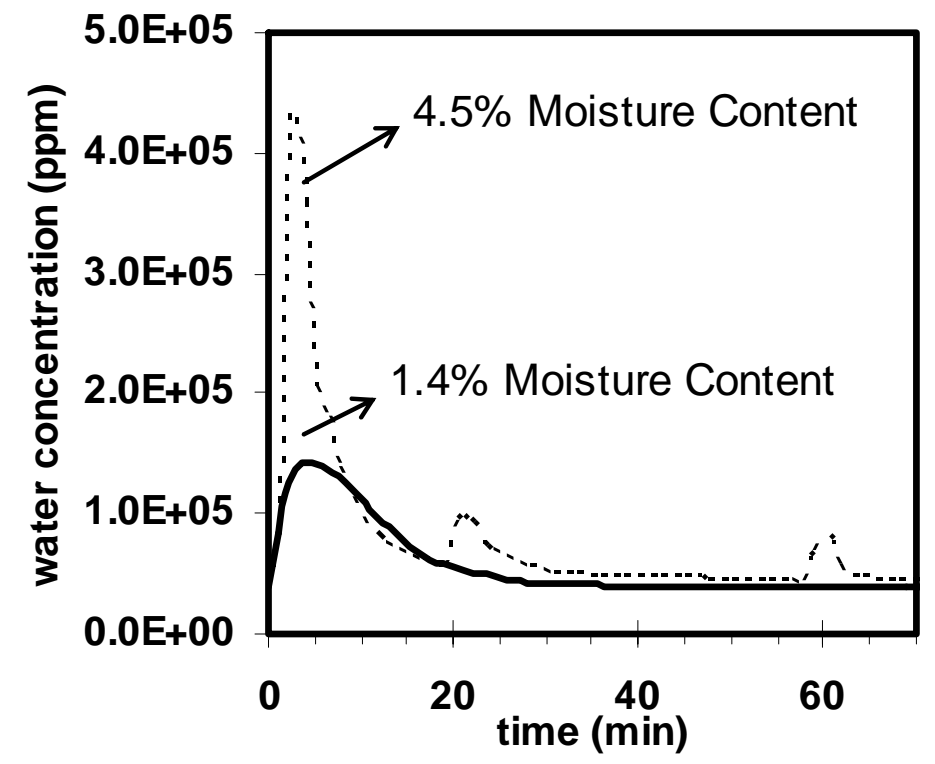

FIGURE 3. Release of water vapor from ESP ash at $105^{\circ} \mathrm{C}$ and $2 \mathrm{~L} / \mathrm{min}$.

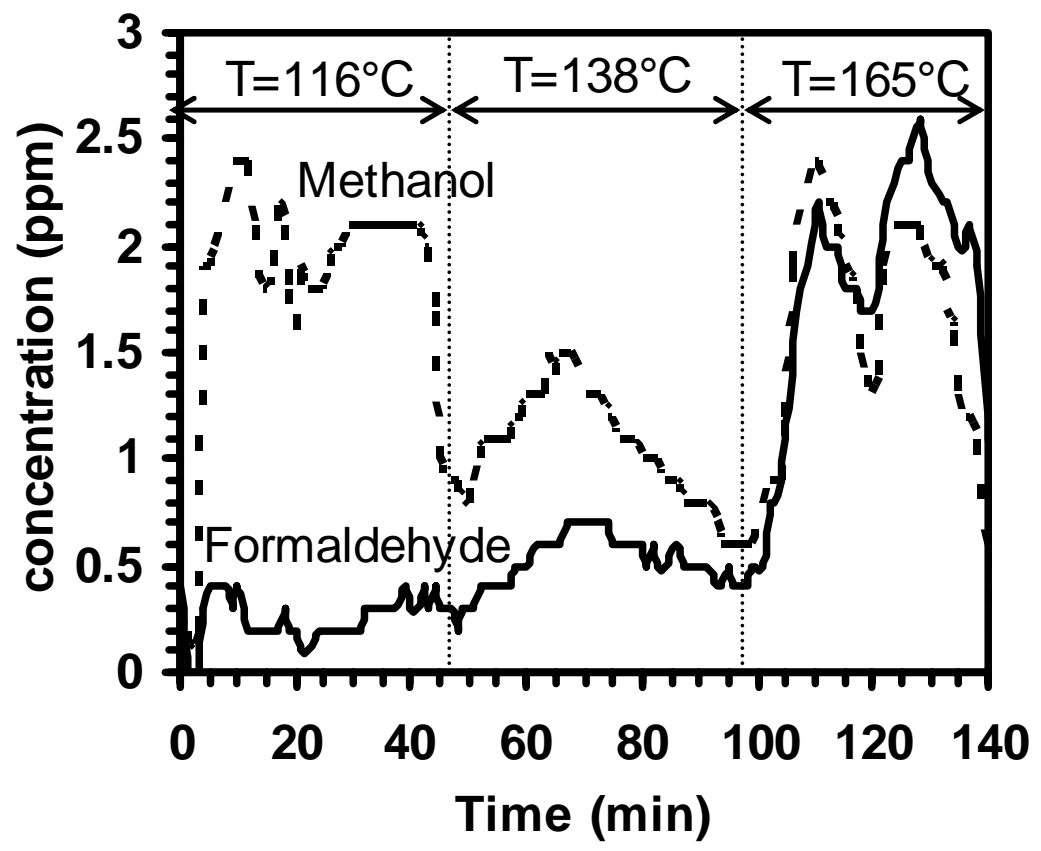

FIGURE 4. Desorption of methanol and formaldehyde from Catawba ash. 


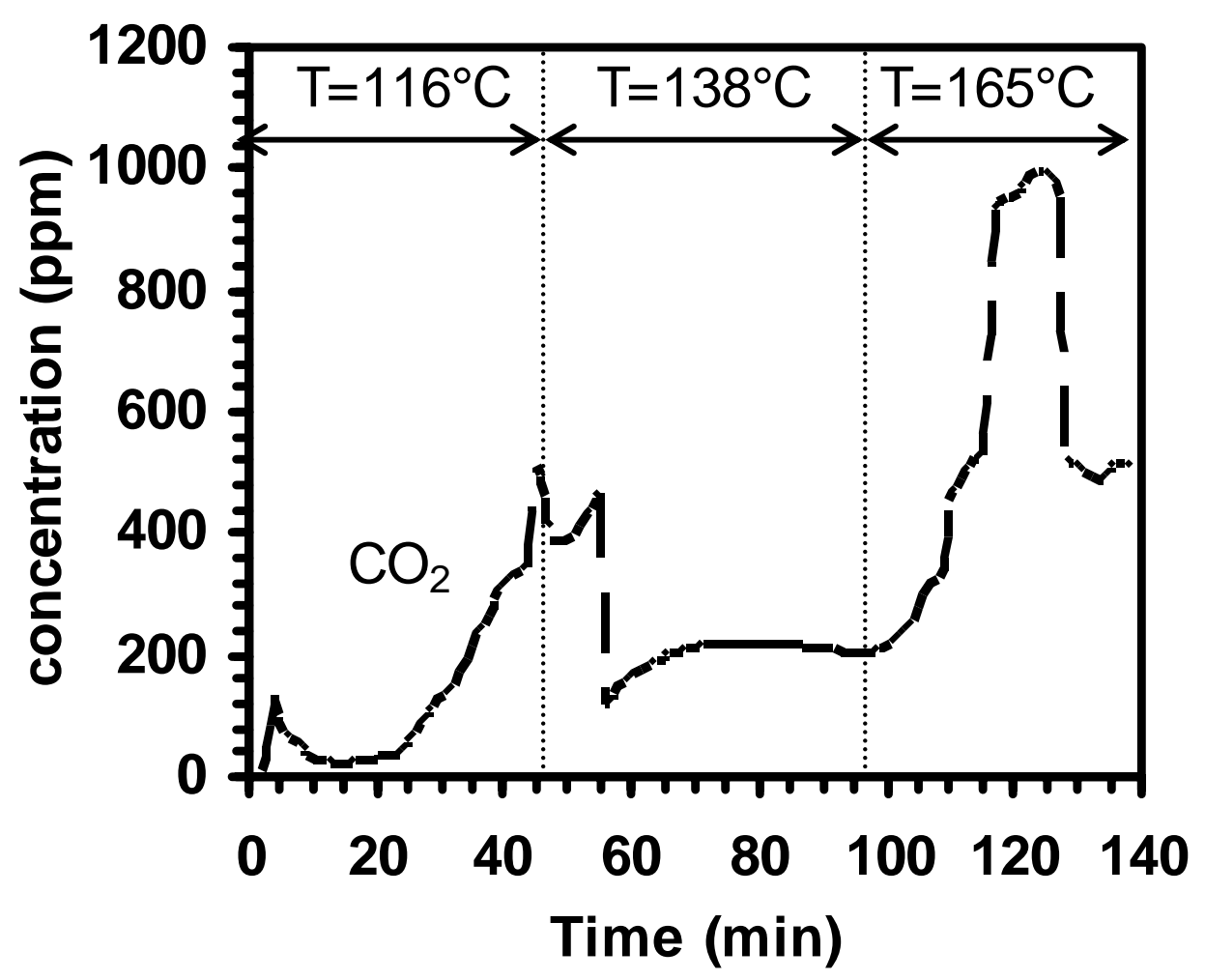

FIGURE 5. Desorption of carbon dioxide from Catawba ash by air. 


\section{Process-Based Control of HAPs Emissions From Drying Wood Flakes}

This section was excerpted from a manuscript submitted to Environmental Science \& Technology. A part of the work was conducted under Contract DE-FCO7-96ID13439

\section{Introduction}

A range of volatile organic compounds (VOCs) is released from drying biomass such as biofuels (1), sludge (2), or wood (3-7). New regulations for controlling emissions from the engineered wood industry, the Plywood and Composite Wood Products (PCWP) wood MACT rule (8), are pending. This rule targets a list of six volatile organic Hazardous Air Pollutants (HAPs), namely methanol, formaldehyde, acetaldehyde, propionaldehyde, phenol, and acrolein, determined to represent the most significant HAPs emitted by this industry segment. Only the first three are commonly found in emissions from pressing and drying wood; propionaldehyde has been reported on occasion. A recent estimate has pegged the cost of compliance through current technology $(9,10)$ at several hundred million dollars $(3)$. Our general objective is to reduce emissions through process changes where possible, in order to reduce our dependence on add-on pollution control equipment that is both a capital/operating cost and an energy burden.

Oriented strand board (OSB) is a major segment of the engineered wood industry with over fifty large installations in North America. Green wood is flaked into thin strands approximately $2.5 \mathrm{~cm}$ wide and $9 \mathrm{~cm}$ long. The flaking process also produces a variable quantity of smaller particles known as "fines". The green strands/fines are typically conveyed through a rotary dryer via a hot air stream generated by a direct-fired burner. HAPs released from the wood principally derive from the thermal breakdown of wood tissue, a process that accelerates sharply at wood tissue temperatures exceeding $160^{\circ} \mathrm{C}(4)$. Increasing temperature also elevates the emissions of terpenes by raising their vapor pressure (11). An obvious route to lower emissions is to decrease the dryer inlet temperature, but this would impose a penalty in wood throughput. Another option is to reduce the fines fraction in the furnish entering the dryer. This fraction generates disproportionately high HAPs emissions because fines tend to lose their evaporative cooling capacity quickly and overdry on account of their high surface:volume ratio. In this paper we establish the temperature dependence of HAPs emissions in both laboratory and full-scale settings and apply it to identify the particle size that contributes most to HAPs emissions.

\section{Experimental}

Both VOCs and HAPs were measured in stack samples with an FTIR spectrometer (model I1106) from Midac Corp., Irving, CA. The samples were drawn through heat-traced Teflon and stainless steel lines into the FTIR by a pump with heated heads to prevent condensation. In order to validate the FTIR method, samples were periodically collected in two chilled-water impingers arranged in series after the FTIR gas cell. The back impinger contained less than 1\% of the analyte collected in the front trap, confirming that collection was substantially complete. Methanol and acetaldehyde in the impinger catch were determined by gc. The acetylacetone method (12) was used for formaldehyde. Results from FTIR and impinger analyses compared to within $30 \%$ at analyte levels of less than 10 ppmv, which was the highest value considered. Propionaldehyde was not detected at an MDL of 1 ppmv. 
For the activation energy measurements, dry pine flakes were obtained from LouisianaPacific's Athens, GA, mill. Green pine flakes were obtained from Georgia-Pacific's Dudley, $\mathrm{NC}$, facility, and freeze-dried at $-70^{\circ} \mathrm{C}$ to a moisture content (MC) of less than $2 \%$. The flakes were cut into strips that were 2-6 mm wide and 4-14 cm long. About $5 \mathrm{~g}$ of these strips were dried isothermally for 30-minutes in a tube furnace at temperatures between 131 and $166^{\circ} \mathrm{C}$ under an airflow of $0.3 \mathrm{~L} / \mathrm{min}$. The exit air was passed through a chilled water impinger. Previous work (4) has shown that a single impinger captures almost all of the emissions.

The inlet temperature in a full-scale direct-fired rotary strand dryer is controlled by the outlet temperature, which is used as an indicator of wood moisture content exiting the dryer. If the outlet temperature rises beyond its setpoint, the inlet temperature falls to reverse the situation. Thus, it is not possible to simply change the inlet temperature while leaving the outlet setting fixed. We were able to overcome this hurdle by varying wood flow. Increasing wood throughput lowered the outlet temperature and the inlet temperature then rose to compensate.

\section{Results and Discussion}

Consider a rectangular piece of wood undergoing drying. The resistance to mass transfer of water vapor from the wood surface to the air should be negligible as compared to the diffusion of water in the wood. This rate is given by eq (1) where $X$ is the concentration of water within

$$
\frac{\partial X}{\partial t}=D_{v}^{\prime} \frac{\partial^{2} X}{\partial s^{2}}
$$

the wood, $D_{v}^{\prime}$ is diffusivity, $s$ represents the distance in the direction of diffusion, and $t$ is time (13). If the diffusivity is assumed to be constant, then the time for loss of water from $X_{1}$ to $X$ is given by equation (2). The reported value of $D_{v}$, for wood is $8.3 \times 10^{-6} \mathrm{~cm}^{2} / \mathrm{s}$ (13). If the tem-

$$
t_{T}=\frac{4 s^{2}}{\pi^{2} D_{v}^{\prime}} \ln \frac{8 X_{1}}{\pi^{2} X}
$$

perature profile along the dryer is assumed to decrease exponentially, then a typical residence time of two minutes leads to boundary conditions of $\mathrm{T}_{1}=593^{\circ} \mathrm{C}$ at $\mathrm{t}=0$ seconds and $\mathrm{T}_{\mathrm{f}}=82^{\circ} \mathrm{C}$ at $\mathrm{t}=120$ seconds, and equation (3) results.

$$
\mathrm{T}=593 \mathrm{e}^{-0.0165 \mathrm{t}}
$$

We have shown earlier $(4,5)$ that HAPs emissions increase sharply when the wood MC drops below $5 \%$ and the tissue temperature rises beyond $160^{\circ} \mathrm{C}$. At this point evaporative cooling is no longer able to cool the flake, and it assumes the temperature of the dryer. If the dryer temperature is high enough, then the wood tissue thermally degrades and the evolution of HAPs ramps up. This situation occurs earlier with fines because of their relatively high surface area. It follows from equations (2) and (3) that under the dryer conditions described above, a $409 \mu \mathrm{m}$ thick piece of wood will reach $5 \% \mathrm{MC}$ at $233^{\circ} \mathrm{C}$, the ignition temperature of wood. It is possible to confirm these results in fieldwork, since particles of this and smaller size should show visible signs of charring. 
Dried furnish collected from the Georgia-Pacific mill in Fordyce, AR, was sieved into the size fractions listed in Table 1. The color of each fraction is illustrated in Figure 1; the pan fraction $(<500 \mu \mathrm{m})$ shows clear signs of early charring. Samples taken from the secondary multicyclone catch, which was comprised of much smaller particles that by-passed the primary product collection cyclone were completely charred. Hence, the experimental results agree quite well with the $409 \mu \mathrm{m}$ estimate from the model. Measurements were also made where the dryer inlet temperature was varied between 593 and $690^{\circ} \mathrm{C}$. The appearance of the various size fractions was very similar to those in Figure 1; i.e. the pan $(<500 \mu \mathrm{m})$ fraction was still the only material that darkened. Results from modeling support this finding. Calculations with the inlet temperature raised to $690^{\circ} \mathrm{C}$ showed that particles smaller than $424 \mu \mathrm{m}$ would begin to char, which is only slightly larger than the $409 \mu \mathrm{m}$ value estimated at $593^{\circ} \mathrm{C}$. Even so, this difference will lead to a significant increase in HAPs emissions as discussed later.

These results are broadly consistent with our work in a hardwood mill where we found that removing green material that passed through a $1-\mathrm{cm}$ screen led to a $70 \%$ reduction in VOC emissions (5) from the remaining furnish. Due to the nature of hardwoods, most of the VOCs tend to be thermal decomposition products. The identification of material smaller than $\sim 500 \mu \mathrm{m}$ as the responsible fraction is important, because rejection of the entire $1-\mathrm{cm}$ screenate is unacceptable because of yield loss. The pan fines $(<500 \mu \mathrm{m})$ represent only $5 \%$ of the total fines in Table 1 . Hence, only a small loss of product yield should lead to a major reduction in HAPs.

Fines are not the only source of dryer HAPs; larger particles will also release HAPs as they dry. Methanol and formaldehyde emissions were measured as a function of flake temperature. The emission rate was constant over the time frame of the measurement, i.e. it followed zero-order kinetics. However, the rates were also quite variable depending on whether the furnish was dried in the laboratory or at a mill, and for how long, which suggested that the HAPs originated from more than one precursor. Emissions were measured from two types of furnish, freeze-dried flakes, and flakes dried in a commercial rotary dryer. These furnishes represent two extremes in the sense that one had experienced no thermal stress, whereas the other had been dried aggressively. Representative Arrhenius plots are illustrated in Figure 2, and the associated data are listed in Table 2. The activation energies $\left(\mathrm{E}_{\mathrm{A}}\right)$ in Table 2 for the two furnishes are quite different. The emission rate must depend upon both the degradation rate of the wood tissue as well as on mass transfer considerations. It is known that high temperature drying promotes pore closure and leads to the movement of extractives to the surface (14), thereby affecting the surface properties of wood. These differences may well alter the mass transfer of the HAPs through the surface and lead to differences in the activation energy for their release.

The temperature dependence of HAPs was also determined in a full-scale trial at a mill in the Southeastern US. The final flake moisture was kept above 5\% to minimize overdrying of the smaller size fraction. The relationship between inlet temperature and the emissions of methanol, formaldehyde, and acetaldehyde is illustrated in Figure 3. The sum of all three HAPs expressed on a production-basis is plotted against inlet temperature in Figure 4. They both show that HAPs generation depends on the inlet temperature under these conditions. 
The Figure 4 data cannot be directly used to obtain an activation energy because the temperature represents that of the dryer inlet and not that of the furnish. The temperature of the dryer decreases along its length, but the flake temperature does not reach that of the dryer until the MC drops below 5\% and the flake is no longer evaporatively cooled. Equations 2 and 3 were used to compute the temperature of the dryer at the point where a $0.5-\mathrm{mm}$ thick flake would reach an $\mathrm{MC}$ of 5\%. This should be the highest temperature experienced by the flake $\left(\mathrm{T}_{\text {flake }}\right)$. These values were calculated at several inlet temperatures $\left(\mathrm{T}_{\text {inlet }}\right)$ and equation 4 was obtained in

$$
\mathrm{T}_{\text {flake }}=98.8+0.08 \mathrm{~T}_{\text {inlet }}
$$

the temperature range of $430-600^{\circ} \mathrm{C}$. Flake temperatures were calculated from eq (4) for the inlet temperature intervals used in Figure 4. These flake temperatures were related to the emissions data in Figure 4 and led to an apparent activation energy of $45 \mathrm{kcal} / \mathrm{mole}$, which is higher than any of the values measured in the laboratory.

The field calculation is based on a model 0.5 -mm flake. However, an increasing inlet temperature would also increase the population of the fines exposed to temperatures much higher than that experienced by the flake. For example, raising the inlet temperature from 593 to $690^{\circ} \mathrm{C}$ as discussed earlier would increase the particle size subject to charring from 409 to $424 \mu \mathrm{m}$ with a concomitant increase in HAPs evolution. Thus raising the inlet temperature would increase HAPs evolution in two ways: by increasing the average temperature of the furnish and also by increasing the fraction subject to overdrying. As a result, the temperature sensitivity of HAPs generation would be higher in the field than in the laboratory and lead to a higher apparent activation energy. From an operational point of view, the field-derived value of $45 \mathrm{kcal} / \mathrm{mole}$ is the result that really matters and it predicts that the HAPs emissions will double for every $50^{\circ} \mathrm{C}$ rise in inlet temperature assuming a constant particle size distribution.

In summary, a model for estimating wood temperature during drying shows that particles smaller than $360 \mu \mathrm{m}$ will thermally degrade and give rise to disproportionately high HAPs. This projection is confirmed in full-scale work where particles smaller than $500 \mu \mathrm{m}$ show signs of charring. Fieldwork demonstrates that the HAPs emissions increase linearly with dryer inlet temperature. The activation energy for the breakdown of wood tissue into methanol and formaldehyde was found to be about $17 \mathrm{kcal}$ in the laboratory. However, field dryer emissions were much more sensitive to temperature, probably because of emissions from overdried fines; dryer HAPs doubled for every $50^{\circ} \mathrm{C}$ increase in temperature. Roughly the same amount of HAPs is released from hardwood and softwood (4), so this value should be quite general and apply to most wood species. Hence, a combination of two approaches could be used to reduce HAPs. Screening out the fine particles below $500 \mu \mathrm{m}$ should reduce emissions by up to $70 \%$. A further reduction could be taken by reducing dryer inlet temperatures, although this approach must be weighed against a loss of throughput. Our results allow theses reductions to be estimated a priori. The PCWP MACT rule allows industry to operate without add-on emissions controls if the overall HAPs emissions are kept below certain process-specific target levels. Adoption of the procedures described here could substantially reduce HAPs to possibly below the regulatory limit. Finally, rotary dryers are also used to dry wood particles for the manufacture of particleboard, and our conclusions should also broadly apply to particle dryers as well as to other biomass drying operations. 


\section{Acknowledgment}

We thank Georgia-Pacific Corporation and the Department of Energy for financial support under contract DE-FC36-01GO10620.

\section{Literature Cited}

1. Wimmerstedt, R.; Recent advances in biofuel drying. Chem Eng Process 1999, 38, 441-447.

2. Cusido, J.A.; Cremades, L.V.; Gonzalez, M. Gaseous emissions from ceramics manufactured with urban sewage sludge during firing processes, Waste Manage. 2003, 23, 273-280.

3. Showalter, J.; Hunt, T.; Price, E. New Direction in VOC/HAP destruction. Solutions 2005, 88(3), 37-39.

4. Otwell, L. P.; Hittmeier, M. E.; Hooda, U.; Yan, H.; Su, W.; Banerjee, S. HAPs release from wood drying. Environ. Sci. Technol. 2000, 34, 2280-2283.

5. Su, W.; Yan, H.; Banerjee, S.; Otwell, L. P.; Hittmeier, M. E. Field-proven strategies for reducing volatile organic carbons from hardwood drying. Environ. Sci. Technol. 1999, 33, 1056-1059.

6. Milota, M. R. HAP and VOC emissions from white fir lumber dried at high and conventional temperatures. For. Prod. J. 2003, 53(3), 60-64.

7. Barry A.O.; Corneau. D. Volatile organic chemicals emissions of OSB as a function of processing parameters. Holzforschung 1999 53, 641-646.

8. U.S. EPA. National Emission Standards for Hazardous Air Pollutants: Plywood and Composite Wood Products, Effluent Limitations Guidelines and Standards for the Timber Products Point Source Category, List of Hazardous Air Pollutants, Lesser Quantity Designations, Source Category List, 2004.

9. Sauer, B.; Franklin, W.; Miner, R.; Word, D.; Upton, B. Environmental tradeoffs: life cycle approach to evaluate the burdens and benefits of emission control systems in the wood panel industry. For. Prod. J. 2002, 52, 50-59.

10. Strader, R. Selection and experience with VOC and HAPs control technologies at wood products plants. Proceedings of TAPPI International Environmental Conference and Exhibit, Portland, OR. 2003, 348-352.

11. Banerjee, S.; Su, W.; Wild, M. P.; Otwell, L. P.; Hittmeier, M. E.; Nichols, K. M. Wet line extension reduces VOCs from softwood drying, Environ. Sci. Technol. 1998, 32, 1303-1307.

12. National Council for Air and Stream Improvement. Method CI/WP-98.01 Chilled Impinger Method for Use at Wood Products Mills to Measure Formaldehyde, Methanol, and Phenol. Methods Manual (03.B.004). 1998.

13. McCabe, W.L.; Smith, J.C.; Harriott, P. Unit Operations of Chemical Engineering. Chap. 24. 5th Ed. McGraw Hill, Inc., Singapore, 1993.

14. Martino, C. J.; Shrauti, S.; Banerjee, S.; Otwell, L. P.; Price, E. W. Flake drying temperature affects mat properties during pressing, Holzforschung 2002, 56, 558-562.

15. Plagemann, W. L.; E. W. Price; W.E. Johns. The response of hardwood flakes and flakeboard to high temperature drying. 1984, J. Adhesion 16, 311-338. 


\begin{tabular}{|c|c|c|c|}
\hline Table 1: Size distribution of dryer fines. \\
\hline ID & sieve size no. & opening size & $\begin{array}{c}\text { percent weight } \\
\text { retained on sieve }\end{array}$ \\
\cline { 3 - 4 } & & $(\mu \mathrm{m})$ & 85.8 \\
\hline 1 & 18 & 1,000 & 6.7 \\
\hline 2 & 25 & 710 & 3.4 \\
\hline 3 & 35 & 500 & 4.1 \\
\hline 4 & pan & & \\
\hline
\end{tabular}

\begin{tabular}{|c|c|c|}
\hline \multicolumn{3}{|c|}{ Table 2: Emissions $(\mu \mathrm{g} / \mathrm{g} / \mathrm{min})$ from dry flakes. } \\
\hline temp $\left({ }^{0} \mathrm{C}\right)$ & formaldehyde & methanol \\
\hline \multicolumn{3}{|l|}{ freeze-dried } \\
\hline 166 & 1.01 & 3.40 \\
\hline 157 & 0.70 & 3.14 \\
\hline 147 & 0.23 & 1.69 \\
\hline 140 & 0.13 & 1.52 \\
\hline 131 & 0.059 & 1.02 \\
\hline $\mathrm{E}_{\mathrm{A}}(\mathrm{kcal} / \mathrm{mole})$ & 30.4 & 12.8 \\
\hline \multicolumn{3}{|l|}{ mill-dried } \\
\hline 166 & 1.64 & 4.01 \\
\hline 157 & 1.03 & 2.69 \\
\hline 147 & 0.56 & 1.48 \\
\hline 140 & 0.40 & 1.08 \\
\hline 131 & 0.33 & 0.79 \\
\hline $\mathrm{E}_{\mathrm{A}}(\mathrm{kcal} / \mathrm{mole})$ & 17.1 & 17.0 \\
\hline
\end{tabular}

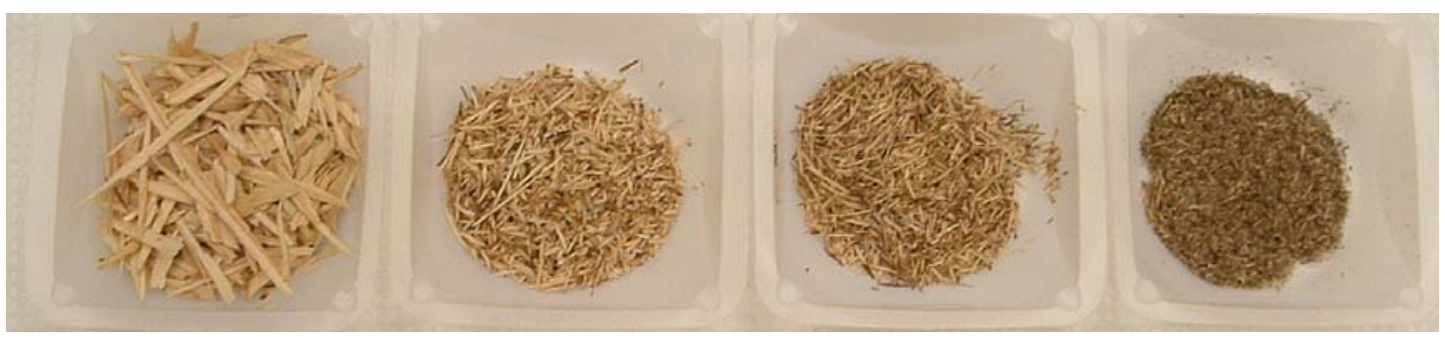

Figure 1: Photographs of fractionated dryer fines. The samples from left to right correspond to ID1-4, respectively, in Table 1. 

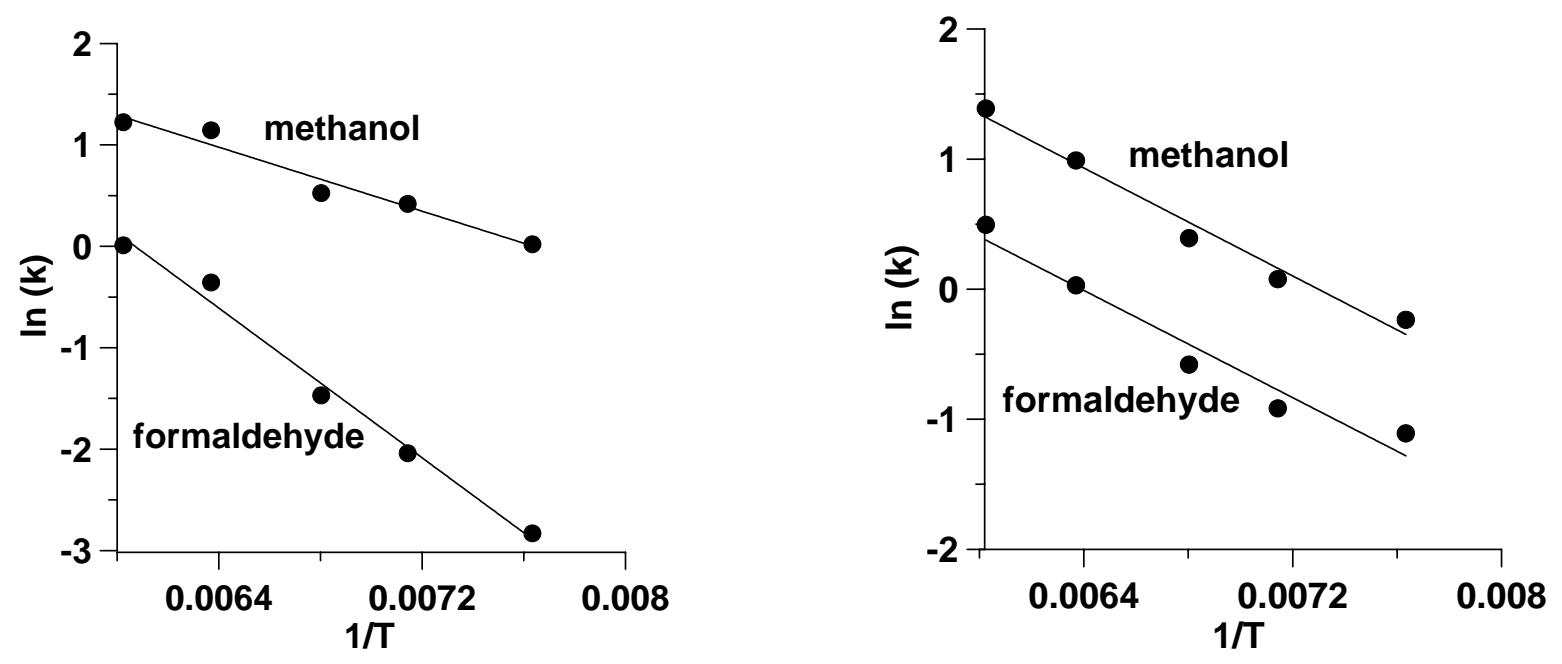

Figure 2: Arrhenius plots for freeze-dried (left) and mill-dried (right) flakes.

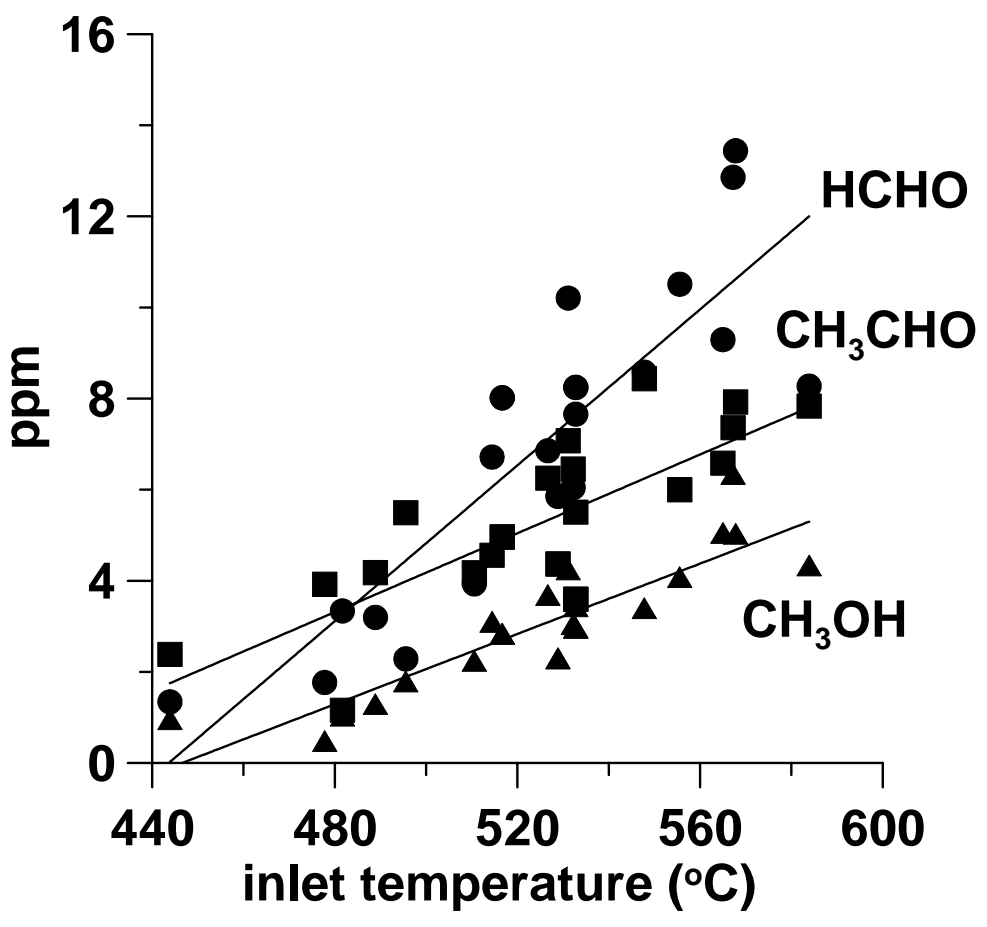

Figure 3: Relationship between HAPs and inlet temperature for individual HAPs. 


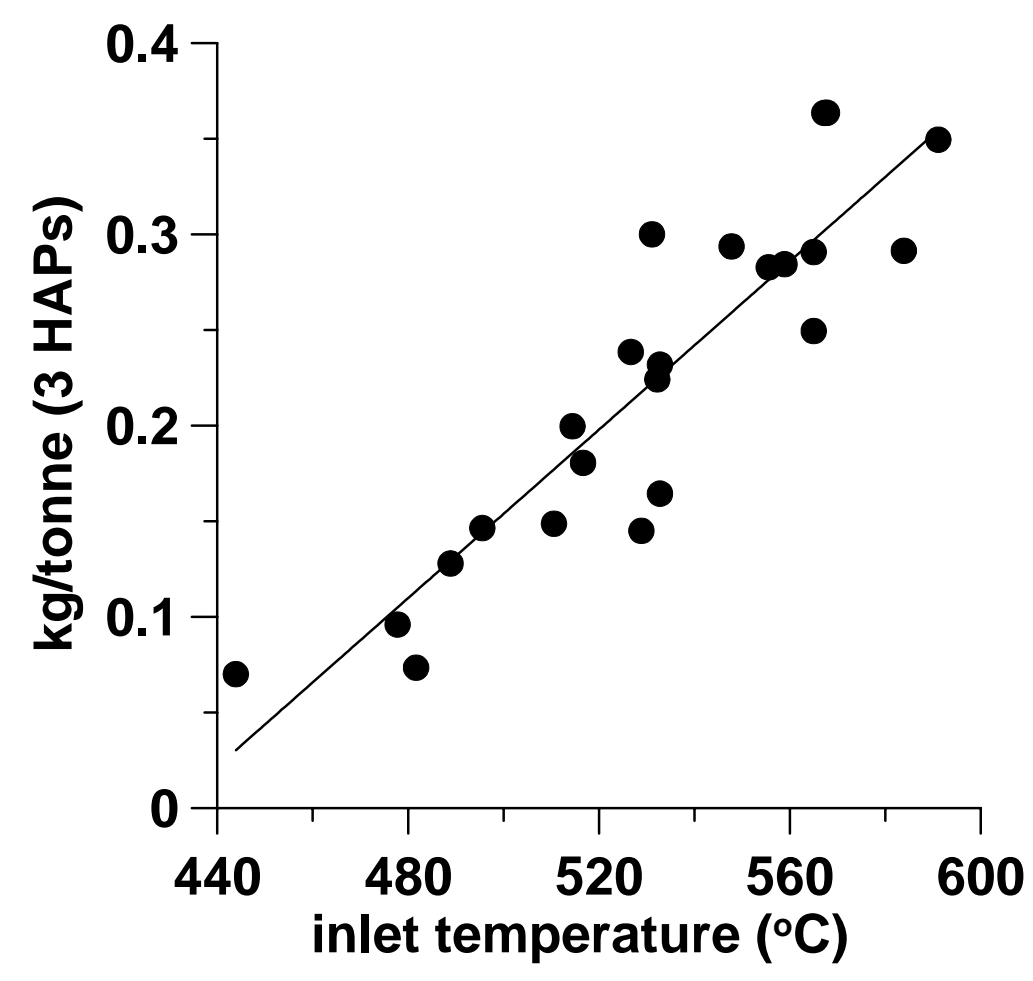

Figure 4: Relationship between the sum of three HAPs (methanol, formaldehyde, acetaldehyde) on a production basis and inlet temperature. 


\section{Publications, Presentations and Technology Transfer}

Publications

- J.P. Radhakrishnan, S.Banerjee, A simple heat transfer model for estimating terpene emissions from hot-pressing softwood, Holzforschung, 58, 384 (2004).

- J.Cowan, M.Abu-Daabes, S.Banerjee, Controlling formaldehyde emissions with boiler ash, Environ. Sci. Technol., 39, 5101 (2005).

- S.Banerjee, K.Pendyala, M.Buchanan, R.Yang, M.Abu-Daabes, L.P.Otwell, Process-based control of HAPs emissions from drying wood flakes, Environmental Science \& Technology, submitted.

\section{$\underline{\text { Presentations }}$}

- S.Banerjee, VOC emissions from wood dryers and presses, Georgia-Pacific corporate-wide environmental conference, Atlanta, GA, 2002.

- S.Banerjee, Approaching the production-based limit for HAPs reduction from OSB drying \& pressing, Structural Board Association Meeting, Phoenix, AZ, 2003.

- S.Banerjee, J.Radhakrishnan, M.Buchanan, T.E.Conners, K.Pendyala, J.Cowan, Use of ash in HAPs removal, Tappi Summit, Atlanta, GA 2004.

- S.Banerjee, J.Yang, M.Buchanan, T.E.Conners, L.P.E.Otwell, S.Conners, HAPs generation and removal, Tappi Summit, Atlanta, GA 2004.

Presentations were also made to Georgia-Pacific and Norbord.

Technology Transfer

Georgia-Pacific presently plans to implement green-screening in order to remove the fine particles identified in this study that are principally responsible for generating HAPs in the dryer. 